NBER WORKING PAPER SERIES

\title{
STATE CAPACITY AND ECONOMIC DEVELOPMENT: A NETWORK APPROACH
}

\author{
Daron Acemoglu \\ Camilo García-Jimeno \\ James A. Robinson \\ Working Paper 19813 \\ http://www.nber.org/papers/w19813
}

\author{
NATIONAL BUREAU OF ECONOMIC RESEARCH \\ 1050 Massachusetts Avenue \\ Cambridge, MA 02138 \\ January 2014
}

We are grateful to Alberto Ciancio, Amanda Culp, and Nicolas Idrobo for superb research assistance, and Maria Angelica Bautista, Flavio Cunha, Frank Ditraglia, Andrew Foster, Elena Paltseva, James Poterba, Pascual Restrepo, Xun Tang, Petra Todd, Ken Wolpin, Roman Zarate, participants at the Stockholm School of Economics/SITE conference on Institutional Challenges in Emerging Economies, participants at the George Mason center for Public Choice Seminar, and participants at the RECODE 2013 Meetings in Ottawa, the BREAD/NBER development meetings in Cambridge, the LACEA/LAMES meetings in Mexico City, the MIT Public Finance/labor Workshop, and the UPenn Empirical Micro Workshop for valuable suggestions. Acemoglu gratefully acknowledges financial support from ARO MURI W911NF-12-1-0509. The views expressed herein are those of the authors and do not necessarily reflect the views of the National Bureau of Economic Research.

NBER working papers are circulated for discussion and comment purposes. They have not been peerreviewed or been subject to the review by the NBER Board of Directors that accompanies official NBER publications.

(C) 2014 by Daron Acemoglu, Camilo García-Jimeno, and James A. Robinson. All rights reserved. Short sections of text, not to exceed two paragraphs, may be quoted without explicit permission provided that full credit, including $(\mathcal{C}$ notice, is given to the source. 
State Capacity and Economic Development: A Network Approach

Daron Acemoglu, Camilo García-Jimeno, and James A. Robinson

NBER Working Paper No. 19813

January 2014

JEL No. H4,H7,P16

\begin{abstract}
$\underline{\text { ABSTRACT }}$
We study the direct and spillover effects of local state capacity using the network of Colombian municipalities. We model the determination of local and national state capacity as a network game in which each municipality, anticipating the choices and spillovers created by other municipalities and the decisions of the national government, invests in local state capacity and the national government chooses the presence of the national state across municipalities to maximize its own payoff. We then estimate the parameters of this model using reduced-form instrumental variables techniques and structurally (using GMM, simulated GMM or maximum likelihood). To do so we exploit both the structure of the network of municipalities, which determines which municipalities create spillovers on others, and the historical roots of local state capacity as the source of exogenous variation. These historical instruments are related to the presence of colonial royal roads and local presence of the colonial state in the 18th century, factors which we argue are unrelated to current provision of public goods and prosperity except through their impact on their own and neighbors' local state capacity. Our estimates of the effects of state presence on prosperity are large and also indicate that state capacity decisions are strategic complements across municipalities. As a result, we find that bringing all municipalities below median state capacity to the median, without taking into account equilibrium responses of other municipalities, would increase the median fraction of the population above poverty from $57 \%$ to $60 \%$. Approximately $57 \%$ of this is due to direct effects and $43 \%$ to spillovers. However, if we take the equilibrium response of other municipalities into account, the median would instead increase to $68 \%$, a sizable change driven by equilibrium network effects.
\end{abstract}

Daron Acemoglu

Department of Economics, E18-269D

MIT

77 Massachusetts Avenue

Cambridge, MA 02139

and CIFAR

and also NBER

daron@mit.edu

Camilo García-Jimeno

Department of Economics

$528 \mathrm{McNeil}$ Building

University of Pennsylvania

3718 Locust Walk

Philadelphia, PA 19104

gcamilo@econ.upenn.edu
James A. Robinson

Harvard University

Department of Government

N309, 1737 Cambridge Street

Cambridge, MA 02138

and NBER

jrobinson@gov.harvard.edu 


\section{Introduction}

Though, in the West, we take for granted the existence of central and local states with the capacity to enforce law and order, regulate economic activity and provide public goods, many states throughout history and today in most less-developed parts of the world lack this capacity. In Migdal's (1988, p. 33) words: "In parts of the Third World, the inability of state leaders to achieve predominance in large areas of their countries has been striking..."

The idea that such state capacity is vital for economic development, though latent in the writings of Thomas Hobbes and Max Weber, began to attract more attention as a consequence of analyses of the "East Asian Miracle". A series of books by Johnson (1982), Amsden (1989) and Wade (1990) argued that a key to the economic success of East Asian economies was that they all had states with a great deal of capacity (which were "strong"). Evans (1995) developed this into a comparative theory of East Asian state strength, arguing that it was the "embedded autonomy" of the South Korean state that made it effective at promoting development. Others, such as Herbst (2000) and Centeno (2002), linked the economic failure of African or Latin American nations to their limited state capacity. ${ }^{1}$ This hypothesis also receives support from the cross-country empirical evidence presented in Gennaioli and Rainer (2007) and the within-country evidence in Michalopoulos and Papaioannou (2013) and Bandyopadhyay and Green (2012). All three papers find a positive impact of historical measures of political centralization across African polities on contemporary public goods provision and various measures of economic development. ${ }^{2}$

In this paper, we contribute to this literature in several dimensions. We study the effect of state capacity of Colombian municipalities on public goods provision and prosperity. We conceptualize "state capacity" as the presence of state functionaries and agencies. This represents one aspect of what Mann $(1986,1993)$ calls the "infrastructural power" of the state (see also Soifer, 2008). Colombia provides an ideal laboratory for such an investigation for several reasons. There is a wide diversity of local state presence, public goods provision and prosperity across the country. In addition, many aspects of local state capacity in Colombia are decided at the local level, including notary offices, health centers, health posts, schools, libraries, fire stations, jails, deed registry offices, or tax collection offices. Finally, and importantly for our empirical strategy, Colombia's history of colonization provides us with sources of potential exogenous variation in local state capacity which

\footnotetext{
${ }^{1}$ There is now a large case study literature in political science and sociology on the role of state capacity in economic development, for example, Waldner (1999) and Kohli (2004)

${ }^{2}$ Relatedly, Evans and Rauch (2000), Acemoglu (2005), Besley and Persson (2009, 2011), and Dincecco and Katz (2013) document positive correlations between tax to GDP ratio or measures of meritocracy in the state bureaucracy and economic development. Bockstette, Chanda and Putterman (2002) show a positive cross-country association between early state centralization and economic development, and Osafo-Kwaako and Robinson (2013) show similar correlations using ethnographic data on political centralization from the Standard Cross-Cultural Sample.
} 
we exploit in order to deal with endogeneity and reverse causality concerns and to isolate the impact of state capacity (rather than other social and institutional factors). In particular, we focus on the historical presence of colonial state officials, colonial state agencies, and the colonial "royal road" network. The road network, for example, was partially based on pre-colonial indigenous roads and was overhauled when the modern system of roads was built in Colombia starting in the 1930s. This network has disappeared and thus provides an attractive source of variation in the historical presence of the state and the cost of building and expanding local state capacity (especially when we control for distance to current roads). We exploit this royal road network, as well as information on the location of various colonial state offices and officials, in order to isolate historical sources of variation in the cost of building state capacity today.

Our main contribution is that, differently from all of the literature in this area, we model the impact of state capacity in one municipality on public goods provision and economic outcomes in neighboring areas. We expect (and empirically find) such neighborhood externalities to be important both because borders across municipalities are porous and because building a functioning bureaucracy in the midst of an area where state capacity is entirely missing is likely to be much more difficult. ${ }^{3}$

Cross-municipality effects also imply that building state capacity will be a strategic choice for each municipality. To the extent that municipalities free-ride on their neighbors' investments, state capacity choices might be strategic substitutes. Conversely, to the extent that municipalities find it harder or less beneficial to build state capacity when it is missing in their neighborhood, these choices will be strategic complements. Other important reasons for strategic complementarities include: (1) when there is a functioning state in the neighborhood, voters may be more likely to demand it of their own politicians; (2) some problems, such as defeating criminal organizations or dealing with contagious diseases, may be beyond the capability of the local state at the municipality level; (3) the judicial system may not function just in a single municipality.

These strategic aspects are incorporated by modeling the building of state capacity as a network game in which each municipality takes the national government's as well as their neighbors' actions into account and chooses its own state capacity. We then estimate the parameters of this model, exploiting both the network structure and the exogenous sources of variation discussed above. The key parameters concern: (1) the impact of own state capacity on own public goods provision and prosperity; (2) externalities on neighbors; and (3) the parameters of the best response equation concerning how state capacity decisions depend on neighbors' state capacities. In the process, we clarify why both empirical approaches that ignore the endogeneity concerns and those that do not

\footnotetext{
${ }^{3}$ An example of the potential importance of such externalities is the research of Di Tella and Schargrodsky (2004) who show how a shock which led to increased policing in one part of Buenos Aires reduced crime there but increased crime in neighboring parts.
} 
model the network structure of interactions will lead to potentially misleading estimates.

Our approach leads to precise estimates of the "best response" equations linking a municipality's state capacity to its neighbors, which indicate that in all cases state capacity decisions are strategic complements. We estimate the effect of own and neighbors' state capacity on various measures of public goods provision (school enrollment, utilities coverage) and prosperity (proxy by indices for quality of life and poverty) using one of three empirical approaches: (1) linear instrumental variables applied to each dimension of prosperity, or (2) generalized method of moments (GMM) and (3) maximum likelihood estimation (MLE) using all dimensions of prosperity simultaneously. In each case, we clarify how the reduced-form parameters map into the structural ones. Our results show large and fairly precise effects of both own and neighbors' state capacity on all measures of prosperity we consider.

Our benchmark estimates imply, for example, that moving all municipalities below median state capacity to the median will have a "partial equilibrium" direct effect (holding the level of state capacity of all municipalities above the median constant) of reducing the median poverty rate by 3 percentage points, increasing the median coverage rate of public utilities (electricity, aqueduct and sewage) by 4 percentage points, and increasing the median secondary enrollment rate by 3 percentage points. About $57 \%$ of this impact is due to a direct effect, while $43 \%$ is due to network spillovers. The "full equilibrium" effect is very different, however. Once we take into account the equilibrium responses to the initial changes in local state capacity in the network, median coverage rate of public utilities increases 10 percentage points, the median fraction of the population in poverty falls by 11 percentage points, and median secondary enrollment rates increase by over 26 percentage points. These large impacts, which are entirely due to network effects, highlight not only the central role that state capacity plays in development but also the importance of taking the full equilibrium effects into account.

We demonstrate that these estimates are quite robust. First, they are very similar if, in addition to relying on our historical sources of variation, we also incorporate the ideas proposed in Bramoulle, Djeebari, and Fortin (2009) and thus exploit only sources of variation of neighbors of neighbors (instead of relying on variation of the neighbors). Second, they are also very similar if we do not control for the current road network (our baseline results do control for this network). Third, the results remain essentially unchanged if we focus on subsets of our instruments. Finally, they are also very similar when we assign different weights on the spillovers from different neighbors or even when we allow spillovers to go beyond adjacent municipalities.

We also extend our structural model to incorporate the decisions of the national government concerning local state capacity. In Colombia, while municipalities themselves hire and pay for a range 
of local state employees (a large part of it with transfers from the central government), the number of police and judges in the municipality are decided by the national government. Incorporating this additional layer of interaction in the structural model has little effect on our estimates of the impact of local state capacity, but allows us to estimate some key features determining the distribution of national state presence across the country.

We are unaware of any other study that either estimates the effect of local (municipality-level) state capacity on local outcomes, or models and estimates the network externalities and strategic interactions in this context. ${ }^{4}$ Nevertheless, our paper relates to several literatures. First, we build on and extend the literature on the effect of state capacity on economic development which has already been discussed. In addition to the empirical and historical studies mentioned above, there has recently been a small literature on the modeling of the emergence of state capacity or persistence of states which lack capacity ("weak"). Acemoglu (2005) constructs a model in which a self-interested ruler taxes and invests in public goods and citizens make investment decisions. Lack of state capacity or weak states are detrimental to economic development because they discourage the ruler from investing in public goods as he anticipates that he will not be able to raise taxes in the future. Besley and Persson $(2009,2011)$ also emphasize the importance of state capacity and suggest that state building will be deterred when each group is afraid that the state they build will be used against them in the future. Acemoglu, Ticchi and Vindigni (2011) and Acemoglu, Robinson and Santos (2013) provide various models of persistence of weak states with low state capacity. ${ }^{5}$ Our model takes a different direction than those, and in the process, highlights a new effect: state building will be deterred unless a national government plays a defining role in this process, because local governments will underinvest in state capacity as they ignore the spillovers they create on their neighbors. Since our estimates suggest that these externalities are sizable, this effect could be quite important in practice.

In utilizing a network game to model state building investments and for our empirical work, our paper also relates to the literature on network games. Theoretically, our model is a variant of Bramoulle, Kranton and D'Amours (2012), extended to allow investments to be strategic complements or substitutes (their model constrains them to be strategic substitutes). Empirically, as mentioned above, Bramoulle et al. (2009) propose a creative approach to identify network effects, while avoiding endogeneity within the network, which relies on using characteristics of neighbors of neighbors. Though we verify the robustness of our results to this alternative approach, our main

\footnotetext{
${ }^{4}$ The only partial exceptions are Dell's (2013) study of how changes in law enforcement shift the activities of drug gangs across the transport network linking Mexican municipalities to the United States; a recent paper by Durante and Guiterrez (2013) on the role of inter-jurisdictional cooperation in crime-fighting across Mexican municipalities; and Case, Hines, and Rosen's (1993) work on the relationship between the public expenditures of neighboring US states.

${ }^{5}$ Another branch of literature, including Thies (2005), Gennaioli and Voth (2011), and Cardenas, Eslava and Ramirez (2011) for Colombia, investigates the historical determinants of state capacity.
} 
strategy instead relies on exploiting historically-exogenous sources of variation in both own and neighbors' state capacity, which ensures consistency even if there are spatially correlated omitted factors affecting state capacity, public goods and prosperity - a first-order concern in this and many other contexts. Other papers dealing with related issues include, among others, Calvo-Argemgol, Patacchini, and Zenou (2009), Topa (2001), Katz, Kling, and Liebman (2001), Bayer, Ross, and Topa (2008), Sacerdote (2002), and Nakajima (2007), though, to the best of our knowledge, no other study uses a similar empirical strategy or combines structural modeling and historical instrumental variables to estimate the structural parameters of this type of model.

In addition to the literature we cited above on the role of state capacity in national economic development, a small literature has emphasized within-country variation in state capacity. O'Donnell (1993) did this in the case of Latin America, arguing that the uneven distribution of state capacity led to variation in the quality of democracy at the sub-national level. Related ideas have emerged in the literature on civil wars with scholars suggesting that conflict starts and persists in parts of countries with low state capacity (e.g., Goodwin, 1999, Fearon and Laitin, 2003, and Kalyvas, 2006, as well as Sanchez, 2007, for the Colombian case). ${ }^{6}$ Research on within-country income differences has pointed to institutional differences as likely causes of this variation (e.g., Acemoglu, and Dell, 2010, Acemoglu, Garcia-Jimeno and Robinson, 2012, Bruhn and Gallego, 2012), but has not focused on variation in state capacity.

The rest of the paper proceeds as follows. Section 2 provides a discussion of the Colombian context, particularly focusing on the weakness of the local and national state. Section 3 presents a simple model of investments in state capacity within a network. Section 4 presents our data. Section 5 discusses our empirical strategy and presents our main estimates and some robustness checks focusing on the simplified model without the national state. Section 6 describes our empirical strategy and results for the general model that includes investments by the national state. Section 7 concludes, while the Appendix contains additional results.

\section{Context}

This section provides a brief overview of some key features of the historical development of state capacity in Colombia. The sources of variation in historical state development are discussed below.

State capacity in Colombian history has been notable in its relative absence on average and its great variability. In 1870, with a total population of around 2.7 million, the total number of both state

\footnotetext{
${ }^{6}$ In the literature on state formation in the 19th-century United States, there is a heavy emphasis on the critical role of federal and local government (e.g., Novak, 2008), and similar concerns have emerged in the literature on Latin America (see, e.g., Soifer, 2012).
} 
and national level public employees in Colombia was 4,500 , or just 0.0015 bureaucrats per inhabitant (Palacios and Safford, 2002). In contrast, public employees per capita in the United States in 1870 were 0.011, an order of magnitude higher (1870 US Census).

The Colombian state also did not have the capacity to raise fiscal revenues, another key aspect of state capacity, which was also lacking all the way into the 20th century (as Deas, 1982, and Rincon and Junguito, 2007, note). As late as 1970, tax revenue was only around 5\% of GDP (Rincon and Junguito, 2007). As a result, some isolated regions, such as the Choco or the eastern plains, have yet to be fully integrated with the rest of the country economically or politically. ${ }^{7}$ For example, commenting on this issue in 1912, Rufino Gutierrez argued that

"...in most municipalities there was no city council, mayor, district judge, tax collector... even less for road-building boards, nor whom to count on for the collection and distribution of rents, nor who may dare collect the property tax or any other contribution to the politically connected..." (Our translation)

There are several historical root causes of state weakness in Colombia. During the colonial period, Spain restricted migration to its American colonies so that the settler population was very small and did not consitute an effective voice pushing for a more effective colonial state. The colonial state also used direct methods to extract rents from indigenous people, such as tribute and forced labor, rather than developing a tax system that would later become the foundation of state capacity. The topography of the country also constrains the reach of the state. The Andean Cordillera running south to north splits the country into a patchwork of relatively disconnected regions. Furthermore, Colombians resisted the Bourbon attempts at state centralization in the late 18th century so that, uniquely in the Americas, the Spanish were not able to set up their new system (see Paquette, 2012, Phelan, 1978, and McFarlane, 1993, for Colombia). Though as a consequence of these reforms, the province of Nueva Granada became a viceroyalty in 1717 and then again in 1739, the colonial state remained absent throughout most of the territory, except in and around a few cities and towns. For example, in 1794, the capital Bogota and the major slave and gold trading port Cartagena housed $70 \%$ of all crown employees in the viceroyalty.

After independence, the colonial fiscal system was continued (Jaramillo, Meisel, and Urrutia, 2006) until the Liberals' rise to power in 1850. The Liberal regime cut tariffs and abolished mo-

\footnotetext{
${ }^{7}$ One of the main purposes of the 1991 Constitution was to increase the extent of decentralization in Colombia and in the process to contribute to local state building. The Constitution mandated transfers from the central government to the local level, which would be used for public good provision at the municipality level. Despite these major institutional changes in the late 20th century, large swathes of Colombia still have very weak state presence. Moreover, it was during the 1990s and early 2000s that the national state lost control of large areas of the country to the hands of private armies of guerrillas and paramilitaries.
} 
nopolies, causing a fiscal crisis and a significant downsizing of the already emaciated state (Deas, 1982). In the mid 19th century Colombia adopted a federal system, further weakening the attempts of national state-building. Each of the states during this federal period had its own army, so that even the monopoly of violence of the state was not attempted until the end of the War of a Thousand Days in 1903. Palacios and Safford (2002, p. 27) describe state weakness in Colombia during this epoch:

"In the decade of the 1870s, an attempt to use national funds to build a railroad that would benefit the east triggered intense antagonism in the west and the [Caribbean] coast... as a result, small, poorly financed and often failed projects proliferated..."

This context, underpinning pervasive and geographically-varied state weakness and lack of state capacity, makes the study of the implications of local state capacity in Colombia particularly relevant.

\section{A Simple Model of State-Building in a Network}

In this section we develop a simple game-theoretic model of the determination of local and national state capacity, building on the literature on games of public goods provision in networks. Our starting point is the idea that the administrative map of a polity can be viewed as a network over which the spillovers take place.

With this approach, the economy consists of a network of municipalities, and a national state. Each municipality is a node in this network, municipalities sharing a border are connected, and all links are undirected. Prosperity in each municipality depends on local state capacity, the spillover effects of state capacity from neighboring municipalities, and on national state capacity allocated to the municipality. We further allow the strength of the spillovers to depend on topographic features of the Colombian landscape. All municipalities and the national state simultaneously choose their levels of state capacity to maximize their payoff, which is a function of the relative costs and benefits of state capacity provision. State capacity positively impacts several dimensions of prosperity, and its provision has a convex cost. The national state has heterogeneous preferences over prosperity across municipalities. This model determines the equilibrium distribution of local and national state capacity across municipalities, and hence the equilibrium distribution of prosperity.

The major simplification of our approach is that we ignore within-municipality political economy and adopt a reduced-form representation of the relationship between the national state and municipalities. Even though such political economy considerations are important in Colombia, our approach exploits differences in the benefits to the inhabitants of the municipality from own and neighbors' state capacity, which is a natural first step. 


\subsection{Network Structure and Preferences}

Let $i$ denote a municipality, and $\mathbf{F}$ be an n-x-n matrix with entries $f_{i j}$ given by

$$
f_{i j}=\frac{1}{1+\delta_{1} d_{i j}\left(1+\delta_{2} e_{i j}\right)},
$$

where $d_{i j}$ denotes the distance along the geodesic connecting the centroids of municipalities $i$ and $j$, and $e_{i j}$ is a measure of variability in altitude along the geodesic connecting the centroids of municipalities $i$ and $j$. The parameters $f_{i j}$ 's allow for differential decay of spillovers between municipalities, depending on topographic features of the landscape. This is important in the Colombian context since topographic conditions are highly variable and rapidly changing.

Let $N(i)$ denote the set of municipalities connected to $i$, meaning the municipalities that will create spillovers on $i$. In our baseline, these will be the municipalities that are adjacent to $i$, though we also experiment with alternative definitions of the set $N(i)$, for example defining a link between any two municipalities within a certain distance of each other, between not only neighbors but also neighbors of neighbors, and between all municipalities with decaying strength of links.

The matrix $\mathbf{N}(\boldsymbol{\delta})$ then denotes the symmetric matrix with entries $n_{i j}$ representing both the presence of a link between two municipalities and the strength of any spillovers that may take place along that link:

$$
n_{i j}= \begin{cases}0 & \text { if } j \notin N(i) \\ f_{i j} & \text { if } j \in N(i)\end{cases}
$$

We allow several dimensions of prosperity in a municipality to depend upon own state capacity and neighboring state capacity in the following way:

$$
p_{i}^{j}=\left(\kappa_{i}+\xi_{i}\right) s_{i}+\psi_{1} s_{i} \mathbf{N}_{i}(\boldsymbol{\delta}) \mathbf{s}+\psi_{2}^{j} \mathbf{N}_{i}(\boldsymbol{\delta}) \mathbf{s}+\epsilon_{i}^{j},
$$

where $p_{i}^{j}$ is prosperity dimension $j=1, \ldots J$ in municipality $i$ and $s_{i} \in[0, \infty)$ is municipality $i$ 's state capacity. In addition, $\kappa_{i}+\xi_{i}$ is the effect of own state capacity on prosperity, which we allow to be municipality specific, and to depend on an observable $\kappa_{i}$ (which will be modeled as a function of historical and other characteristics of a municipality) and an unobservable (for the econometrician) component $\xi_{i}$ (which will be modeled as a random effect). In addition, $\psi_{1}$ captures any interaction (or cross) effects between own prosperity and neighbors' state capacity, while $\psi_{2}^{j}$ is the direct effect of neighboring state capacity on own prosperity outcome $j . \mathbf{N}_{i}(\boldsymbol{\delta})$ denotes the $i$ 'th row of the network

matrix, and $\mathbf{s}$ denotes the full column vector of state capacity levels. Finally, the $\epsilon_{i}^{j}$,s are mean-zero unobservables for both the municipality and the econometrician. We will rely on both direct measures of prosperity and on measures of public goods provision.

Notice that though $\psi_{2}^{j}$ is allowed to vary across the different dimensions of prosperity, the other parameters are not. This is because, as we will see below, these other parameters will be in part 
identified from the best response equations which do not depend on the dimension of prosperity we are considering. ${ }^{8}$

As just pointed out, the parameters $\left(\kappa_{i}, \xi_{i}\right)$ in equation (1) capture the heterogeneous effects of own state presence on prosperity in municipality $i$. Many factors will affect these parameters. Geographic, historical, political and social factors will create heterogeneity in the effectiveness of state capacity, for example, because there is greater need for the local state to provide health care or public services in some municipalities, or because patronage appointments driven by the highly clientelistic nature of local Colombian politics (e.g., Davila and Leal, 2010) may be reducing the impact of measured state presence on prosperity in some municipalities.

\subsection{The General Case}

The most general model we consider allows state capacity in municipality $i$ to be a constant elasticity of substitution (CES) composite of both locally chosen $l_{i} \in[0, \infty)$, and nationally-chosen state capacity, $b_{i} \in[0, \infty)$ :

$$
s_{i}=\left[\alpha l_{i}^{\frac{\sigma-1}{\sigma}}+(1-\alpha)\left(\tau b_{i}\right)^{\frac{\sigma-1}{\sigma}}\right]^{\frac{\sigma}{\sigma-1}} \quad \sigma>0,
$$

where $\tau>0$ allows for a national bureaucrat or agency to have a different impact than a local state employee.

Each municipality decides its own state capacity $l_{i}$ taking as given the choices of its neighbors and the national government. Clearly, in the case $\alpha=1$, national choices are irrelevant. Preferences for municipality $i$ are assumed to take the form

$$
U_{i}=\mathbb{E}_{\epsilon}\left[\frac{1}{J} \sum_{j} p_{i}^{j}-\frac{\theta}{2} l_{i}^{2}\right],
$$

where $J$ is the total number of prosperity outcomes. Preferences of the national level are

$$
W_{i}=\mathbb{E}_{\epsilon}\left[\sum_{i}\left\{U_{i} \zeta_{i}-\frac{\eta}{2} b_{i}^{2}\right\}\right],
$$

where the $\zeta_{i}$ 's are the heterogeneous weights that the national state puts on each municipality, determined by political economy factors, for example, depending on the distribution of swing voters (e.g., Stromberg, 2008), or on who is in control of local politics (e.g., Acemoglu, Robinson and Santos, 2013). ${ }^{9}$

We assume, as noted above, that local and national state capacities are chosen simultaneously. The first-order conditions for the municipalities and the national state determine the equilibria of

\footnotetext{
${ }^{8}$ The $p_{i}^{j}$ 's will be standardized in our empirical setting, so that the same cross-effects as captured by the parameter $\psi_{1}$ are not implausible.

${ }^{9}$ Equation (3) rules out, however, a situation in which the national state just cares about extracting resources from some municipalities.
} 
this game. Those with respect to $l_{i}$ give the best response of the state capacity choice of municipality $i$ as:

$$
\alpha\left[\frac{s_{i}}{l_{i}}\right]^{\frac{1}{\sigma}}\left[\left(\kappa_{i}+\xi_{i}\right)+\psi_{1} \mathbf{N}_{i}(\boldsymbol{\delta}) \mathbf{s}\right]-\theta l_{i}\left\{\begin{array}{cc}
<0 & l_{i}=0 \\
=0 & l_{i}>0
\end{array},\right.
$$

which is written in complementary slackness form. ${ }^{10}$ The sign of $\psi_{1}$ determines whether this is a game of strategic substitutes $\left(\psi_{1}<0\right)$ or strategic complements $\left(\psi_{1}>0\right)$. Equation (5) then implies that with strategic complements, in any equilibrium all municipalities will invest in a strictly positive level of state capacity (see the Appendix).

For the national level, the first-order conditions with respect to each $b_{i}$ imply that the national state's best responses yield

$(1-\alpha) \tau^{\frac{\sigma-1}{\sigma}}\left[\frac{s_{i}}{b_{i}}\right]^{\frac{1}{\sigma}}\left\{\zeta_{i}\left[\left(\kappa_{i}+\xi_{i}\right)+\psi_{1} \mathbf{N}_{i}(\boldsymbol{\delta}) \mathbf{s}\right]+\psi_{1} \mathbf{N}_{i}(\boldsymbol{\delta})(\mathbf{s} * \boldsymbol{\zeta})+\frac{\sum_{j} \psi_{2}^{j}}{J} \mathbf{N}_{i}(\boldsymbol{\delta}) \boldsymbol{\zeta}\right\}-\eta b_{i}\left\{\begin{array}{ll}<0 & b_{i}=0 \\ =0 & b_{i}>0\end{array}\right.$,

where $*$ designates element by element multiplication. Notice from equation (6) that for any set of non-negative weights $\zeta$ such that $\zeta_{k}>0$ for at least one $k \in N(i)$ for all $i, \psi_{1}>0$ and $\psi_{2}^{j}>0$ for all $j$ is a sufficient condition for $b_{i}>0$ in any equilibrium. In other words, if spillovers are positive and the game is one of strategic complements, the only way the national level could allocate no state presence in municipality $i$ is if both this municipality's weight and the weights of all of its neighbors are zero. As we will describe below, in our data both local and national state capacity choices are strictly positive for all municipalities. This will allow us to focus on interior equilibria. The following result is straightforward.

Proposition 1. Sufficient conditions for a pure-strategy equilibrium of this game to exists are either (i) $\psi_{1}>0$, or (ii) $\alpha<l_{i}^{\frac{\sigma+1}{\sigma}} s_{i}^{\frac{\sigma-1}{\sigma}}$.

Existence of pure-strategy equilibria in this game follows either from strategic complementarities $\left(\psi_{1}>0\right)$ or from Kakutani's fixed point theorem and the concavity of the payoff function in own strategy (the strategy space can be made compact by putting an arbitrary bound on state capacity). The inequality in Proposition 1 ensures that the payoff function of municipality $i$ is concave in its strategy. If neither condition (i) nor (ii) in this proposition is satisfied, existence can still be guaranteed for sufficiently small magnitudes of the interaction effect $\psi_{1}$ (see the Appendix).

Regarding uniqueness, recent research by Allouch (2012) establishes that for network games with nonlinear best responses, a bound on the slope of the best responses is a sufficient condition for uniqueness. This bound is a function of the lowest eigenvalue of the network matrix $\mathbf{N}(\boldsymbol{\delta})$. This is because the eigenvalues capture the extent to which the spillovers across agents are either dampened

\footnotetext{
${ }^{10}$ Note that if, as is natural, $\left(\kappa_{i}+\xi_{i}\right) \geq 0$, then $\psi_{1}<0$ is necessary for $l_{i}=0$.
} 
or magnified through the network structure. This result can be adapted to our setting. Denoting the smallest eigenvalue of the matrix $\mathbf{N}(\boldsymbol{\delta})$ by $\lambda_{\min }$, we have the following:

Proposition 2. (Allouch (2012)). If for every player $1+\frac{1}{\lambda_{\min }(\mathbf{N}(\boldsymbol{\delta}))}<\left(\frac{\partial l_{i}}{\partial \mathbf{N}_{i}(\boldsymbol{\delta}) \mathbf{s}}\right)^{-1}<1$, then the game has a unique Nash equilibrium.

For the estimated parameter vector $\left(\alpha, \sigma, \theta, \psi_{1}, \boldsymbol{\delta}\right)$, the conditions in Propositions 1 and 2 are readily verifiable. Equations (1), (5), and (6) determine the joint equilibrium distribution of state capacity, both local and national, and prosperity.

\subsection{The Linear Case $(\alpha=1)$ :}

Our model simplifies considerably in the case where $\alpha=1$, which imposes $s_{i}=l_{i}$ in equation (5), so that the national state's choices are irrelevant. In this case, the best response equation (5) becomes linear in neighbors' state capacity:

$$
s_{i}=\frac{\psi_{1}}{\theta} \mathbf{N}_{i}(\boldsymbol{\delta}) \mathbf{s}+\frac{\kappa_{i}}{\theta}+\tilde{\xi}_{i}
$$

where $\tilde{\xi}_{i} \equiv \frac{\xi_{i}}{\theta}$. Equation (7) also illustrates that even if properly identified, the interpretation of the linear regression estimate of the "endogenous effect" should take into account that it is a reduced-form coefficient. ${ }^{11}$ It corresponds not to a simple causal effect, but to the ratio of the interaction (cross) effect to the elasticity of the marginal cost of investment in state capacity.

Now substituting for $s_{i}$ from (7) into (1), we obtain the observed relationship between prosperity and own and neighbors' state capacity as:

$$
p_{i}^{j}=\theta s_{i}^{2}+\psi_{2}^{j} \mathbf{N}_{i}(\boldsymbol{\delta}) \mathbf{s}+\epsilon_{i}^{j} .
$$

Equation (8) highlights that the identification of the impact of own state capacity on prosperity, $\left(\kappa_{i}, \xi_{i}\right)$, and of the interaction effect, $\psi_{1}$, requires some care. This is because the optimizing choices of a municipality ensure that $\kappa_{i}, \xi_{i}$, and $\psi_{1}$ drop out of the relationship between prosperity and state capacity. Instead, such a regression can only identify (in addition to the spillover parameter $\psi_{2}$ ) the cost parameter $\theta$. Our empirical approach, detailed below, will overcome this difficulty as well. ${ }^{12}$

With $\alpha=1$, existence of pure strategy equilibria follows immediately from concavity (and Kakutani's fixed point theorem as explained above). Uniqueness of an interior (positive) equilibrium

\footnotetext{
${ }^{11}$ In particular, $\frac{\psi_{1}}{\theta}$ in equation (7) is referred to in the peer effects literature as an "endogenous effect," corresponding to the effect of neighbors' or peers' choice on own choice, while the $\psi_{2}^{j}$ 's in equation (8) are referred to as "contextual effects" (see, e.g., Manski, 1993).

${ }^{12}$ In addition, the spillovers and feedbacks between municipality choices within the network game imply a quadratic reduced-form relationship between own state capacity and prosperity, so linear regressions may lead to misspecification, though we will see below that marginal effects from the estimation of "naive" linear regressions, when properly instrumented, are similar to our structural estimates.
} 
(where all municipalities choose a positive investment in state capacity) is also guaranteed, since such an equilibrium is given by the solution to a set of linear equations. However, multiple equilibria with some municipalities choosing zero investment is possible. A sufficient condition for equilibrium uniqueness is given by Bramoulle, Kranton, and D'Amours (2012) and can be applied directly here. Applying this condition and combining it with the existence of equilibrium, we obtain:

Proposition 3. (Bramoulle, Kranton, and D'Amours (2012)). If $\left|\lambda_{\min }(\mathbf{N}(\boldsymbol{\delta}))\right|<\left(\frac{\psi_{1}}{\theta}\right)^{-1}$, then there exists a unique equilibrium.

For an estimated parameter vector $\left(\theta, \psi_{1}, \boldsymbol{\delta}\right)$, the uniqueness condition in this proposition can also be verified empirically.

Equations (7) and (8) determine the joint distribution of local state capacity and prosperity across municipalities, and will be the focus of the first part of the paper. The identification challenge mentioned above notwithstanding, all the key parameters $\left(\theta, \psi_{1}, \boldsymbol{\psi}_{2}, \boldsymbol{\delta}\right)$ can be identified by estimating both equations simultaneously and with the appropriate sources of variation. The parameter $\theta$ is identified from (8), and given this parameter, $\psi_{1}$ can be recovered from the endogenous effect estimated in (7) and the local average of the $\kappa_{i}$ 's from the intercept of the same equation. Of course, the $\xi_{i}$ and $\epsilon_{i}^{j}$ are also likely to include unobserved "correlated effects" (and in fact, throughout we allow arbitrary spatial correlation in these unobservables). Our empirical strategy tackles this problem relying on historical sources of variation in local state presence.

\section{Data}

For our empirical implementation, the data we use, summarized as $\left\{\left(\mathbf{p}_{i}, l_{i}, b_{i}, \mathbf{x}_{i}, \mathbf{c}_{i}\right)_{i=1}^{n}, \mathbf{D}, \mathbf{E}, \mathbf{A}\right\}$, include cross-sectional information on several dimensions of prosperity $\mathbf{p}_{i}$, local $\left(l_{i}\right)$ and national $\left(b_{i}\right)$ choices of state capacity, municipality characteristics $\mathbf{x}_{i}$, and colonial state presence characteristics $\mathbf{c}_{i}$. In addition, $\mathbf{D}, \mathbf{E}$, and $\mathbf{A}$ are $n \times n$ matrices containing the geodesic distances between the centroids of all pairs of municipalities, an index of variability in altitude along these geodesics, and the adjacency status of each pair of municipalities, respectively. We describe the nature and sources of these data below.

We compiled the data from several sources. The Fundacion Social (FS), a Colombian NGO, collected and put together detailed data on state presence at the municipality level in 1995. Out of a total of 1,103 municipalities in Colombia, FS collected data for 1,019 of them, which comprise our main sample and the number of nodes in our network.

Descriptive statistics for all of our data are presented in Table 1. For each municipality, FS recorded the number of municipality (local) public employees, the number of national stated public 
employees, the number of police stations, courts, notary offices, Telecom offices, post offices, agricultural bank branches, public hospitals, public health centers, public health posts, public schools, public libraries, fire stations, jails, deed registry offices, and tax collection offices.

Because our theoretical framework stresses and exploits the difference between locally and nationally chosen levels of state capacity, we rely on the Colombian legislation to establish the presence and the number of employees of agencies which are decided at the local level, and those which are decided at the national level. ${ }^{13}$ Police, courts, and public hospitals fall under the responsibility of the national government. The location of agricultural bank branches was also partly determined centrally. All other agencies are under the jurisdiction of the municipality. Because, as noted in the Introduction, our interest is closely related to the "infrastructural" features of state capacity, we construct two measures of local state capacity $l_{i}$ : (a) the number of municipality-level bureaucrats, which excludes police officers, judges, all other judicial employees, and public hospital employees, and (b) the total count of municipality state agencies, namely, notary offices, Telecom offices, post offices, health centers, health posts, schools, libraries, fire stations, jails, deed registry offices, and tax collection offices. We treat these two variables as alternative measures of local state capacity. We use the number of national public employees as our measure of national state capacity $b_{i}$.

Municipalities have three main revenue sources to finance public spending and investment in state infrastructure and bureaucracy: Local taxes (industry and commerce tax, and property tax, mainly), royalties from mining activities, and transfers from the central government. The bulk of central government transfers ("situado fiscal") are allocated to each municipality using a fixed rule (geographically, this allocation is at the departmental level). These resources directly enter into the municipality's budget. Though the law stipulates that at least $60 \%$ of these transfers must go to education, and at least $20 \%$ to health (Law 60 of 1993), it also grants full discretion to the municipality on their specific allocation and use. In particular, mayors (who are elected officials since 1988) propose a budget to elected municipality councils, which is implemented if approved by the council.

To measure local prosperity, we collected available data from various sources. The Centro de Estudios sobre Desarrollo Economico (CEDE) at Universidad de los Andes provided us with average 1992-2002 primary and secondary enrollment rates. From the OCHA group at the United Nations, we collected data on aqueduct, sewage, and electricity household coverage rates in 2002, and on vaccination rates in 2002. Finally, from the Colombian national statistics bureau (DANE) we have data on the fraction of the population in poverty (under the poverty line) in 1993 and 2005, and on

\footnotetext{
${ }^{13}$ Law 60 of 1993 and Law 04 of 1991 establish the distribution of responsibilities among the national and subnational levels in Colombia.
} 
a life quality index for 1998. Based on these data, we focus on four prosperity outcomes which are likely to depend on local state capacity: (a) the life quality index $p_{i}^{1}$, (b) the average public utilities coverage in 2002 (aggregating aqueduct, sewage, and electricity) $p_{i}^{2}$, (c) the population above the poverty line in $2005 p_{i}^{3}$, and (d) the secondary enrollment rate $p_{i}^{4}$. All of our prosperity measures are standardized $z$-scores (number of standard deviations the observation is above the mean for that measure). We focus on these four prosperity outcomes because, although they are positively correlated, as Figure 2 shows the shape of each distribution is significantly different. Thus, each of these dimensions of prosperity is likely to provide relevant information.

In contrast to these measures, primary school enrollment and vaccination coverage should not depend on local state capacity. Public investments targeting these outcomes are highly centralized. In fact, the Colombian Constitution mandates universal primary school enrollment. The descriptive statistics in Table 1 show the very high average levels of primary enrollment, and the small variation of this variable across municipalities. Moreover, the Ministry of Health directly operates the vaccination efforts through national campaigns. In our robustness section below we use these two development outcomes in a falsification exercise, showing their lack of relationship to own and neighbors' state capacity. Additionally, we constructed historical literacy and school enrollment rates from the 1918 National Census.

We built the adjacency matrix of municipalities $\mathbf{A}$ based on the Colombian national geographic institute (IGAC). ${ }^{14}$ Using Arc-GIS georeferenced data, we computed the geodesic ("as the bird flies") distance between the centroid of each pair of municipalities $d_{i j}$, and organize this data in matrix $\mathbf{D}$. Also using Arc-GIS and georeferenced topographic data for Colombia, we computed $e_{i j}$, the index of the variability in altitude along the geodesic connecting the centroid of every pair of municipalities, capturing the frictions that a more uneven path connecting two municipalities imposes over the opportunities for contact and spillovers between them. More specifically, we divided each geodesic into a number of intervals for a given altitude range along the geodesic itself, and computed the average altitude of each of the intervals. The $e_{i j}$ is then computed as the variance of the average altitude across intervals, where each interval is appropriately weighted by its length. We organize these data into the matrix $\mathbf{E}$.

As already mentioned, we exploit variation in several dimensions of Spanish colonial state presence in Colombia by using historical data originally collected by Duran y Diaz (1794). ${ }^{15}$ This document

\footnotetext{
${ }^{14}$ We are excluding from our analysis the two municipalities in the Department of San Andres, which is an archipelago in the Caribbean comprised of several smaller islands and located $775 \mathrm{kms}$. from the mainland.

${ }^{15}$ This source is located at the National Library in Bogota that contains a full account of state officials, salaries, the military, tariffs, taxes and fiscal revenue among others for all of the Viceroyalty of Nueva Granada in the late 18th century. We thank Malcolm Deas for pointing us to this document.
} 
specifies the location of officials and state administrations. Of particular interest, Duran y Diaz (1794) has a complete record of every colonial official and of several state agencies throughout the viceroyalty. From this document we compiled municipality-level data on the number of crown employees, and indicators on the presence of an alcabala, ${ }^{16}$ a tobacco or playing cards estanco, ${ }^{17}$ a liquor or gunpowder estanco, and a post office. In addition to these variables, we collected information from historical maps in Useche (1995) which depict the location of colonial royal roads. We georeferenced these maps using Arc-GIS, and computed the distance between the centroid of each municipality and the closest royal road. Based on these data, we then constructed three measures of colonial state presence: (a) the number of crown employees, denoted by $c_{i}^{1}$, (b) a count of the number of agencies reported by Duran y Diaz, denoted by $c_{i}^{2},{ }^{18}$ and (c) the distance to the closest royal road, denoted by $c_{i}^{3}$. We also collected the population data from the 1843 National Census, which we use as an instrument for current population in specifications where we allow for current population to be endogenous.

Finally our main covariates included in all specifications (in the vector $\mathbf{x}_{i}$ ) are distance to a current highway, longitude, latitude, surface area, altitude, and average annual rainfall (all obtained from CEDE) as well as (log) population in 1995 (obtained from the Colombian government's national statistical institution, the DANE). In some specifications, we also use the following additional covariates: the density of primary, secondary, and tertiary rivers (from CEDE), and the distribution of land in each municipality by land quality, coded as the share of each of eight qualities, and by land type, classified as under water, valley, mountain, hill and plain (obtained from IGAC).

\section{$5 \quad$ Empirical Strategy and Results}

Our structural model fully determines the cross-sectional distribution of equilibrium state capacity choices and prosperity outcomes. ${ }^{19}$ Our empirical strategy has multiple components. In this section we first discuss the exclusion restrictions implied by our use of several historical variables as instruments in the context of the simplified game where $\alpha=1$. The same arguments also apply to the general model discussed in the next section. We then turn to various estimation strategies and empirical findings. As a preview, we find municipalities' state capacity investment decisions are strategic complements, and that the complementarity is weak enough that our parameter estimates

\footnotetext{
${ }^{16}$ The alcabala was a sales tax (usually at $2 \%$ ). The indicator denotes the presence of the local agency in charge of collecting the tax.

${ }^{17}$ An estanco was a state monopoly over the sale of a particular good, which also often allocated production rights and regulated quantities. The indicator denotes the presence of the local agency in charge of administering the estanco.

${ }^{18}$ Thus, this variable takes values in the set $\{0,1,2,3,4\}$.

${ }^{19}$ One could suppose that our cross-sectional data reflect the resting point of a long-run dynamical process, for example, reflecting some sort of adaptive dynamics. If these dynamics are driven by the best responses of the model outlined above, then the conditions for uniqueness in Propositions 2 and 3 also ensure convergence (stability) of the dynamical process to the equilibrium characterized above.
} 
are always consistent with the network game having a unique equilibrium. Our findings indicate that all of our prosperity outcomes are strongly dependent on the overall levels of state capacity in a municipality, and that state capacity spillovers are significant. Quantitatively, we find that in partial equilibrium, the own effect of state capacity on prosperity is larger than the average effect of neighbors' state capacity. The picture is very different in full equilibrium, when the endogenous responses of state capacity in the network are factored in. In this case, network effects are about 5-10 times the own effect of a municipality's state capacity.

\subsection{Exclusion Restrictions}

We face three distinct challenges in our empirical work. First, recall that in the network equilibrium, the best response of each municipality implies that in the reduced-form relationship between prosperity and state capacity, both the interaction effect, $\psi_{1}$, and the own effect, $\kappa_{i}$, drop out (see equation (8)), and cannot be identified from the relationship between prosperity outcomes and state capacity. Nevertheless, they can both be recovered from the best response equation (9). In particular, the slope of this equation is proportional to the interaction effect, and its intercept is proportional to the "own effect". Recall also from our previous discussion that this own effect is likely to be heterogeneous across municipalities for several reasons. We argue that colonial state presence may have altered the relative costs and benefits of subsequent investments in local state presence and thus, the magnitude of the own effect. This means that colonial state presence (and distance to royal roads) can be interpreted as shifters of the best response equations.

Second, the investigation of the extent of strategic complementarities or substitutabilities (i.e., the estimation of $\psi_{1}$ ) involves the estimation of an "endogenous effect" where own state capacity depends on neighbors' state capacity. This is a more challenging empirical problem because of the reflection problem and the presence of spatially (across neighbors) correlated effects (Manski, 1993). In our setting, the network interactions imply that even if the $\tilde{\xi}_{i}$ 's in equation (7) were pure noise, we would still have $\operatorname{cov}\left(\mathbf{N}_{i}(\boldsymbol{\delta}) \mathbf{s}, \tilde{\xi}_{i}\right) \neq 0$ (throughout, we allow arbitrary spatial correlation in the $\tilde{\xi}_{i}$ 's as well as in the error term in the prosperity equation, the $\epsilon_{i}$ 's).

The estimation of the effect of neighbors' state capacity requires sources of variation in neighbors' state capacity distinct from shifters of own state capacity. Common in the literature is an approach that exploits network structure, based on Bramoulle, Djeebari, and Fortin's (2009) idea of using covariates of neighbors of neighbors (that are not direct neighbors themselves) as instruments. Though creative, this approach may not fully overcome correlated effects that go beyond direct neighborhoods. Our approach also uses the network structure of municipalities but crucially relies on the use of measures of colonial state presence and the royal roads network as sources of 
variation (shifters of $\kappa_{i}$ ). In practice, to identify the slope of $i$ 's best response function, we use the colonial state of municipality $i$ 's neighbors and neighbors of neighbors as shifters of $i$ 's neighbors' best response functions.

Differently from the strategy of using contemporary covariates, the strategy of using historical colonial state presence (and distance to royal roads) as shifters of the best response functions will be robust to correlated effects in state capacity today, public goods provision and prosperity. Indeed, the key identifying (exclusion) restrictions for us are that these historical variables are orthogonal to the error terms in the best response equation (7), and to any correlated effects. In the notation introduced above, this requires $\operatorname{cov}\left(\mathbf{N}_{i}(\boldsymbol{\delta}) \mathbf{c}, \tilde{\xi}_{i}\right)=0$ and $\operatorname{cov}\left(\mathbf{N}_{i}^{2}(\boldsymbol{\delta}) \mathbf{c}, \tilde{\xi}_{i}\right)=0$, where $\mathbf{N}^{2}(\boldsymbol{\delta})$ denotes the matrix of neighbors of neighbors.

Third, the estimation of the prosperity equation (8) also faces empirical challenges. Even in the absence of spillovers and strategic interactions, state capacity is endogenous (which implies $\operatorname{cov}\left(s_{i}, \boldsymbol{\epsilon}_{i}\right) \neq 0$ and $\operatorname{cov}\left(\mathbf{N}_{i}(\boldsymbol{\delta}) \mathbf{s}, \boldsymbol{\epsilon}_{i}\right) \neq 0$, a problem made worse by spatial correlation of these outcomes). Hence, credible estimates of both $\theta$ and $\psi_{2}$ will require sources of variation that satisfy plausible exclusion restrictions. Estimation of $\theta$ will allow us to identify the magnitudes of both $\psi_{1}$ and $\kappa_{i}$, and estimation of $\psi_{2}$ will inform us about the magnitude of the state capacity spillovers. Under the assumption (exclusion restriction) that neighbors' and neighbors of neighbors' colonial state presence and distance to royal roads variables are orthogonal to omitted own and neighborhood unobservables, these can be used as instruments, regardless of any correlated effects that impact current public good provision and prosperity. In terms of our notation, the exclusion restrictions are $\operatorname{cov}\left(\mathbf{N}_{i}(\boldsymbol{\delta}) \mathbf{c}, \epsilon_{i}^{j}\right)=0$ and $\operatorname{cov}\left(\mathbf{N}_{i}^{2}(\boldsymbol{\delta}) \mathbf{c}, \epsilon_{i}^{j}\right)=0$. Thus, we are exploiting shifts in the best responses of municipality $i$ 's neighbors. ${ }^{20}$

Our exclusion restrictions are motivated by the nature of the colonial state in Colombia. Figure 1 presents the geographic distribution of two of our measures of colonial state presence, the size of the crown bureaucracy, and the number of state agencies. The salient feature of these figures is the lack of uniformity in colonial state presence across (contemporary) municipalities. The clustering of state presence around specific areas, beyond which the colonial state was mostly absent, is notable. The colonial settlement strategy led to the concentration of bureaucracies and agencies in particular cities, which would have control and jurisdiction over surrounding areas. As such, towns with relatively high levels of colonial state presence got to be surrounded by towns with relatively low presence. The main reasons for this specific state-building strategy by the Spanish colonial state are related to the objectives and constraints faced by the Spanish authorities, which were likely to be varied

\footnotetext{
${ }^{20}$ The fact that we have more instruments than endogenous variables also enables us to check the robustness of our results to assuming different types of network interactions.
} 
and heterogeneous across space. For example, in regions heavily involved in gold mining during the 17th and 18th centuries, the presence of colonial officials and crown agencies was narrowly related to taxation functions and followed the gold reserves. In regions with higher densities of Spanish settlers and their descendants, on the other hand, the demand for public services such as legal adjudication and market regulation translated into a different type of colonial state. Finally, in strategically located places such as the Caribbean coast or key outposts along the Magdalena River (the main communications channel at the time) the presence of the Spanish colonial state was related to military objectives such as the provision of services to the Spanish fleet.

In our data, consistent with the heterogeneous objectives of the colonial authorities, the spatial correlation of the colonial state is very weak or negative. This can be seen in Table 2 , which presents the within-department spatial correlation matrix of our three colonial state presence variables. Own colonial state employees are weakly negatively correlated with neighbors' and neighbors of neighbors' colonial state employees $(-0.061$ and -0.062 respectively). Similarly, own colonial state agencies are basically uncorrelated with neighbors' and neighbors of neighbors' colonial state agencies (0.022 and 0.078 respectively). This pattern is reassuring for our exclusion restrictions, which require that these historical variables are orthogonal to any unobserved correlated effects influencing current state capacity, public goods or prosperity. Thus their weak and negative spatial correlation bolsters our confidence in our exclusion restriction.

As mentioned above, we additionally collected information on royal roads as a proxy for colonial state presence. The royal roads network was the main investment in communications infrastructure during the colonial period (see Useche, 1995). It was partially inherited from pre-colonial roads, and partially built under Spanish authority. Pre-colonial roads often involved steep flights of steps unsuited to horse or cart traffic (see Langebaek, Giraldo, Bernal, Monroy, and Barragan, 2000). There is also archaeological evidence that indigenous roads were partly developed for pilgrimage to sacred places which were irrelevant to the Spanish. The difficulties of converting colonial royal roads into modern motor roads were significant (see Pachon and Ramirez, 2006). Some were built for porterage along difficult geographic paths such as mountain edges, making them hard to subsequently reconvert to railroads or highways. As a result, though the location of these roads reflects accurately the presence of the colonial state and thus the regions where the Spanish authorities were more interested in controlling the territory, most of the royal roads network was subsequently abandoned and is unlikely to be a direct influence on current state capacity, public goods or prosperity (especially since we also control for the current road network). Moreover, and somewhat surprisingly for a distance measure, the spatial correlation of our distance to royal roads variable is also only very weak (but this time positive). Table 2 shows that own and neighboring distance to royal roads has only a 
0.28 correlation, and the correlation falls to 0.045 between own and neighbors of neighbors' distance to royal roads. In conjunction with the colonial state presence variables that are spatially negatively correlated, this pattern alleviates any concerns resulting from spatially correlated instruments leading to biased estimates.

\subsection{Estimates of the Linear Model}

We propose several alternative estimation strategies, all relying on the exclusion restrictions outlined above. First, we assume that $\alpha=1$, which ensures that the equilibrium relationships in equations (7) and (8) are linear (in the reduced-form parameter $\frac{\psi_{1}}{\theta}$, and $\theta$ and $\psi_{2}^{j}$ ). As pointed out above, we posit the intercept of the best response equation $\frac{\kappa_{i}}{\theta}$ (or equivalently $\kappa_{i}$ ), to be an unknown function $g(\cdot)$ of $\left(\mathbf{c}_{i}, \mathbf{x}_{i}\right)$ and also to depend arbitrarily on the department in which the municipality is located. The form of equation (7) we estimate then becomes:

$$
s_{i}=\frac{\psi_{1}}{\theta} \mathbf{N}_{i}(\boldsymbol{\delta}) \mathbf{s}+g\left(\mathbf{c}_{i} \boldsymbol{\varphi}+\mathbf{x}_{i} \boldsymbol{\beta}\right)+\varsigma^{D}+\tilde{\xi}_{i}
$$

where the $\varsigma^{D}$ are department fixed effects. Similarly, in our estimating equations for the prosperity outcomes, we include municipality characteristics and department fixed effects as potential shifters, so that equation (8) can be written as: ${ }^{21}$

$$
p_{i}^{j}=\theta s_{i}^{2}+\psi_{2}^{j} \mathbf{N}_{i}(\boldsymbol{\delta}) \mathbf{s}+\mathbf{x}_{i} \tilde{\boldsymbol{\beta}}^{j}+\tilde{\varsigma}^{j D}+\epsilon_{i}^{j} .
$$

The first and most straightforward approach we pursue is to fix $\boldsymbol{\delta}$ and let $g(\cdot)$ be approximated by a linear function (or more generally a polynomial), which enables us to estimate equations (9) and (10) using linear instrumental variables. We thus estimate (7) and (8) independently. In practice, we use six instruments for $\mathbf{N}_{i}(\boldsymbol{\delta}) \mathbf{s}$ in our benchmark specification of (9): Neighbors' crown employees, number of neighbors' colonial agencies, neighbors' distance to royal roads, and neighbors of neighbors' crown employees, number of neighbors of neighbors' colonial agencies, and neighbors of neighbor's distance to royal roads.

Our model is overidentified, enabling us to perform overidentification tests to verify the (internal) validity of our instruments (and also below we report estimates using only subsets of the instruments). For our benchmark specification of equation (10) we use the same set of instruments, but also exploit the nonlinear reduced-form relationship between prosperity and state capacity by including a quartic of these instruments. For the case of the prosperity equation, we have two first stages, one for $s_{i}^{2}$ and one for $\mathbf{N}_{i}(\boldsymbol{\delta}) \mathbf{s}$.

\footnotetext{
${ }^{21}$ With the same argument as for $\kappa_{i}, \xi_{i}$ and $\psi_{1}$ dropping out from (1), $g\left(\mathbf{c}_{i} \boldsymbol{\varphi}+\mathbf{x}_{i} \boldsymbol{\beta}\right)$ in (9) drops out and does not appear in (10), but we allow these characteristics to enter as independent shifters of the prosperity measures.
} 
Table 3 presents the estimates for equation (9), where we impose $\boldsymbol{\delta}=(1,1)$ and assume $g(\cdot)$ to be a linear function: $g\left(\mathbf{c}_{i} \boldsymbol{\varphi}+\mathbf{x}_{i} \boldsymbol{\beta}\right)=a+\mathbf{c}_{i} \boldsymbol{\varphi}+\mathbf{x}_{i} \boldsymbol{\beta}$. In our benchmark estimates, as noted in the previous section, our vector of covariates $\mathbf{x}_{i}$ includes longitude, latitude, surface area, elevation, rainfall, a dummy for department capital, distance to a current highway, and current (1995) population. We measure state capacity alternately as the number of public agencies (columns 1-3) or the number of municipality employees (columns 5-7). All reported values are average marginal effects for ease of comparison. Throughout, all standard errors are corrected for spatial correlation using the Conley (1996) adjustment, adapted to our network structure. ${ }^{22}$ Standard errors for the reported marginal effects are computed using the delta method.

Columns 1 and 5 present OLS estimates as a benchmark. Columns 2 and 6 present the instrumental variables estimates for the same equation (with log population treated as an exogenous covariate). Estimates for the first stage of this model are presented in the bottom panel of Table 3, together with the results of an overidentification test on the IV models. The bottom panel includes the first stage for $\mathbf{N}_{i}(\boldsymbol{\delta})$ s, where we can see a clear positive and strong correlation between neighboring measures of colonial state presence, and neighboring contemporary state capacity. In no specification do we reject the null hypothesis that instruments are valid, giving us some confidence in our exclusion restrictions. Columns 3 and 7 treat population as endogenous, instrumenting it using the 1843 population (we also include a dummy for municipalities without population data in the 1843 Census).

All of our estimates in Table 3 show a positive and precisely estimated slope for the best response equation, also implying a positive interaction effect $\psi_{1}$. These estimates imply that the game between municipalities exhibits strategic complementarities. Interestingly, the IV estimates are always close to the OLS estimates. The estimate in the top of column 3, 0.020 (s.e.=0.003), implies that moving the number of state agencies of a neighbor from the median (10) to the mean (21) leads to a $1.5 \%$ increase in own state agencies at the median of the distribution. ${ }^{23}$ Notice this is only the direct ("partial equilibrium") response, and does not take into account equilibrium feedbacks that take place through network effects as other municipalities also respond (due to strategic complementarities).

\footnotetext{
${ }^{22}$ The robust spatial correlation-corrected variance matrix of the IV estimator takes the form

$$
\begin{gathered}
\left(\mathbf{X}^{\prime} \mathbf{Z}\left(\mathbf{Z}^{\prime} \mathbf{Z}\right)^{-1} \mathbf{Z}^{\prime} \mathbf{X}\right)^{-1} \mathbf{X}^{\prime} \mathbf{Z}\left(\mathbf{Z}^{\prime} \mathbf{Z}\right)^{-1} \mathbf{Z}^{\prime} \hat{\mathbf{W}} \mathbf{Z}\left(\mathbf{Z}^{\prime} \mathbf{Z}\right)^{-1} \mathbf{Z}^{\prime} \mathbf{X}\left(\mathbf{X}^{\prime} \mathbf{Z}\left(\mathbf{Z}^{\prime} \mathbf{Z}\right)^{-1} \mathbf{Z}^{\prime} \mathbf{X}\right)^{-1}, \text { where } \\
\hat{\mathbf{W}}=\boldsymbol{\Omega} * \mathbf{I}+\sum_{j=1}^{t} \frac{t+1-j}{t+1}\left(\boldsymbol{\Omega} * \mathbf{N}^{t}(\boldsymbol{\delta})+\left[\boldsymbol{\Omega} * \mathbf{N}^{t}(\boldsymbol{\delta})\right]^{\prime}\right)
\end{gathered}
$$
}

$t$ is the highest network degree at which we truncate spatial correlation (we truncate the spatial correlation at seconddegree adjacency, in practice allowing for arbitrary decaying spatial correlation between neighbors and neighbors of neighbors), $\boldsymbol{\Omega}$ is the outer product of the residuals, $*$ denotes element-by-element multiplication, and $\mathbf{N}^{t}(\boldsymbol{\delta})$ denotes the $t$-th degree network matrix (the matrix whose $i j$ 'th entry is zero if $i$ and $j$ are not neighbors of degree $t$, and $f_{i j}$ otherwise).

${ }^{23} 10.15=\exp ((0.02) \ln (22 / 11)+\ln (11))-1$, which is a $1.5 \%$ increase from the median state capacity of 10. 
Column 6 of Table 3 presents the results of the IV estimate of $\psi_{1} / \theta(0.022$, s.e. $=0.004)$ with the alternative measure of state capacity, municipality employees. The estimates in this case have very similar magnitude to those using the number of local state agencies and are also estimated with similar precision.

The bottom panel of the table presents the first stages. Throughout, colonial state presence is associated with increased current state capacity. When all measures of historical state presence are introduced simultaneously, colonial state officials remain significant. Due to collinearity among them, the number of colonial state agencies and distance to royal roads are typically insignificant (except in the System GMM estimates discussed below). Nevertheless, in all models where we introduce only subsets of our colonial state measures, colonial state agencies and distance to royal roads are statistically significant with the expected sign. Results are also very similar when we treat $(\log )$ population as endogenous and instrument it by historical population (compare columns 2 to 3 and 6 to 7$)$.

Marginal effects from the estimates of equation (10) are presented in Tables 4A and 4B. Similarly to the estimates reported for equation (9), we present benchmark OLS and IV results from the estimation of each of our four prosperity outcomes equations separately. Columns 1-3 present results for the life quality index, columns 5-7 for utilities coverage, columns 9-11 for the fraction of the population above the poverty line, and columns 13-15 for the secondary enrollment rate. Table $4 \mathrm{~A}$ presents the estimates for the models using the number of agencies, and Table $4 \mathrm{~B}$ presents the estimates for the models using the number of municipality employees. Once again, we first control for population and subsequently instrument it with historical (1843) population. In all cases, we find both strong own effects that are quite significant and also very precisely estimated spillover effects. Across outcomes and specifications, we find an own marginal effect $(2 \theta \bar{s})$ that is an order of magnitude larger than the spillover effect. ${ }^{24} \mathrm{~A}$ p-value for the joint significance of the set of instruments in both first stages is reported in the bottom panel of Tables 4A and 4B. IV estimates are somewhat smaller than OLS estimates, and very similar regardless of whether log population is treated as exogenous or endogenous. ${ }^{25}$

To assess the quantitative magnitudes of our estimates, Table 5 presents the results of a counterfactual experiment showing the implications of increasing local state presence to the median, in

\footnotetext{
${ }^{24}$ The average spillover effect is computed as $\psi_{2}^{j} \bar{n}_{i}$, where $\overline{n_{i}}$ is the average number of "weighted" neighbors of a municipality, with $f_{i j}$ 's as weights. Because this spillover is on more than one municipality, in the quantitative exercise in Table 5 the partial equilibrium direct effect and spillovers are roughly of the same order of magnitude.

${ }^{25}$ Moreover, in all specifications, at our estimated parameters, the uniqueness condition from Proposition 3 is comfortably satisfied. This still leaves the question of whether, for a different set of parameters, there might be multiple equilibria and we may incorrectly estimate a parameter vector implying uniqueness. We believe this is unlikely, since our estimates are far from the values that would imply multiplicity.
} 
all municipalities below median local state presence. The first two panels of the table present the results from the linear IV estimates reported in this subsection (the third and fourth panels contain estimates from the general model and will be discussed in the next subsection). The first panel depicts the partial equilibrium effects (holding the response of other municipalities constant) and shows significant and sizable impacts on the quality of life index, the fraction of the population above poverty, utilities coverage and secondary enrollment. For example, the median fraction of the population above poverty increases from $57 \%$ to $60 \%$. The table also indicates that about $57 \%$ of this is due to direct effects, so that spillover effects are not implausibly large, though still sizable. The second panel then factors in the full equilibrium responses through network effects. Now the quantitative magnitudes are much larger - reflecting the positive responses due to strategic complementarities. For example, the median fraction above poverty now rises to $68 \%$. This is indicative of the importance of network effects in this setting.

\subsection{System GMM}

Separately estimating equations (9) and (10) is in general inefficient because that the system of $J+1$ equations imposes several cross-equation restrictions due to their joint dependence on $\theta, \psi_{1}$ and $\boldsymbol{\delta}$. Moreover, since the shape of the function $g(\cdot)$ is in general unknown, we would like to allow the intercept of the best response to depend on the covariates in $\mathbf{x}_{i}$ and colonial state $\mathbf{c}_{i}$ more flexibly. Motivated by this reasoning, we estimate equations (9) and (10) as a system through a semiparametric GMM approach building on Ichimura and Lee (1991). Following this methodology, we created moment conditions using the orthogonality of our instruments and the residuals in equations (9) and (10), and estimated the parameters of this system through a semi-parametric GMM estimator. This enables us to explictly include the cross-equation restrictions, to allow for the network links to depend nonlinearly on topographic features, and to estimate $g(\cdot)$ semi-parametrically. ${ }^{26}$

To identify $\boldsymbol{\delta}$ (when it is not imposed), we include as moment conditions functions of $d_{i j}$ and $e_{i j}$. In particular, we use the average distance of each municipality to neighboring municipalities, and the

\footnotetext{
${ }^{26}$ Following Ichimura and Lee (1991), we use a flexible semi-parametric index-function approach for the purpose of estimating $g(\cdot)$ by constructing the conditional expectation of the unknown function using only the empirical distribution. To smooth out the distribution, we use a density kernel that gives greater weights the closer observations. In particular, we divide the range of the function in many bins.
}

$$
\mathbb{E}\left[g\left(\mathbf{c}_{i} \boldsymbol{\varphi}+\mathbf{x}_{i} \boldsymbol{\beta}\right)\right]=\frac{\sum_{j=1}^{n}\left[s_{j}-\frac{\psi_{1}}{\theta} \mathbf{N}_{i}(\boldsymbol{\delta}) \mathbf{s}-\varsigma^{D}\right] K\left(\frac{\left(\mathbf{c}_{i}-\mathbf{c}_{j}\right) \boldsymbol{\varphi}+\left(\mathbf{x}_{i}-\mathbf{x}_{j}\right) \boldsymbol{\beta}}{a_{n}}\right)}{\sum_{k=1}^{n} K\left(\frac{\left(\mathbf{c}_{i}-\mathbf{c}_{j}\right) \boldsymbol{\varphi}+\left(\mathbf{x}_{i}-\mathbf{x}_{j}\right) \boldsymbol{\beta}}{a_{n}}\right)},
$$

where $j$ denotes observations and $i$ is the grid point. 
average variation in elevation along geodesics connecting municipality $i$ to its neighbors. ${ }^{27}$

For ease of comparison with our IV estimates, the system GMM estimates are also presented in Tables 3, 4A and 4B. The results in column 4 of Table 3 are jointly estimated with the results of columns 4, 8, 12 and 16 of Table 4A, where we measure state capacity with the number of local agencies, and column 8 of Table 3 is jointly estimated with columns 4, 8, 12 and 16 of Table 4B. Marginal effects based on GMM estimates are remarkably similar to the linear IV estimates, but are estimated more precisely. This partly reflects the fact that by estimating the full system of five equations jointly, we are imposing the restriction that the coefficient of $s_{i}^{2}$ is the same for all of our prosperity outcomes, leading to a gain in efficiency (and this explains why the estimate for the own effect is the same across columns in Tables $4 \mathrm{~A}$ and $4 \mathrm{~B}) .^{28}$

Figure 3 below presents our estimated function $g\left(\mathbf{c}_{i} \boldsymbol{\varphi}+\mathbf{x}_{i} \boldsymbol{\beta}\right)$ from the System GMM. Over most of its range, the function is very precisely estimated. Recall that in our model, $g_{i}()=.\frac{\kappa_{i}}{\theta}$, is proportional to the average effect of own state capacity on prosperity. The figures show that this function is positive for all its relevant range and is decreasing nonlinearly but monotonically. Table 3 also presents the average marginal effects $\varphi g^{\prime}\left(\mathbf{c}_{i} \boldsymbol{\varphi}+\mathbf{x}_{i} \boldsymbol{\beta}\right)$ for the historical state presence variables, where $g^{\prime}(\cdot)$ is the average slope. These estimates show that own colonial state officials and state agencies have a positive effect on own contemporary state.

\footnotetext{
${ }^{27}$ Letting $\boldsymbol{\gamma}=\left(\theta, \psi_{1}, \boldsymbol{\psi}_{2}, \boldsymbol{\varphi}, \boldsymbol{\beta}, \boldsymbol{\varsigma}, \tilde{\boldsymbol{\beta}}, \tilde{\boldsymbol{\varsigma}}\right)$, our semi-parametric system GMM estimator is given by
}

$$
\min _{\boldsymbol{\gamma}, \boldsymbol{\delta}}\left[\sum_{i=1}^{n} \mathbf{Z}_{i}(\boldsymbol{\delta})^{\prime} \mathbf{q}_{i}(\boldsymbol{\gamma}, \boldsymbol{\delta})\right]^{\prime}\left(\sum_{i=1}^{n} \mathbf{Z}_{i}\left(\boldsymbol{\delta}_{0}\right)^{\prime} \hat{\mathbf{W}}_{i} \mathbf{Z}_{i}\left(\boldsymbol{\delta}_{0}\right)\right)^{-1}\left[\sum_{i=1}^{n} \mathbf{Z}_{i}(\boldsymbol{\delta})^{\prime} \mathbf{q}_{i}(\boldsymbol{\gamma}, \boldsymbol{\delta})\right],
$$

where $\mathbf{q}_{i}(\boldsymbol{\gamma}, \boldsymbol{\delta})=\left[\epsilon_{i}^{1}, \ldots, \epsilon_{i}^{J}, \tilde{\xi}_{i}\right]^{\prime}, \quad \hat{\mathbf{W}}_{i}=\hat{\mathbf{u}}_{i} \hat{\mathbf{u}}_{i}^{\prime}+\sum_{j=1}^{t} \frac{t+1-j}{t+1+20}\left(\boldsymbol{\Omega}_{i j}+\boldsymbol{\Omega}_{i j}^{\prime}\right), \boldsymbol{\Omega}_{i j}=\frac{\sum_{j \in N^{t}(i)} f_{i j} \hat{\mathbf{u}}_{i} \hat{\mathbf{u}}_{j}^{\prime}}{\left|N^{t}(i)\right|}, t$ is the highest network degree at which we truncate spatial correlation (in practice we allow spatial correlation between neighbors and neighbors of neighbors), $\hat{\mathbf{u}}_{i}$ are residuals from a first stage estimate, given by $\hat{\mathbf{u}}_{i}=\mathbf{q}_{i}\left(\boldsymbol{\gamma}_{0}, \boldsymbol{\delta}_{0}\right)$ and $\left(\boldsymbol{\gamma}_{0}, \boldsymbol{\delta}_{0}\right)=$ $\arg \min _{\boldsymbol{\gamma}, \boldsymbol{\delta}}\left[\sum_{i=1}^{n} \mathbf{Z}_{i}(\boldsymbol{\delta})^{\prime} \mathbf{q}_{i}(\boldsymbol{\gamma}, \boldsymbol{\delta})\right]^{\prime}\left(\sum_{i=1}^{n} \mathbf{Z}_{i}(\mathbf{1})^{\prime} \mathbf{Z}_{i}(\mathbf{1})\right)^{-1}\left[\sum_{i=1}^{n} \mathbf{Z}_{i}(\boldsymbol{\delta})^{\prime} \mathbf{q}_{i}(\boldsymbol{\gamma}, \boldsymbol{\delta})\right]$. Moreover,

$$
\mathbf{Z}_{i}(\boldsymbol{\delta})=\left[\begin{array}{cc}
\mathbf{I}_{J} \otimes \mathbf{z}_{i}^{p}(\boldsymbol{\delta}) & \mathbf{0} \\
\mathbf{0} & \mathbf{z}_{i}^{B R}(\boldsymbol{\delta})
\end{array}\right]
$$

is the matrix of instruments for observation $i, \mathbf{z}_{i}^{p}(\boldsymbol{\delta})$ is the vector of instruments for the prosperity equations, and $\mathbf{z}_{i}^{B R}(\boldsymbol{\delta})$ is the vector of instruments for the best response equation. These are exactly the same as the set of instruments we used with the linear IV strategy in the previous subsection.

The analytic spatial correlation consistent asymptotic variance for this estimator is given by

$$
\left(\left[\sum_{i=1}^{n} \mathbf{Z}_{i}(\hat{\hat{\boldsymbol{\delta}}})^{\prime} \nabla_{\boldsymbol{\gamma}, \boldsymbol{\delta}} \mathbf{q}_{i}(\hat{\hat{\boldsymbol{\gamma}}}, \hat{\hat{\boldsymbol{\delta}}})\right]^{\prime}\left(\sum_{i=1}^{n} \mathbf{Z}_{i}\left(\boldsymbol{\delta}_{0}\right)^{\prime} \hat{\mathbf{W}}_{i} \mathbf{Z}_{i}\left(\boldsymbol{\delta}_{0}\right)\right)^{-1}\left[\sum_{i=1}^{n} \mathbf{Z}_{i}(\hat{\hat{\boldsymbol{\delta}}})^{\prime} \nabla_{\boldsymbol{\gamma}, \boldsymbol{\delta}} \mathbf{q}_{i}(\hat{\hat{\boldsymbol{\gamma}}}, \hat{\boldsymbol{\delta}})\right]\right)^{-1}
$$

Notice this estimator allows for both arbitrary spatial and across-equations correlation. The choice of weights for the spatial correlation terms must be such that they approach 1 as $t \rightarrow \infty$, and $\left(\sum_{i=1}^{n} \mathbf{Z}_{i}\left(\boldsymbol{\delta}_{0}\right)^{\prime} \hat{\mathbf{W}}_{i} \mathbf{Z}_{i}\left(\boldsymbol{\delta}_{0}\right)\right)^{-1}$ is positive definite.

${ }^{28}$ The conditions for a unique equilibrium in Proposition 3 are again easily satisfied at our parameter estimates. At our GMM estimates, when measuring state capacity through agencies, we have $\left(\psi_{1} / \theta\right)^{-1}=1.113>\left|\lambda_{\text {min }}(\mathbf{N}(\boldsymbol{\delta}))\right|=$ 0.235. When measuring state capacity through local bureaucracies, we have $\left(\psi_{1} / \theta\right)^{-1}=2.0934>\left|\lambda_{\min }(\mathbf{N}(\boldsymbol{\delta}))\right|=$ 0.235 . 
Because the parameter estimates from the system GMM are very similar to those from the linear IV models discussed in the previous subsection, the implied quantitative magnitudes are also very similar to those reported in the first two panels of Table 5 and are omitted to save space.

Finally, the left panel of Figure A1 in the Appendix presents scatterplots of the observed and predicted values of the endogenous variables (when state capacity is measured with public employees) from the System GMM estimates. The implied fit is very good. The right panel of Figure A1 shows the corresponding fit from the general model, discussed in the next section, and the comparison of the two sets of figures indicates that there is little loss in capturing the variation in the data when we focus on the linear model as we have done in this section.

\subsection{Falsification Exercises}

We now report two falsification exercises, supporting the validity of the exclusion restrictions used in our analysis so far. The first exercise, reported in Table 6, investigates whether own and neighbors' local state presence is correlated with two outcomes, primary enrollment and vaccination coverage, that are mostly determined at the national level and are thus unlikely to be affected by local state presence. In particular, we report OLS and IV estimates of equation (10) for the these two outcomes. This table shows that these variables are indeed unaffected by own and neighbors' local state presence, bolstering our confidence in the exclusion restrictions and the estimates reported so far.

The second exercise, reported in Table 7, examines whether the reduced-form correlation between neighbors' historical variables (colonial state presence and royal roads) and current prosperity and public good outcomes may reflect persistent unobservables affecting historical and current prosperity. In particular, one concern may be that this correlation is a consequence of the fact that these colonial variables impacted historical prosperity and historical prosperity has persisted and affected both current local state presence and current prosperity. Using data on literacy and school enrollment from the 1918 National Census, which are available for around 70 percent of the municipalities in our sample, Table 7 shows that this is unlikely to be the case. The top panel of the table presents the key reduced-form relationship underlying our IV estimates in Tables 4A and 4B between our four key prosperity outcomes and the excluded instruments in these tables (but focusing on the sample of 683 municipalities with the historical data on prosperity). Consistent with the results presented so far, there is a strong and robust positive relationship between neighbors' state presence and current prosperity. The pattern in the bottom panel, which presents analogous reduced-form estimates for the 1918 outcomes, is quite different, however. Though a few of the estimates have a similar size, none are statistically significant. This pattern is reassuring and bolsters our interpretation that the effects of colonial state presence and royal roads variables on current prosperity and public goods 
provision are working through current, or at the very least recent, presence of the local state.

\subsection{Robustness}

Table 8 presents OLS and IV results from a misspecified but simpler model where own state capacity enters linearly. This is very similar to the type of equation estimated in most of the rest of the peer effects literature. The estimates reported in Table 8 are still significant and quantitatively very similar to those in Table 4 (e.g., with state capacity measured with the number of agencies, the estimates in Table 4 are between 0.23 and 0.56, while those in Table 8 are between 0.1 and 0.36). This is reassuring as it suggests that both the general qualitative and the specific quantitative aspects of our estimation are not overly dependent on functional forms.

Tables A1-A5 in the Appendix show that our results are also robust to a series of variations. For brevity, we focus on linear IV estimates of equation (10) for our four prosperity outcomes. In Panel I we estimate the model without controlling for the distance to a current highway, which is a useful robustness check against the potential endogeneity of the location of current highways. In Panel II, we control for a range of additional geographic covariates, including the density of primary, secondary and tertiary rivers, and the full distribution of land by qualities and type as described in Section 4. The estimates in this table are remarkably similar to our baseline estimates. The only exceptions are the own effect on secondary enrollment when we do not control for the proximity to a current highway, which is now significant only at 5\% (columns 4 and 8 of Panel I in Table A1), and the own effect on the fraction of the population above poverty when we control for an additional 14 covariates and measure state presence with agencies, which becomes statistically insignificant (column 3 of Panel II in Table A1).

Table A2 presents robustness exercises related to the network structure itself. In Panel I we combine our IV strategy with Bramoulle, Djeebari, and Fortin's (2009) approach of using neighbors of neighbors' characteristics. In case our historical instruments are potentially spatially correlated, but we are willing to assume that our specification of the network captures the full set of spillovers, then using the third-degree neighbors' historical variables as instruments (instead of our benchmark first and second-degree neighbors' historical variables) will lead to consistent estimates - even though our baseline estimates may have been biased. In Panel II we present the results of redefining the meaning of a link, by considering both adjacent and second-degree adjacent municipalities as connected to check whether allowing longer-range spillovers has a meaningful impact on our results. Finally, in Panel III we allow for links to exist between every pair of municipalities with decaying link strength according to matrix F. Reassuringly, in all three cases, the results are very similar to our baseline estimates (if anything, they become more precisely estimated). 
In Table A3 we look at the sensitivity of our estimates to using subsets of our colonial state presence instruments. In Panel I we exclude all functions of distance to royal roads from the instrument set, and in Panel II we exclude all functions of colonial state agencies from the instrument set. This is of course related to the overidentification tests we have already reported, but it shows more transparently that our estimates remain very stable when we vary the set of instruments we use.

Table A4 presents additional robustness results focusing on the best response equation and our use of local state agencies as a measure of state capacity. We unbundle our count of all agencies, and separate them into four distinct types: health-related, regulation-related, services-related, and education-related. We then re-estimate the best response equation for each subset of agencies, controlling for its complement and the neighbor's complement. In all specifications, we find broadly similar results and a consistent pattern of strategic complementarity. This suggests that our baseline estimates are not driven by the averaging of different dimensions, some of which are strategic complements and others strategic substitutes. Rather, in all dimensions, local state capacity choices appear to be strategic complements.

Finally, another concern is that some areas of Colombia have been under the control of guerrillas and paramilitaries, creating a general lawlessness, which would supposedly reduce the effectiveness of the local and national state in these areas. In Table A5, we show that our results are not driven by municipalities most likely to suffer from such lawlessness. In particular, we exclude from our sample, or from the network entirely, municipalities with historically high levels of violence as measured by paramilitary attacks during the 1998-2004 period. In Panel I of Table A5 we report linear IV results when we exclude from the sample (but not from the network) municipalities above the 90th percentile of the distribution of paramilitary attacks. In Panel II we exclude this same subset of municipalities from the network. The results show that our baseline results are quite robust to these changes in sample and network.

\subsection{Controlling for National Bureaucracy}

As a preparation for the results in the next section, in Tables 9 and 10 we also control for the national state's employees (bureaucrats). In our baseline estimates, these employees are effectively included in the error term and if they are correlated with our instruments, this could lead to inconsistent estimates. The results are very similar to our baseline, and are in fact more precisely estimated, which is plausible as the omission of national bureaucracy from our baseline models likely created additional residual variance. 


\section{General Case}

In this section, we turn to the general model which relaxes the assumption that $\alpha=1$ and thus allows national state capacity choices to matter. Our objective is to estimate whether national and local state capacities are complements or substitutes and investigate whether fully allowing for the endogenous determination of national state capacity affects the extent of direct and spillover effects of state capacity. The reason why we view those presented in the previous section as our main results is that estimates from this more general model lead to very similar qualitative and quantitative patterns.

\subsection{Empirical Strategy}

Our empirical strategy relies on the same historical sources of variation (and same exclusion restrictions), but combines them with the first-order conditions of our more general model. In particular, in this case, we have two sets of first-order conditions, one for the national state, corresponding to (6) in the general model, and the other for the local state, corresponding to (5). These two first-order conditions can be written as

$$
h_{b}\left(l_{i}, \mathbf{p}_{i}, b_{i} \mid \boldsymbol{\zeta}\right) \equiv(1-\alpha) \tau^{\frac{\sigma-1}{\sigma}}\left[\frac{s_{i}}{b_{i}}\right]^{\frac{1}{\sigma}}\left\{\frac{\theta}{\alpha} \zeta_{i} l_{i}\left[\frac{l_{i}}{s_{i}}\right]^{\frac{1}{\sigma}}+\mathbf{N}_{i}(\boldsymbol{\delta})\left[\left(\psi_{1} \mathbf{s}+\frac{\sum_{j} \psi_{2}^{j}}{J} \boldsymbol{\iota}\right) * \boldsymbol{\zeta}\right]\right\}-\eta b_{i}=0
$$

and

$$
h_{\xi}\left(l_{i}, \mathbf{p}_{i}, b_{i}\right) \equiv \frac{\theta}{\alpha} l_{i}\left[\frac{l_{i}}{s_{i}}\right]^{\frac{1}{\sigma}}-\psi_{1} \mathbf{N}_{i}(\boldsymbol{\delta}) \mathbf{s}-g\left(\mathbf{c}_{i} \boldsymbol{\varphi}+\mathbf{x}_{i} \boldsymbol{\beta}\right)-\varsigma^{D}=0,
$$

where $\iota$ is a column vector consisting of $1 \mathrm{~s}$, and with overall state capacity $s_{i}$ defined by equation (2). In addition, we rewrite the prosperity equation, (1), for this case after substituting for $\left(\kappa_{i}+\right.$ $\left.\xi_{i}\right) s_{i}+\psi_{1} s_{i} \mathbf{N}_{i}(\boldsymbol{\delta}) \mathbf{s}$ from (12):

$$
h_{\epsilon^{j}}\left(l_{i}, \mathbf{p}_{i}, b_{i}\right) \equiv p_{i}^{j}-\frac{\theta}{\alpha} l_{i} s_{i}\left[\frac{l_{i}}{s_{i}}\right]^{\frac{1}{\sigma}}-\psi_{2}^{j} \mathbf{N}_{i}(\boldsymbol{\delta}) \mathbf{s}-\mathbf{x}_{i} \tilde{\boldsymbol{\beta}}^{j}-\tilde{\varsigma}^{j D}=0 .
$$

These three equations summarize the moment conditions for the general model. They show that this general model is identified up to a scaling: either $(\alpha, \eta)=(1,0)$ or $(\tau, \eta)=(0,0)$ make the first-order condition of the national state vanish. Nevertheless, equations (12) and (13) do contain enough information to identify the parameters $\alpha, \tau$ and $\sigma$ characterizing the CES state capacity composite. We therefore proceed by first taking the national state's choices as predetermined and estimate these parameters based only on the variation coming from equations (12) and (13). We then estimate the entire system (11)-(13), by imposing the CES parameter estimates to obtain the full estimates from this most general model. 


\subsection{Maximum Likelihood with Predetermined National Choices}

When national state capacity choices, the $b_{i}$ 's, are treated as predetermined in the network game between municipalities, the model reduces to equations (12) and (13). Then, conditional on the $b_{i}$ 's, these equations can be estimated straightforwardly by maximum likelihood. In particular, suppose that the $\epsilon_{i}^{j}$ 's and the $\xi_{i}$ 's have a joint normal distribution, i.e., $\left(\epsilon_{i}^{1}, \ldots, \epsilon_{i}^{J}, \xi_{i}\right)^{\prime} \sim N\left(\mathbf{0}_{(J+1) \times 1}, \boldsymbol{\Sigma}\right)$, with

$$
\boldsymbol{\Sigma}=\left[\begin{array}{cccccc}
\sigma_{\epsilon^{1}}^{2} & 0 & . & \cdot & 0 & 0 \\
0 & \sigma_{\epsilon^{2}}^{2} & 0 & . & . & 0 \\
. & \cdot & . & \cdot & . & . \\
0 & . & . & & \sigma_{\epsilon^{J}}^{2} & 0 \\
0 & 0 & . & & 0 & \sigma_{\xi}^{2}
\end{array}\right]
$$

We can now invert equations (12)-(13) to derive the joint density of $\left(l_{i}, \mathbf{p}_{i}\right)$. Defining $h_{\xi}\left(l_{i}, \mathbf{p}_{i}\right) \equiv$ $h_{\xi}\left(l_{i}, \mathbf{p}_{i} \mid \mathbf{b}\right)$, and $h_{\epsilon^{j}}\left(l_{i}, \mathbf{p}_{i}\right) \equiv h_{\epsilon^{j}}\left(l_{i}, \mathbf{p}_{i} \mid \mathbf{b}\right)$, the likelihood for $\left(l_{i}, \mathbf{p}_{i}\right)$ can be written as:

$$
\mathcal{L}_{i}\left(l_{i}, \mathbf{p}_{i} \mid \mathbf{b}, \mathbf{l}_{-i}, \mathbf{c}_{i}, \mathbf{x}_{i} ; \boldsymbol{\gamma}, \boldsymbol{\delta}, \boldsymbol{\Sigma}\right)=\phi\left(h_{\epsilon^{1}}\left(l_{i}, \mathbf{p}_{i}\right), \ldots, h_{\epsilon^{J}}\left(l_{i}, \mathbf{p}_{i}\right), h_{\xi_{i}}\left(l_{i}, \mathbf{p}_{i}\right) ; \boldsymbol{\Sigma}\right)\left|\boldsymbol{J}_{i}\right|
$$

where $\left|\boldsymbol{J}_{i}\right|=\frac{\partial h_{\xi}}{\partial l_{i}}{ }^{29}$ and $\boldsymbol{\gamma}$ now includes $\alpha, \tau$, and $\sigma \cdot{ }^{30}$ Thus, the conditional MLE problem solves

$$
\max _{\boldsymbol{\gamma}, \boldsymbol{\delta}, \boldsymbol{\Sigma}}\left\{\sum_{i} \ln \mathcal{L}_{i}\left(l_{i}, \mathbf{p}_{i} \mid \mathbf{b}, \mathbf{l}_{-i}, \mathbf{c}_{i}, \mathbf{x}_{i} ; \boldsymbol{\gamma}, \boldsymbol{\delta}, \boldsymbol{\Sigma}\right)\right\} .
$$

The corresponding maximum likelihood estimates are reported in the first column of Table 11. To compute standard errors, we use the outer product of the score as the estimator for the variancecovariance matrix of the parameter vector. The table presents the estimates when we use the number of state agencies as our measure of state capacity. The parameter $\alpha$ is estimated at 0.18 (standard

${ }^{29}$ In particular,

$$
\left|\boldsymbol{J}_{i}\right|=\frac{\partial h_{\xi}}{\partial l_{i}}=\frac{\theta}{\alpha} \frac{1}{\sigma}\left[(\sigma+1)\left[\frac{l_{i}}{s_{i}}\right]^{\frac{1}{\sigma}}-\alpha \frac{l_{i}}{s_{i}}\right] .
$$

This can be derived by noting that

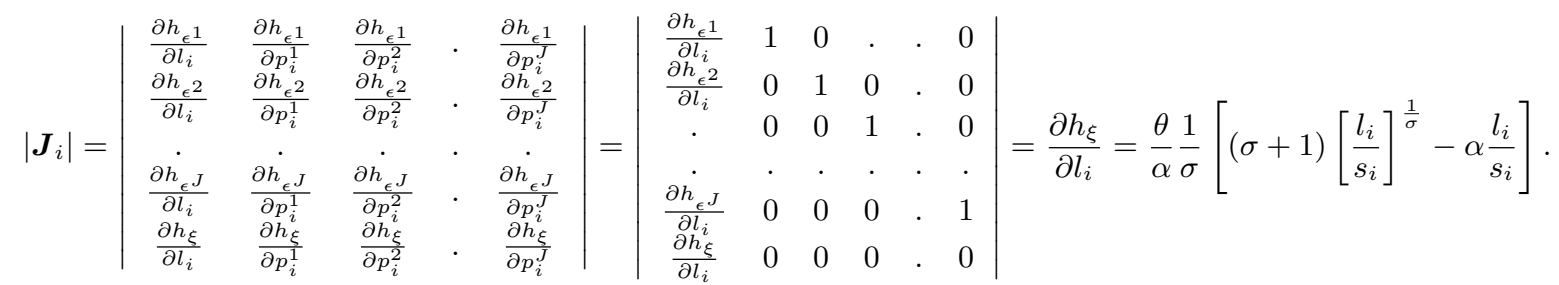

${ }^{30}$ Notice that $h_{\xi}\left(l_{i}, \mathbf{p}_{i}\right)$ and $h_{\epsilon j}\left(l_{i}, \mathbf{p}_{i}\right)$ are one-to-one mappings with

$$
\begin{gathered}
\frac{\partial h_{\xi}}{\partial l_{i}}=\frac{\theta}{\alpha} \frac{1}{\sigma}\left[(\sigma+1)\left[\frac{l_{i}}{s_{i}}\right]^{\frac{1}{\sigma}}-\alpha \frac{l_{i}}{s_{i}}\right] ; \frac{\partial h_{\xi}}{\partial p_{i}^{j}}=0 \quad \forall j \\
\frac{\partial h_{\epsilon^{j}}}{\partial l_{i}}=-\frac{\theta}{\alpha} \frac{1}{\sigma}\left[(\sigma+1)\left[\frac{l_{i}}{s_{i}}\right]^{\frac{1}{\sigma}} s_{i}+(\sigma-1) \alpha l_{i}\right] ; \frac{\partial h_{\epsilon^{j}}}{\partial p_{i}^{j}}=1 \text { and } \frac{\partial h_{\epsilon^{j}}}{\partial p_{i}^{k}}=0 \quad \text { for }: k \neq j .
\end{gathered}
$$

Therefore, the joint density can be inverted to yield (14). 
error $=0.003$ ), while the elasticity of substitution between local and national state, $\sigma$, is estimated as 1.2 (standard error $=0.36$ ). This implies that we can comfortably reject the special case corresponding to the linear model (with $\alpha=1$ ), but we cannot reject the hypothesis that state capacity is a Cobb-Douglas in local and national state presence. The estimate for the interaction effect $\psi_{1}$ indicates that this is again estimated to be a game of strategic complementarities, and the magnitude of these complementarities is very similar to that estimated from our linear model. The table also presents the average (across the sample of municipalities) value of $\kappa_{i}$, the direct effect of own state capacity on prosperity, which we recover in our estimation as $\kappa_{i}=\theta g\left(\mathbf{c}_{i} \boldsymbol{\varphi}+\mathbf{x}_{i} \boldsymbol{\beta}\right)$. The table presents the standard deviation of the estimated $\kappa_{i}$ 's. ${ }^{31}$

Throughout, the quantitative magnitudes of the estimates are very similar to those from the linear model. For example, the average slope of the best response equation (the average $\left.\frac{\partial l_{i}}{\partial l_{j}}\right|_{h_{\xi}}$ from equation (12)) at our MLE estimates is 0.022, compared to the average slopes of the linear best response reported in Table 4, which are between 0.016 and 0.022. Similarly, the average own effect in the prosperity equation (the average $\left.\frac{\partial p_{i}}{\partial s_{i}}\right|_{h_{\epsilon}}$ from equation (13)) is 0.32 , which is very close to our GMM estimate for the linear model of 0.3 reported in the first row of Table 4A. Finally, the average spillover effects in the prosperity equations $\left(\left.\frac{\partial p_{i}}{\partial s_{j}}\right|_{h_{\epsilon}}\right)$ are $(0.0237,0.0231,0.0219,0.0039)$ for the life quality index, utilities coverage, fraction above the poverty line, and secondary enrollment rates, respectively, which are very close to the corresponding estimates in the second row of Table 4A, all lying between 0.02 and 0.035 .

We perform the same counterfactual exercise as in the bottom two panels of Table 5 and the results are reported in the next two panels of Table 5. The implementation of this counterfactual experiment requires us to compute the Nash equilibrium profile under the proposed change. Because the best responses are nonlinear, we cannot simply use the estimated parameters (and shocks) to predict the equilibrium outcomes. We therefore numerically solve for the equilibrium state capacities (using a Newton-Raphson approximation). Using the resulting equilibrium values of $l_{i}$ 's, we then compute the implied values for $\mathbf{p}_{i}$ using equation (13). The bottom two panels of Table 5 show that the quantitative results are very similar to those we obtain from the linear model (with $\alpha=1$ ). This is the basis of the statement above that the qualitative and quantitative results from this general model are similar to those from the linear model.

The explicit presence of national state capacity variables, the $b_{i}$ 's, enables us to perform another counterfactual exercise in which we shock the national state capacities. In particular, we again consider increasing all $b_{i}$ 's below the median to the median value. In contrast to the counterfactual

\footnotetext{
${ }^{31}$ Once again, at the parameter estimates in Table A3, the condition for uniqueness in Proposition 2 is easily satisfied. In particular, we have $1+\frac{1}{\lambda_{\min }(\mathbf{N}(\boldsymbol{\delta}))}=-3.24<\min \left\{\left(\frac{\partial l_{i}}{\partial \mathbf{N}_{i}(\boldsymbol{\delta}) \mathbf{s}}\right)^{-1}\right\}=0.1932<\max \left\{\left(\frac{\partial l_{i}}{\partial \mathbf{N}_{i}(\boldsymbol{\delta}) \mathbf{s}}\right)^{-1}\right\}=0.3540<1$.
} 
experiment in which local state capacity levels were shocked, the implied magnitudes are now small as shown in Table A6 Appendix. Following this exercise, median local state agencies increase from 10 to 10.87 , leading to a $1.1 \%$ increase in the median life quality index, a $3.5 \%$ increase in median public utilities coverage, a $1.6 \%$ increase in the median fraction of population above the poverty line, and a $2.5 \%$ increase in median secondary enrollment rates. The reason for these more limited effects of a shock to national state capacity is that the estimate of $\tau$ (recall equation (2)) is relatively low, implying that it is local state capacity decisions that matter for local public goods and prosperity (and thus justifying our overall focus on local state presence as a key determinant of economic development in Colombia).

\subsection{Estimation of the Full Model by Simulated Method of Moments}

We next estimate the full model given by equations (11), (12), and (13). Relative to the estimates in the previous subsection, this involves imposing the additional restrictions that national state capacities satisfy the first-order condition as given in equation (6).

Because national state's weights, the $\zeta_{i}$ 's, are unobserved, we model them to be a function of a vector of observable characteristics related to within-network centrality of the municipalities, political variables, and an unobserved component modeled as

$$
\zeta_{i}=\exp \left(\mathbf{v}_{i} \boldsymbol{\pi}+\omega_{i}\right)
$$

In addition to a constant, $\mathbf{v}_{i}$ here includes three covariates: two standard network centrality statistics, the betweenness centrality and the Bonacich centrality (see Jackson, 2008), and a proxy for the extent of historical political competitiveness of the municipality, which we measure as the standard deviation of the Liberal Party's elections share across the 1974-1994 presidential elections.

Because the national state's first-order conditions involve the full vector of unobserved weights for each municipality, we cannot obtain an explicit expression for the Jacobian of the system. So, rather than MLE, we use a simulated method of moments (SMM) estimator using the moment conditions implied by (11), (12), and (13). Our SMM estimator is similar to the GMM estimator we used in the previous section (see footnote 27 ), except that we have $\mathbf{q}_{i}(\boldsymbol{\gamma}, \boldsymbol{\delta}$ ) = $\left[h_{\epsilon^{1}}\left(l_{i}, \mathbf{p}_{i}, b_{i}\right), \ldots, h_{\epsilon^{J}}\left(l_{i}, \mathbf{p}_{i}, b_{i}\right), h_{\xi}\left(l_{i}, \mathbf{p}_{i}, b_{i}\right), \widehat{h}_{b}\left(l_{i}, \mathbf{p}_{i}, b_{i}\right)\right]^{\prime}$, where

$$
\mathbf{Z}_{i}(\boldsymbol{\delta})=\left[\begin{array}{ccc}
\mathbf{I}_{J} \otimes \mathbf{z}_{i}^{p}(\boldsymbol{\delta}) & \mathbf{0} & \mathbf{0} \\
\mathbf{0} & \mathbf{z}_{i}^{B R}(\boldsymbol{\delta}) & \mathbf{0} \\
\mathbf{0} & \mathbf{0} & \mathbf{z}_{i}^{N L}(\boldsymbol{\delta})
\end{array}\right]
$$

Here $\mathbf{z}_{i}^{N L}(\boldsymbol{\delta})$ is a vector of instruments for the national state's best response equation, including $\mathbf{v}_{i}$, $\mathbf{x}_{i}$, historical population, average distance to neighboring municipalities, and average variability in 
altitude along geodesics to neighboring municipalities. We write the average (simulated) national state's first-order condition as

$$
\widehat{h}_{b}\left(l_{i}, \mathbf{p}_{i}, b_{i}\right)=\int h_{b}\left(l_{i}, \mathbf{p}_{i}, b_{i} \mid \boldsymbol{\omega}\right) f_{\omega}(\boldsymbol{\omega}) d \boldsymbol{\omega}
$$

In equation $(15), f_{\omega}(\cdot)$ is the joint density of the unobserved component of the national state's random weights, and the vector $\gamma$ now also includes $\eta$ and $\boldsymbol{\pi}$. Notice that the full vector of weights is assumed to be known to all players.

In the estimation, we restrict the $\zeta_{i}$ 's to be nonnegative, and test for the robustness of our estimator to several different densities $f_{\omega}(\cdot)$. Our benchmark specification presents results when using a standard normal density for the $\omega_{i}$ 's, and where the draws are independent across $i$. As noted above, we are imposing the MLE CES parameter estimates $(\alpha, \sigma, \tau)$, which allow the national state's weights to be estimated very precisely.

Estimates for the general model are presented in the second column of Table 11. The parameters are similar to those estimated by MLE taking the $b_{i}$ 's as predetermined, and as a result the counterfactual exercises conducted in the previous subsection give similar results. The one notable difference is in the magnitude of $\psi_{1}$. More interestingly, our estimates imply that the national state's weights, the $\zeta_{i}$ 's, are fairly homogeneous, with a mean of 0.01 and a standard deviation of 0.0014 , and close to normally distributed. This relative homogeneity of weights implies that a large part of the significant variation in national state presence reflects local characteristics of municipalities. In particular, local characteristics of the network, such as a municipality's centrality and political competitiveness, significantly impact the variation in the national state's choices. Quantitative exercises similar to those in Tables 5 and A6 yield very similar results to the ones using the linear model or the MLE estimates using pre-determined national state choices and are not reported to save space.

\section{Conclusions}

In this paper we developed a framework for estimating the direct and spillover effects of local state capacity using the network of Colombian municipalities. We modeled the determination of local and national state capacity as a network game, where each municipality, anticipating the choices and spillovers created by other municipalities and the decisions of the national government, invests in local state capacity and the national government chooses the presence of the national state in various areas to maximize its own objective. Our methodology emphasizes the need for a structural model to correctly interpret the estimates within a framework of strategic investments.

We estimated the parameters of this model, which show large (but plausible) direct and spillover effects of local state capacity, both using instrumental variables techniques and using GMM, simulated 
GMM or maximum likelihood. In all of our estimations, we exploited both the structure of the network of municipalities, determining which municipalities create spillovers on which others, and the historical roots of local state capacity as the source of exogenous variation for identifying both own and spillover effects. These are related to the presence of colonial royal roads and the historical presence of the colonial state, factors which we argued are unrelated to current provision of public goods and prosperity except through their impact on own and neighbors' local state capacity.

Our estimates imply that local state presence is indeed a first-order determinant of current prosperity, but much of this impact works through network effects. For example, bringing all municipalities below median state capacity to the median, without taking into account equilibrium responses of other municipalities, would increase the median fraction of the population above the poverty line from $57 \%$ to $60 \%$. Approximately $57 \%$ of this is due to direct effects and $43 \%$ due to spillovers. However, if we take the equilibrium responses of other municipalities into account, there are further network effects, reflecting in part the estimated strategic complementarities. Once these adjustments are made, the median of the fraction of the population above poverty would increase to $68 \%$ - a very large change driven by equilibrium network effects. This indicates not only that network effects are important, but also suggests why the national government must play a central role in effective state building: local state building will lead to major under-provision of state capacity (and thus public goods) because municipalities do not take into account these network effects.

We view our paper as a first step in the modeling and estimation of the direct and spillover effects of local state capacity. There are several interesting and important research directions. First, our results have focused only on some aspects of local state capacity. The typical view of the Weberian rational bureaucracy also stresses such things as meritocracy and predictability of the bureaucracy, which would be interesting to investigate at the local level as well. Second and more importantly, we have not addressed another aspect of Weberian state capacity, the monopoly of violence. This is a central issue in Colombia, where the local state often lacks this monopoly of violence. Third, our approach has been reduced-form in one crucial dimension: we have abstracted from political economy interactions. Though this is reasonable as a first-step simplification, political economy factors may be crucial underpinnings for some of these spillovers; this might be because high state capacity in one municipality puts pressure on politicians in neighboring municipalities to also improve state capacity, or because some municipalities are under the control of politicians or armed groups with very different objectives with different spillovers on neighboring municipalities. Finally, we believe that an important next step is to apply a similar approach to other settings in which law enforcement and policing are determined at the local level and create different types of spillovers on neighbors. 


\section{References}

Acemoglu, Daron (2005). "Politics and Economics in Weak and Strong States", Journal of Monetary Economics, 52, 1199-1226.

Acemoglu, Daron and Melissa Dell (2010). "Productivity Differences Between and Within Countries," American Economic Journal: Macroeconomics, 2(1), 169-188.

Acemoglu, Daron, Camilo Garcia-Jimeno and James A. Robinson (2012). "Finding El Dorado: Slavery and Long-Run Development in Colombia," Journal of Comparative Economics, 40(4), 534564.

Acemoglu, Daron, James A. Robinson and Rafael J. Santos (2013). "The Monopoly of Violence: Theory and Evidence from Colombia," Journal of the European Economic Association, 11(1), 5-44.

Acemoglu, Daron, Davide Ticchi and Andrea Vindigni (2011). "Emergence and Persistence of Inefficient States" Journal of the European Economic Association, 9(2), 177-208.

Allouch, Nizar (2012). "On the Private Provision of Public Goods on Networks", Unpublished.

Amsden, Alice H. (1989). Asia's Next Giant: South Korea and Late Industrialization, New York: Oxford University Press.

Ballester, Coralio and Antoni Calvo-Armengol (2010). "Interactions with Hidden Complementarities", Regional Science and Urban Economics 40, 397-406.

Ballester, Coralio, Antoni Calvo-Armengol, and Yves Zenou (2006). "Who's who in Networks: Wanted: The Key Player", Econometrica, 74(5), 1403-1417.

Bandyopadhyay, Sanghamitra and Elliot D. Green (2012). "Pre-Colonial Political Centralization and Contemporary Development in Uganda", APSA 2012 Annual Meeting Paper.

Bayer, Patrick, Stephen Ross, and Giorgio Topa (2008). "Place of Work and Place of Residence: Informal Hiring Networks and Labor Market Outcomes", Journal of Political Economy, 116(6), 11501196.

Besley, Timothy and Torsten Persson (2009). "The Origins of State Capacity: Property Rights, Taxation and Politics", American Economic Review, 99(4), 1218-44.

Besley, Timothy and Torsten Persson (2011). Pillars of Prosperity, Princeton: Princeton University Press.

Blume, Lawrence, William Brock, Steven Durlauf, and Yannis Ioannides (2010). "Identification of Social Interactions", in J. Benhabib, A. Bisin, and M. Jackson (eds.). Handbook of Social Economics (Forthcoming).

Bockstette, Valerie, Areendam Chanda and Louis Putterman (2002). "States and Markets: The Advantage of an Early Start", Journal of Economic Growth, 7: 347-69. 
Bramoulle, Yann, Rachel Kranton and Martin D'Amours (2012). "Strategic Interaction and Networks", American Economic Review (Forthcoming).

Bramoulle, Yann, Habiba Djebbari, and Bernard Fortin (2009). "Identification of Peer Effects through Social Networks", Journal of Econometrics, 150, 41-55.

Bruhn, Miriam and Francisco Gallego (2012). "Good, Bad, and Ugly Colonial Activities: Do They Matter for Economic Development?", Review of Economics and Statistics, 94(2), 433-461.

Calvo-Armengol, Antoni, Eleonora Patacchini, and Yves Zenou (2009). "Peer Effects and Social Networks in Education", Review of Economic Studies, 76, 1239-1267.

Cardenas, Mauricio, Marcela Eslava and Santiago Ramirez (2011). "State Capacity and Conflict", Unpublished, Department of Economics, Universidad de los Andes.

Case, Anne, James Hines, and Harvey Rosen (1993). "Budget Spillovers and Fiscal Policy Interdependence. Evidence from the States", Journal of Public Economics, 52, 285-307.

Centeno, Miguel A. (2002). Blood and Debt: War and Statemaking in Latin America, Princeton: Princeton University Press.

Conley, Timothy (1996). "GMM Estimation with Cross-Sectional Dependence", Journal of Econometrics, 92(1), 1-45.

Davila, Andres and Francisco Leal (2010). Clientelismo: el Sistema Politico y su Expresion Regional, 3rd Edition, Bogota. Universidad de los Andes.

Deas, Malcolm (1982). "Fiscal Problems of Nineteenth Century Colombia", Journal of Latin American Studies, 14(2), 287-328.

Dell, Melissa (2013). "Trafficking Networks and the Mexican Drug War". Unpublished.

Dincecco, Mark abd Gabriel Katz (2013). "State Capacity and Long-Run Economic Performance", Unpublished, Department of Economics, University of Michigan.

Di Tella, Rafael and Ernesto Schargrodsky (2004). "Do Police Reduce Crime? Estimates Using the Allocation of Police Forces after a Terrorist Attack", American Economic Review, 94(1), 115-133.

Duran y Diaz, Joaquin (1794). Estado General de todo el Virreynato de Santafe de Bogota, Bogota.

Durante, Ruben and Emilio Guiterrez (2013). "Fighting Crime with a Little Help from My Friends: Party Affiliation, Inter-Jurisdictional Cooperation and Crime in Mexico" Sciences Po. mimeo.

Evans, Peter B. (1995). Embedded Autonomy, Princeton: Princeton University Press.

Evans, Peter B. and James E. Rauch (2000). "Bureaucratic Structure and Bureaucratic Performance in Less Developed Countries", Journal of Public Economics, 75, 49-71.

Fearon James and David D. Laitin (2003). "Ethnicity, insurgency and civil war", American 
Political Science Review, 97(1), 75-90.

Fundacion Social (1998). Municipios y Regiones de Colombia: Una Mirada desde la Sociedad Civil, Fundacion Social, Bogota.

Gennaioli, Nicola and Ilia Rainer (2007). "The Modern Impact of Pre-Colonial Centralization in Africa", Journal of Economic Growth, 12(3), 185-234.

Gennaioli, Nicola and Hans-Joachim Voth (2011). "State Capacity and Military Conflict", unpublished.

Goodwin, Jeffrey (1999). No Other Way Out: States and Revolutionary Movements 1945-1991, Cambridge University Press, Cambridge.

Gutierrez, Rufino (1920). Monografias. Imprenta Nacional, Bogota.

Herbst, Jeffrey I. (2000). States and Power in Africa, Princeton: Princeton University Press.

Ichimura, Hidehiko and Lung-fei Lee (1991). "Semiparametric Least Squares Estimation of Multiple Index Models: Single Equation Estimation", in W.A. Barnett, J. L. Powell, and G. Tauchen (eds.). Nonparametric and Semiparametric Methods in Econometrics and Statistics, Cambridge, Cambridge University Press, 3-49.

Johnson, Chalmers A. (1982). MITI and the Japanese Miracle, Stanford University Press.

Jackson, Matthew (2008). Social and Economic Networks. Princeton University Press, Princeton.

Jaramillo, Jaime, Adolfo Meisel and Miguel Urrutia (2006) "Continuities and Discontinuities in the Fiscal and Monetary Institutions of New Granada 1783-1850," in Michael D. Bordo and Roberto Cortes Conde eds. Transferring Wealth and Power from the Old to the New World, New York: Cambridge University Press.

Langebaek, Carl Henrik, Santiago Giraldo, Alejandro Bernal, Silvia Monroy and Andres Barragan (2000). Por los Caminos del Piedemonte: Una Historia de las Comunicaciones entre los Andes Orientales y los Llanos, siglos XVI a XIX, Bogota, Ediciones Uniandes.

Langebaek, Carl Henrik, and Jorge Morales (2000). Historia de las Comunicaciones entre los Andes Orientales y los Llanos, siglos XVI a XIX, Bogota, Ediciones Uniandes.

Lee, Lung-fei and Xiaodong Liu (2009). "Specification and Estimation of Social Interaction Models with Network Structures", Unpublished.

Kalyvas, Stathis N. (2006). The Logic of Violence in Civil War, Cambridge University Press, New York.

Katz, Lawrence, Jeffrey Kling, and Jeffrey Liebman (2001). "Moving to Opportunity in Boston: Early Results of a Randomized Mobility Experiment", Quarterly Journal of Economics, 116(2), 607654.

Kohli, Atul (2004). State-Directed Development: Political Power and Industrialization in the 
Global Periphery, New York, Cambridge University Press.

Mann, Michael (1986). The Sources of Social Power, Volume I, Cambridge University Press, New York.

Mann, Michael (1993). The Sources of Social Power, Volume II, Cambridge University Press, New York.

Manski, Charles (1993). "Identification of Endogenous Social Effects: The Reflection Problem", Review of Economic Studies, 60(3), 531-542.

Mcfarlane, Anthony (1993). Colombia before Independence: Economy, Society, and Politics under Bourbon Rule, New York, Cambridge University Press.

Michalopoulos, Stelios and Elias Papaioannou (2013). "Pre-Colonial Ethnic Institutions and Contemporary African Development", Econometrica, 81(1), 113-152.

Migdal, Joel S. (1988). Strong Societies and Weak States, New York, Cambridge University Press.

Nakajima, Ryo (2007). "Measuring Peer Effects in Youth Smoking Behaviour", Review of Economic Studies, 74, 897-935.

Novak, William (2008). "The Myth of the Weak American State", American Historical Review, 113(3), 752-772

O'Donnell, Guillermo (1993). "On the state, democratization and some conceptual problems: a Latin American view with glances at some postcommunist countries", World Development, 21(1), $355-369$.

Osafo-Kwaako, Philip and James A. Robinson (2013). "Political Centralization in Pre-Colonial Africa," Journal of Comparative Economics", Journal of Comparative Economics, 41(1), 534-564.

Pachon, Alvaro and Maria Teresa Ramirez (2006). La Infraestructura de Transporte en Colombia durante el siglo XX, Bogota, Banco de la Republica, Ediciones Fondo de Cultura Economica.

Palacios, Marco and Frank Safford (2002). Colombia Pais Fragmentado, Sociedad Dividida, Bogota, Editorial Norma.

Paquette, Gabriel B. (2012). Bankruptcy of Empire: Mexican Silver and the Wars between Spain, Britain, and France, 1760-1810, New York, Palgrave-Macmillan.

Phelan, John L. (1978). The People and the King: The Comunero Revolution in Colombia, 1781, Madison, University of Wisconsin Press.

Rincon, Hernan and Roberto Junguito (2007). "La Politica Fiscal en el Siglo XX en Colombia", in James A. Robinson and Miguel Urrutia (eds.), Economia Colombiana del Siglo XX: Un Analisis Cuantitativo, Bogota and Mexico D.F., Fondo de Cultura Economica.

Sacerdote, Bruce (2002). "Peer Effects with Random Assignment: Results for Dartmouth Roommates", Quarterly Journal of Economics, 116(2), 681-704. 
Sanchez, Fabio (2007). Las cuentas de la violencia. Ensayos economicos sobre el crimen y el conflicto en Colombia, Bogota: Editorial Norma.

Soifer, Hillel (2012). Authority at a Distance: Institutions and Long-Run Variation in State Development in Latin America, Unpublished.

Soifer, Hillel (2008). "State Infrastructural Power: Conceptualization and Measurement in Empirical Analysis", Studies in Comparative International Development, 43(3-4), 231-251.

Stromberg, David (2008). "How the Electoral College Influences Campaigns and Policy: The Probability of Being Florida", American Economic Review, 98(3), 769-807.

Thies, Cameron G. (2005). "War, Rivalry, and State Building in Latin America", American Journal of Political Science, 49(3), 451-465.

Topa, Giorgio (2001). "Social Interactions, Local Spillovers and Unemployment", Review of Economic Studies, 68(2), 261-295.

Useche, Mariano (ed.) (1995). Caminos Reales de Colombia, Bogota, Fondo FEN Colombia.

Wade, Robert H. (1990). Governing the Market, Princeton, Princeton University Press.

Waldner, David (1999). State-Building and Late Development, Ithaca, Cornell University Press. 


\section{Figures}

Figure 1: Colonial state presence, 1794

Number of crown employees
Number of state agencies (alcabalas, estancos, post offices)

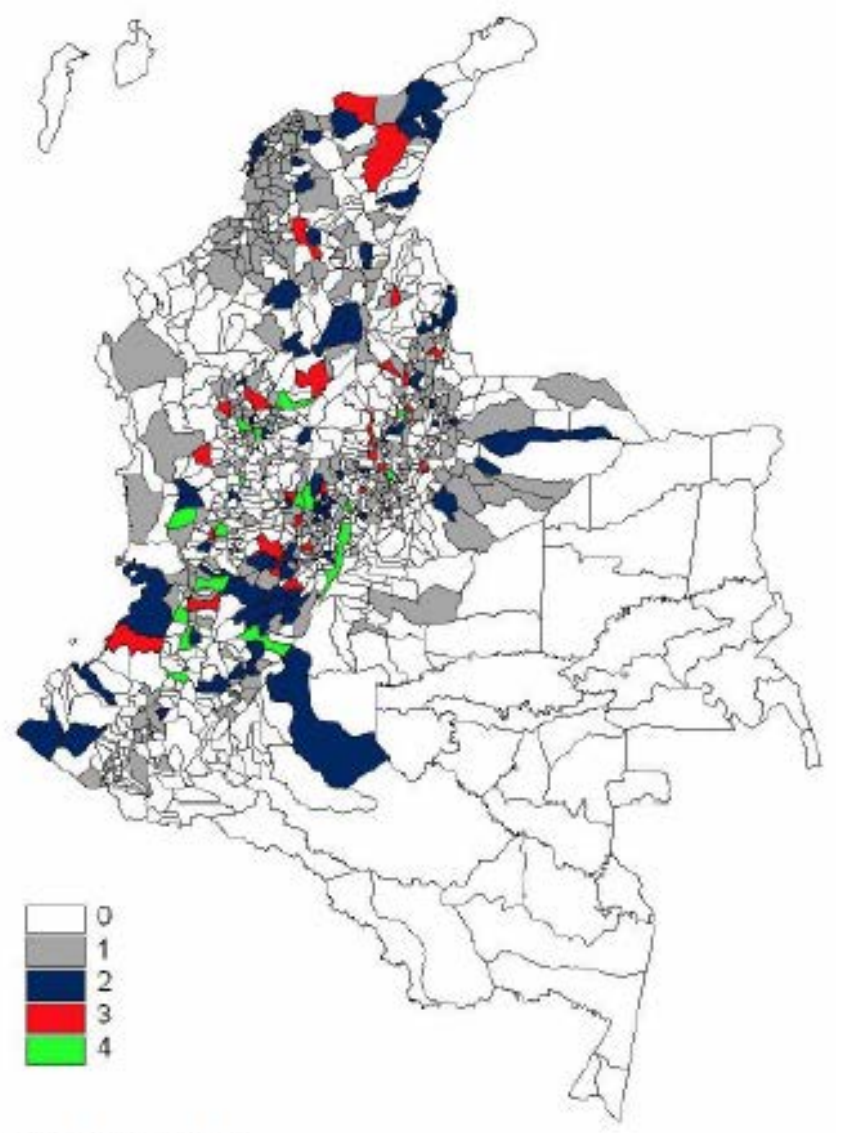

Source: Duran y Díaz (1794)

The left-hand-side figure presents the current municipality-level spatial distribution of Spanish crown employees in 1794. The right-hand-side figure presents the current municipality-level spatial distribution of the count of Spanish colonial state agencies in 1794, including alcabalas, tobacco and playing cards estancos, liquor and gunpowder estancos, and post offices. 
Figure 2: Distribution of prosperity outcomes
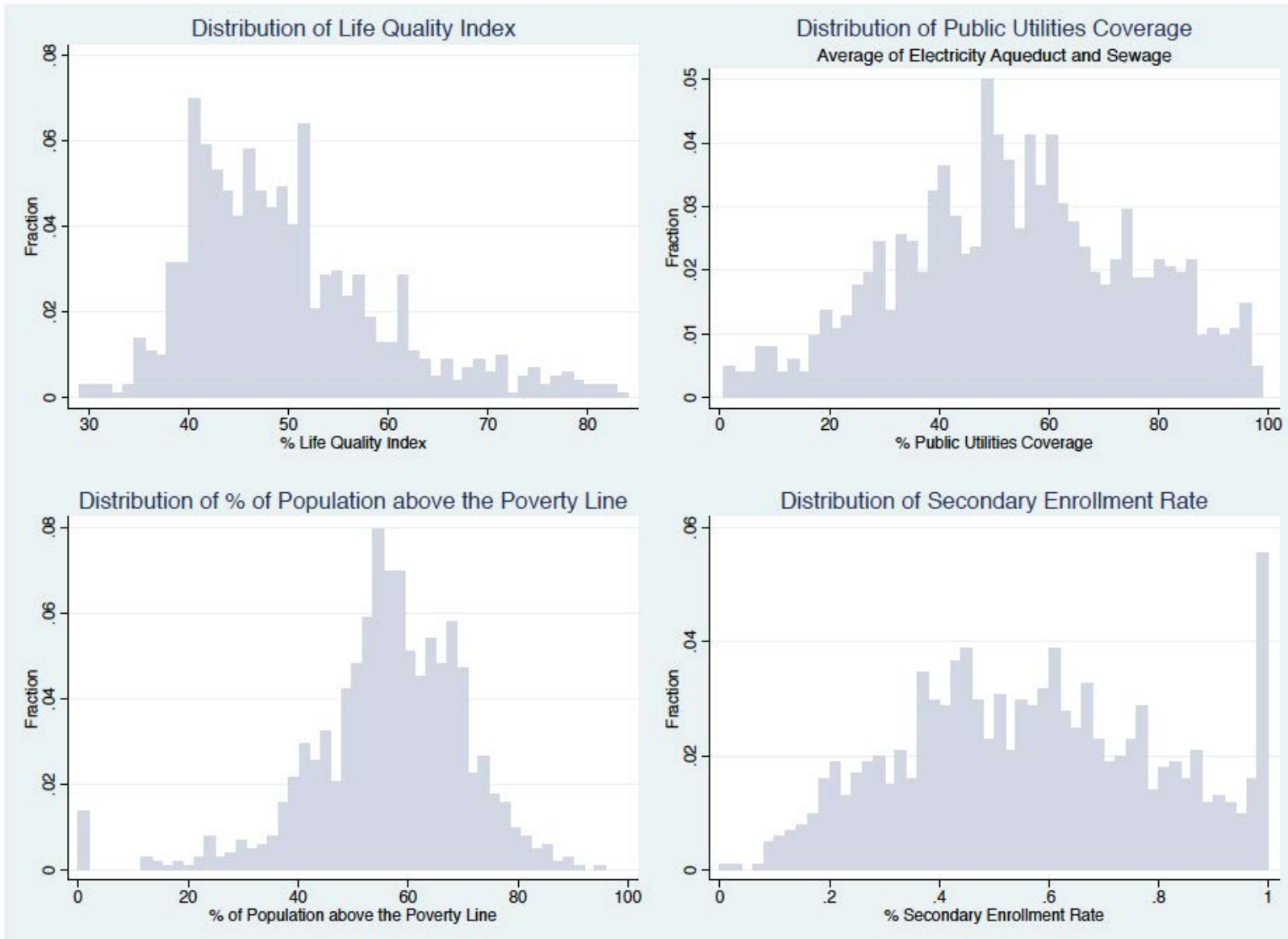

The figure plots the empirical distributions for the four prosperity outcomes in the sample of Colombian municipalities. The top left panel presents the distribution of the life quality index in 1998. The top right panel presents the distribution of the public utilities coverage (average of aqueduct, electricity, and sewage) in 2002. The bottom left panel presents the distribution of the fraction of the population above the poverty line in 2005. The bottom right panel presents the distribution of the average 1992-2002 secondary enrollment rate.

Figure 3: Estimated $g\left(\mathbf{c}_{i} \boldsymbol{\varphi}+\mathbf{x}_{i} \boldsymbol{\beta}\right)$ function

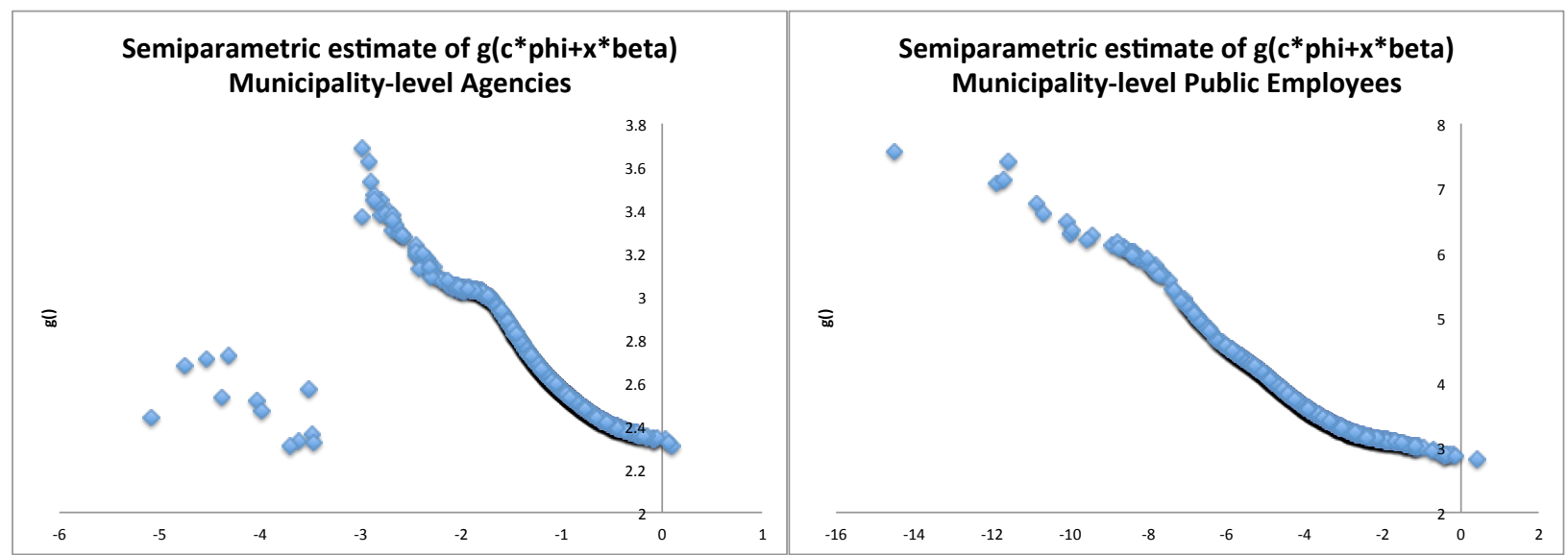

The figure plots the semi-parametric index function estimate of $g($.$) , the intercept of the best response equation, under the system GMM$ estimation strategy. The left-hand-side panel presents the estimate for the model using municipality-level agencies as the measure of local state capacity. The right-hand-side panel presents the estimate for the model using municipality-level public employees as the measure of local state capacity. 


\section{Tables}

Table 1. Descriptive statistics

\begin{tabular}{|c|c|c|c|c|}
\hline & Variables & Mean & Median & Std. Dev. \\
\hline \multirow{3}{*}{ State capacity } & Local-level state agencies & 21.6 & 10.0 & 105.1 \\
\hline & Local-level municipality employees & 99.6 & 20.0 & 843.4 \\
\hline & National-level municipality employees & 1038.9 & 220.0 & 7900.2 \\
\hline \multirow{6}{*}{ Prosperity } & Life quality index & 49.8 & 48.0 & 9.9 \\
\hline & Public utilities coverage rate & 53.7 & 53.4 & 21.5 \\
\hline & Fraction of population above poverty line & 56.4 & 57.2 & 14.3 \\
\hline & Secondary enrollment rate & 56.9 & 56.4 & 23.5 \\
\hline & Primary enrollment rate & 96.8 & 100.0 & 9.5 \\
\hline & Vaccination coverage rate & 45.2 & 43.8 & 16.8 \\
\hline \multirow{4}{*}{ Historical variables } & Colonial state officials & 5.7 & 0.0 & 122.9 \\
\hline & Colonial state sagencies & 0.6 & 0.0 & 0.9 \\
\hline & Distance to royal roads (Kms.) & 26.1 & 13.8 & 34.6 \\
\hline & Population in $1843(000)$ & 2.9 & 2.9 & 2.1 \\
\hline \multirow{3}{*}{ Network variables } & Number of neighbors & 5.5 & 5.0 & 1.8 \\
\hline & Geodesic distance to neighbors (Kms.) & 27.8 & 22.7 & 17.7 \\
\hline & Geodesic variability in elevation to neighbors & 0.8 & 0.7 & 0.5 \\
\hline \multirow{8}{*}{ Covariates } & Distance to current highway (Kms.) & 3.1 & 1.5 & 6.5 \\
\hline & Longitude & -74.8 & -74.8 & 1.5 \\
\hline & Latitude & 5.6 & 5.5 & 2.4 \\
\hline & Surface area (sq. kms) & 669.3 & 273.5 & 1425.1 \\
\hline & Elevation (mts.) & 1206.7 & 1265.0 & 897.7 \\
\hline & Average annual rainfall (mm.) & 1894.6 & 1630.5 & 1067.1 \\
\hline & Population (000) & 37.4 & 13.8 & 200.5 \\
\hline & Number of municipalities & & & 1019 \\
\hline
\end{tabular}

Sample mean, median and standard deviation for our main variables. Please see the text for variable definitions and sources.

Table 2. Within-department spatial correlation of historical state presence variables

\begin{tabular}{|c|c|c|c|c|c|c|c|c|c|}
\hline & 1 & 2 & 3 & 4 & 5 & 6 & 7 & 8 & 9 \\
\hline 1. Own distance to royal roads & 1.000 & & & & & & & & \\
\hline 2. Neighbors' average distance to royal roads & 0.283 & 1.000 & & & & & & & \\
\hline 3. Neighbors of neighbors' distance to royal roads & 0.045 & 0.615 & 1.000 & & & & & & \\
\hline 4. Own colonial officials & -0.095 & -0.072 & -0.047 & 1.000 & & & & & \\
\hline 5. Neighbors' average colonial officials & -0.146 & 0.039 & 0.060 & -0.061 & 1.000 & & & & \\
\hline 6. Neighbors of neighbors' colonial officials & -0.044 & 0.063 & 0.072 & -0.062 & -0.070 & 1.000 & & & \\
\hline 7. Own colonial state agencies & -0.135 & -0.039 & -0.017 & 0.545 & -0.006 & -0.002 & 1.000 & & \\
\hline 8. Neighbors' average colonial state agencies & -0.208 & 0.250 & 0.283 & -0.053 & 0.490 & 0.008 & 0.022 & 1.000 & \\
\hline 9. Neighbors of neighbors' colonial state agencies & -0.193 & 0.244 & 0.334 & -0.036 & 0.031 & 0.408 & 0.078 & 0.289 & 1.000 \\
\hline
\end{tabular}

Correlations reported are the average across-departments of the correlations for each department. 
Table 3. Contemporary State Equilibrium Best Response

\begin{tabular}{|c|c|c|c|c|c|c|c|c|}
\hline \multirow{2}{*}{$\frac{\text { State capacity measured as log of: }}{\text { Panel I }}$} & \multicolumn{4}{|c|}{ Number of state agencies } & \multicolumn{4}{|c|}{ Number of municipality employees } \\
\hline & (1) & $(2)$ & (3) & (4) & $(5)$ & $(6)$ & $(7)$ & (8) \\
\hline & OLS & IV & IV & Sys. GMM & OLS & IV & IV & Sys. GMM \\
\hline & \multicolumn{8}{|c|}{ Equilibrium best response } \\
\hline \multirow[t]{2}{*}{$\mathrm{dsi} / \mathrm{dsj}$} & 0.016 & 0.017 & 0.019 & 0.020 & 0.021 & 0.022 & 0.022 & 0.016 \\
\hline & $(0.002)$ & $(0.003)$ & $(0.003)$ & $(0.003)$ & (0.003) & $(0.004)$ & $(0.004)$ & $(0.003)$ \\
\hline \multirow[t]{2}{*}{ dsi/dcolonial state officialsi } & 0.127 & 0.128 & 0.108 & -0.040 & 0.129 & 0.130 & 0.105 & 0.087 \\
\hline & $(0.031)$ & $(0.031)$ & $(0.033)$ & $(0.050)$ & (0.043) & $(0.043)$ & $(0.047)$ & (0.069) \\
\hline \multirow[t]{2}{*}{ dsi/dcolonial state agenciesi } & 0.003 & 0.001 & -0.016 & 0.096 & 0.017 & 0.017 & -0.002 & 0.085 \\
\hline & $(0.033)$ & $(0.033)$ & $(0.033)$ & $(0.055)$ & (0.058) & $(0.059)$ & $(0.060)$ & $(0.085)$ \\
\hline \multirow[t]{2}{*}{ dsi/ddistance to royal roadi } & 0.008 & 0.010 & 0.007 & 0.074 & -0.035 & -0.035 & -0.038 & -0.036 \\
\hline & $(0.019)$ & (0.019) & $(0.021)$ & $(0.034)$ & $(0.034)$ & $(0.035)$ & $(0.036)$ & $(0.044)$ \\
\hline Panel II & \multicolumn{8}{|c|}{ First stage for $\mathrm{Ni}(\delta) \mathrm{s}$} \\
\hline \multirow{2}{*}{ Neighbors' colonial state officials } & & 0.320 & 0.338 & & & 0.556 & 0.637 & \\
\hline & & $(0.096)$ & $(0.100)$ & & & $(0.143)$ & $(0.155)$ & \\
\hline \multirow[t]{2}{*}{ Neighbors' colonial state agencies } & & 1.275 & 1.242 & & & 1.673 & 1.631 & \\
\hline & & $(0.126)$ & $(0.131)$ & & & $(0.211)$ & (0.223) & \\
\hline \multirow[t]{2}{*}{ Neighbors' distance to royal road } & & -1.031 & -0.992 & & & -1.497 & -1.456 & \\
\hline & & $(0.219)$ & $(0.223)$ & & & $(0.278)$ & $(0.287)$ & \\
\hline \multirow[t]{2}{*}{ Neighbors of neighbors' colonial state officials } & & 0.209 & 0.269 & & & 0.311 & 0.427 & \\
\hline & & $(0.170)$ & $(0.177)$ & & & $(0.240)$ & $(0.258)$ & \\
\hline \multirow[t]{2}{*}{ Neighbors of neighbors' colonial state agencies } & & 0.649 & 0.568 & & & 1.085 & 0.937 & \\
\hline & & $(0.181)$ & $(0.190)$ & & & $(0.264)$ & $(0.281)$ & \\
\hline \multirow[t]{2}{*}{ Neighbors of neighbors' distance to royal road } & & 0.178 & 0.172 & & & 0.268 & 0.296 & \\
\hline & & $(0.169)$ & $(0.173)$ & & & $(0.231)$ & $(0.236)$ & \\
\hline First-stage R-squared: & & 0.681 & 0.671 & & & 0.681 & 0.658 & \\
\hline F-test for excluded instruments: & & 17.0 & 145.6 & & & 19.55 & 171.0 & \\
\hline F-test $p$-value & & 0.000 & 0.000 & & & 0.000 & 0.000 & \\
\hline Overidentification test: & & 4.053 & 6.350 & & & 4.399 & 5.775 & \\
\hline Chi-squared(2) & & 0.542 & 0.385 & & & 0.494 & 0.449 & \\
\hline Log population & Control & Control & Instrum & Instrum & Control & Control & Instrum & Instrum \\
\hline Observations & 975 & 975 & 975 & 963 & 1017 & 1017 & 1017 & 1003 \\
\hline \multicolumn{9}{|c|}{$\begin{array}{l}\text { All reported estimates are average marginal effects. All models include department fixed effects and the following vector of controls: longitude, latitutde, surface area, } \\
\text { elevation, annual rainfall, distance to current highway, and a department capital dummy. Columns (1)-(4) use the log number of local state agencies as the measure of } \\
\text { state capacity, and columns (5)-(8) use the log number of municipality employees as the measure of state capacity. Panel I reports the estimates of the best response } \\
\text { equation, and Panel II reports the first stage for the instrumental variables models of columns (2),(3), (6), and (7). In the models reported in columns (2) and (6), log } \\
\text { population is treated as exogenous. In the models reported in columns (3), (4), (7), and (8), log population is instrumented using } 1843 \text { population. Models in column (4) are } \\
\text { estimated as a system together with those reported in columns (4), (8), (12), and (16) of Table 4A. Models in column (8) are estimated as a system together with those } \\
\text { reported in columns (4), (8), (12), and (16) of Table 4B. Standard errors reported in parenthesis are robust to arbitrary heteroskedasticity and allow for arbitrary spatial }\end{array}$} \\
\hline
\end{tabular}


Table 4A. Prosperity and Public Goods Structural Equation

State capacity measured as: log of number of municipality state agencies

\begin{tabular}{|c|c|c|c|c|c|c|c|c|}
\hline \multirow{3}{*}{$\begin{array}{l}\text { State } \\
\begin{array}{c}\text { Dependent variable } \\
\text { Panel I }\end{array}\end{array}$} & me & d as: I & of numb & $r$ of munici & lity sta & encies & & \\
\hline & \multicolumn{4}{|c|}{ Life quality index } & \multicolumn{4}{|c|}{ Public utilities coverage } \\
\hline & (1) & $(2)$ & (3) & (4) & (5) & $(6)$ & (7) & (8) \\
\hline \multirow{4}{*}{$\mathrm{dpi} / \mathrm{dsi}$} & OLS & IV & IV & Sys. GMM & OLS & IV & IV & Sys. GMM \\
\hline & \multicolumn{8}{|c|}{ Prosperity equation } \\
\hline & 0.802 & 0.394 & 0.389 & 0.314 & 0.602 & 0.563 & 0.567 & 0.314 \\
\hline & $(0.044)$ & $(0.135)$ & $(0.143)$ & $(0.041)$ & $(0.037)$ & $(0.127)$ & $(0.134)$ & $(0.041)$ \\
\hline \multirow[t]{2}{*}{$\mathrm{dpi} / \mathrm{dsj}$} & 0.015 & 0.024 & 0.025 & 0.025 & 0.022 & 0.020 & 0.020 & 0.027 \\
\hline & (0.004) & $(0.006)$ & $(0.006)$ & (0.004) & $(0.004)$ & $(0.006)$ & $(0.006)$ & $(0.003)$ \\
\hline Panel II & \multicolumn{8}{|c|}{ First stage for $\mathrm{si}^{2}$} \\
\hline \multirow{3}{*}{$\begin{array}{l}\text { F-test for excluded instruments: } \\
\text { F-test } p \text {-value } \\
\text { First-stage R-squared }\end{array}$} & & 31.23 & 35.39 & & & 31.01 & 35.06 & \\
\hline & & 0.000 & 0.000 & & & 0.000 & 0.000 & \\
\hline & & 0.670 & 0.655 & & & 0.670 & 0.655 & \\
\hline First-stage linear model: & \multicolumn{8}{|c|}{ First stage for $\mathrm{Ni}(\delta) \mathrm{s}$} \\
\hline F-test for excluded instruments: & & 526.7 & 523.7 & & & 524.6 & 522.1 & \\
\hline F-test $p$-value & & 0.000 & 0.000 & & & 0.000 & 0.000 & \\
\hline First-stage R-squared & & 0.769 & 0.770 & & & 0.769 & 0.770 & \\
\hline Log population & Control & Control & Instrum & Instrum & Control & Control & Instrum & Instrum \\
\hline Observations & 973 & 973 & 973 & 963 & 975 & 975 & 975 & 963 \\
\hline
\end{tabular}

State capacity measured as: log of number of municipality state agencies

\begin{tabular}{|c|c|c|c|c|c|c|c|c|}
\hline \multirow{2}{*}{$\begin{array}{c}\text { Dependent variable } \\
\text { Panel I }\end{array}$} & \multicolumn{4}{|c|}{ Not in poverty } & \multicolumn{4}{|c|}{ Secondary enrollment } \\
\hline & (9) & $(10)$ & (11) & $(12)$ & $(13)$ & (14) & (15) & $(16)$ \\
\hline & OLS & IV & IV & Sys. GMM & OLS & IV & IV & Sys. GMM \\
\hline & \multicolumn{8}{|c|}{ Prosperity equation } \\
\hline \multirow[t]{2}{*}{$\mathrm{dpi} / \mathrm{dsi}$} & 0.520 & 0.342 & 0.353 & 0.314 & 0.515 & 0.178 & 0.223 & 0.314 \\
\hline & $(0.038)$ & $(0.141)$ & $(0.147)$ & $(0.041)$ & (0.049) & (0.179) & $(0.186)$ & $(0.041)$ \\
\hline \multirow[t]{2}{*}{$\mathrm{dpi} / \mathrm{dsj}$} & 0.019 & 0.021 & 0.021 & 0.021 & 0.023 & 0.036 & 0.035 & 0.035 \\
\hline & $(0.004)$ & $(0.006)$ & $(0.006)$ & $(0.003)$ & $(0.005)$ & $(0.007)$ & $(0.007)$ & $(0.004)$ \\
\hline Panel II & \multicolumn{8}{|c|}{ First stage for $\mathrm{si}^{2}$} \\
\hline F-test for excluded instruments: & & 31.01 & 35.06 & & & 30.46 & 35.70 & \\
\hline F-test $p$-value & & 0.000 & 0.000 & & & 0.000 & 0.000 & \\
\hline First-stage R-squared & & 0.670 & 0.655 & & & 0.675 & 0.662 & \\
\hline First-stage linear model: & \multicolumn{8}{|c|}{ First stage for $\mathrm{Ni}(\delta) \mathrm{s}$} \\
\hline F-test for excluded instruments: & & 524.6 & 522.1 & & & 579.3 & 583.1 & \\
\hline F-test $p$-value & & 0.000 & 0.000 & & & 0.000 & 0.000 & \\
\hline First-stage R-squared & & 0.769 & 0.770 & & & 0.771 & 0.773 & \\
\hline Log population & Control & Control & Instrum & Instrum & Control & Control & Instrum & Instrum \\
\hline Observations & 975 & 975 & 975 & 963 & 965 & 965 & 965 & 963 \\
\hline
\end{tabular}

All reported estimates are average marginal effects. All models include department fixed effects and the following vector of controls: longitude, latitutde, surface area, elevation, annual rainfall, distance to current highway, and a department capital dummy. Panel I reports the estimates of the prosperity equation for each of the four outcomes, and Panel II reports the F-tests for joint significance of the excluded instruments in the first stages for the instrumental variables models of columns (2), (3), (6), (7), (10), (11), (14), and (15). The life quality index is for 1998, the public utilities coverage (aqueduct, electricity, and sewage) is for 2002, the fraction of the population above the poverty line is for 2005 , and the secondary enrollment rate is the 1992-2002 average. All prosperity outcomes are standardized. In the models reported in columns (2), (6), (10), and (14), log population is treated as exogenous. In the models reported in columns (3), (4), (7), (8), (11), (12), (15), and (16), log population is instrumented using 1843 population. Models in columns (4), (8), (12), and (16) are estimated as a system together with those reported in column (4) of Table 3. Standard errors reported in parenthesis are robust to arbitrary heteroskedasticity and allow for arbitrary spatial correlation within the network following Conley (1996) adapted to the network structure as described in the text. For models with more than one endogenous right-hand-side variable, the F-test is corrected following Angrist and Pischke (2009). 
Table 4B. Prosperity and Public Goods Structural Equation

State capacity measured as: log of number of municipality employees

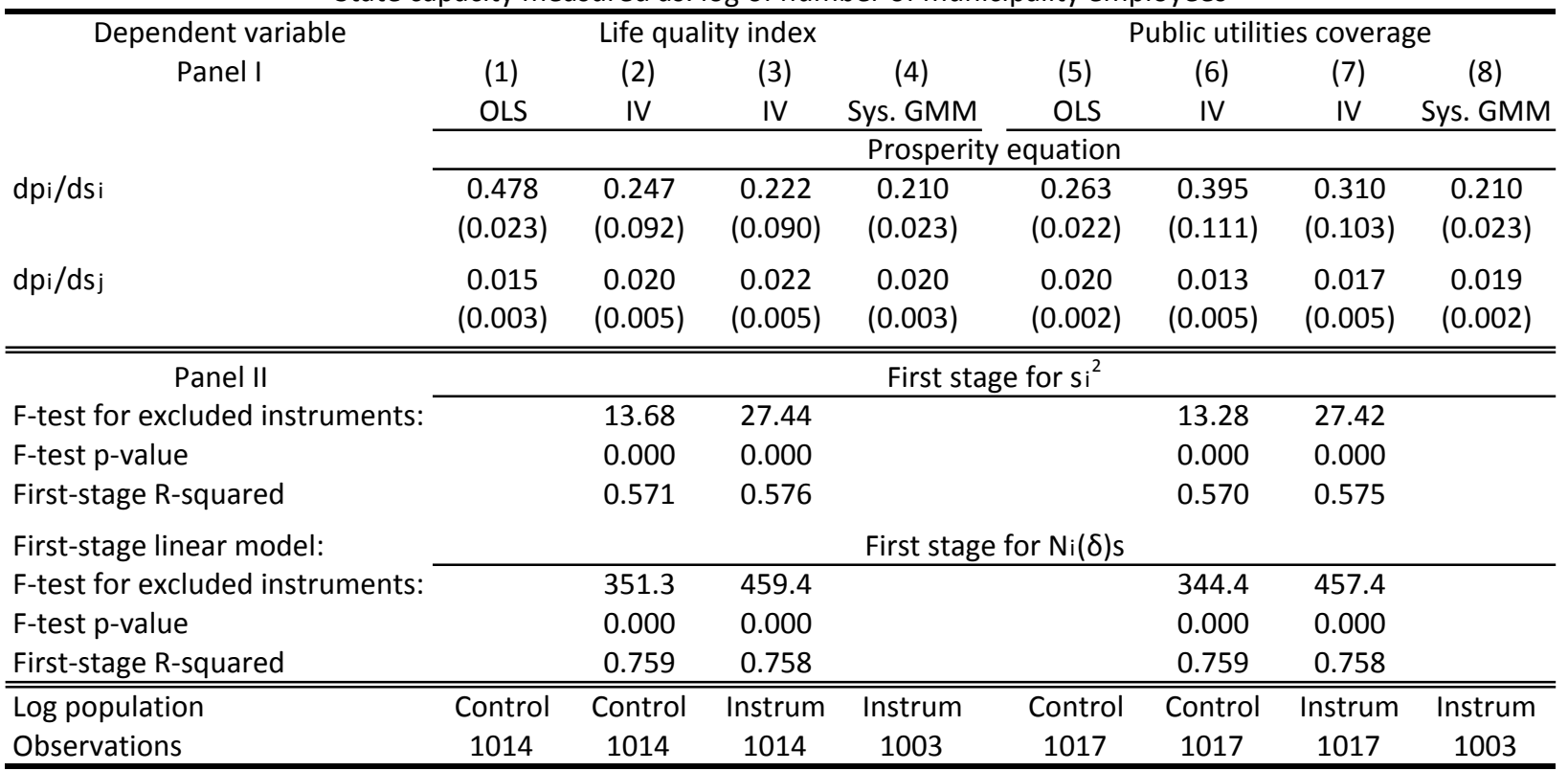

State capacity measured as: log of number of municipality employees

\begin{tabular}{|c|c|c|c|c|c|c|c|c|}
\hline \multirow{2}{*}{$\begin{array}{c}\text { Dependent variable } \\
\text { Panel I }\end{array}$} & \multicolumn{4}{|c|}{ Not in poverty } & \multicolumn{4}{|c|}{ Secondary enrollment } \\
\hline & (9) & $(10)$ & (11) & $(12)$ & (13) & (14) & (15) & $(16)$ \\
\hline & OLS & IV & IV & Sys. GMM & OLS & IV & IV & Sys. GMM \\
\hline & \multicolumn{8}{|c|}{ Prosperity equation } \\
\hline $\mathrm{dpi} / \mathrm{dsi}$ & 0.233 & 0.305 & 0.275 & 0.210 & 0.222 & 0.144 & 0.216 & 0.210 \\
\hline & $(0.021)$ & $(0.119)$ & $(0.111)$ & $(0.023)$ & $(0.025)$ & $(0.138)$ & $(0.133)$ & $(0.023)$ \\
\hline $\mathrm{dpi} / \mathrm{dsj}$ & 0.019 & 0.013 & 0.014 & 0.016 & 0.020 & 0.024 & 0.022 & 0.024 \\
\hline & $(0.003)$ & $(0.005)$ & $(0.005)$ & $(0.002)$ & $(0.003)$ & $(0.006)$ & $(0.006)$ & $(0.003)$ \\
\hline Panel II & \multicolumn{8}{|c|}{ First stage for $\mathrm{si}^{2}$} \\
\hline F-test for excluded instruments: & & 13.28 & 27.42 & & & 14.89 & 29.61 & \\
\hline F-test $p$-value & & 0.000 & 0.000 & & & 0.000 & 0.000 & \\
\hline First-stage R-squared & & 0.570 & 0.575 & & & 0.585 & 0.597 & \\
\hline First-stage linear model: & \multicolumn{8}{|c|}{ First stage for $\mathrm{Ni}(\delta) \mathrm{s}$} \\
\hline F-test for excluded instruments: & & 344.4 & 457.4 & & & 378.2 & 495.3 & \\
\hline F-test $p$-value & & 0.000 & 0.000 & & & 0.000 & 0.000 & \\
\hline First-stage R-squared & & 0.759 & 0.758 & & & 0.767 & 0.768 & \\
\hline Log population & Control & Control & Instrum & Instrum & Control & Control & Instrum & Instrum \\
\hline
\end{tabular}

All reported estimates are average marginal effects. All models include department fixed effects and the following vector of controls: longitude, latitutde, surface area, elevation, annual rainfall, distance to current highway, and a department capital dummy. Panel I reports the estimates of the prosperity equation for each of the four outcomes, and Panel II reports the F-tests for joint significance of the excluded instruments in the first stages for the instrumental variables models of columns (2), (3), (6), (7), (10), (11), (14), and (15). The life quality index is for 1998, the public utilities coverage (aqueduct, electricity, and sewage) is for 2002, the fraction of the population above the poverty line is for 2005 , and the secondary enrollment rate is the 1992-2002 average. All prosperity outcomes are standardized. In the models reported in columns (2), (6), (10), and (14), log population is treated as exogenous. In the models reported in columns (3), (4), (7), (8), (11), (12), (15), and (16), log population is instrumented using 1843 population. Models in columns (4), (8), (12), and (16) are estimated as a system together with those reported in column (8) of Table 3 . Standard errors reported in parenthesis are robust to arbitrary heteroskedasticity and allow for arbitrary spatial correlation within the network following Conley (1996) adapted to the network structure as described in the text. For models with more than one endogenous right-hand-side variable, the F-test is corrected following Angrist and Pischke (2009). 
Table 5. Experiment: Implications of Moving All Municipalities below Median State Capacity to Median

Panel la

Partial equilibrium change in:

Change in median:

Fraction due to own effect:

Fraction due to spillovers:

\begin{tabular}{|c|c|c|c|c|c|c|c|c|c|}
\hline \multicolumn{2}{|c|}{ Local agencies: } & \multicolumn{2}{|c|}{ Life quality index } & \multicolumn{2}{|c|}{ Utilities coverage } & \multicolumn{2}{|c|}{$\%$ not in poverty } & \multicolumn{2}{|c|}{ Secondary enroll. } \\
\hline From & To & From & To & From & To & From & To & From & To \\
\hline \multirow[t]{3}{*}{10} & 10 & 48.0 & 49.0 & 53.3 & 57.2 & 57.1 & 60.0 & 56.6 & 59.2 \\
\hline & & \multicolumn{2}{|c|}{$53.4 \%$} & \multicolumn{2}{|c|}{$51.7 \%$} & \multicolumn{2}{|c|}{$57.1 \%$} & \multicolumn{2}{|c|}{$45.5 \%$} \\
\hline & & \multicolumn{2}{|c|}{$46.6 \%$} & \multicolumn{2}{|c|}{$48.3 \%$} & \multicolumn{2}{|c|}{$43.0 \%$} & \multicolumn{2}{|c|}{$54.5 \%$} \\
\hline
\end{tabular}

Panel Ib

General equilibrium change in:

Change in median:

Local agencies:

Life quality index

$\begin{array}{cc}\text { From } & \text { To } \\ 10 & 20.6\end{array}$

From

To

Fraction due to direct effect:

Fraction due to network effects:

$48.0 \quad 58.2$

$9.8 \%$

$90.2 \%$

Utilities coverage

$\%$ not in poverty Secondary enroll.

From To From To From To

$53.3 \quad 73.7$

68.3

$56.6 \quad 82.4$

$18.9 \%$

$25.5 \%$

$10.1 \%$

$81.1 \%$

$74.5 \%$

$89.9 \%$

\begin{tabular}{|c|c|c|c|c|c|c|c|c|c|c|}
\hline \multirow{4}{*}{$\begin{array}{c}\text { Panel Ila } \\
\text { Partial equilibrium change in: }\end{array}$} & \multicolumn{10}{|c|}{ Non-linear model (under MLE parameter estimates) } \\
\hline & \multicolumn{2}{|c|}{ Local agencies: } & \multicolumn{2}{|c|}{ Life quality index } & \multicolumn{2}{|c|}{ Utilities coverage } & \multicolumn{2}{|c|}{$\%$ not in poverty } & \multicolumn{2}{|c|}{ Secondary enroll. } \\
\hline & From & To & From & To & From & To & From & To & From & To \\
\hline & 10 & 10 & 48.0 & 48.5 & 53.3 & 54.5 & 57.1 & 58.5 & 56.6 & 58.0 \\
\hline
\end{tabular}

Panel IIb

General equilibrium change in: Local agencies: Life quality index Utilities coverage \% not in poverty Secondary enroll.

$\begin{array}{ccccccccccc} & \text { From } & \text { To } & \text { From } & \text { To } & \text { From } & \text { To } & \text { From } & \text { To } & \text { From } & \text { To } \\ \text { Change in median: } & 10 & 28.8 & 48.0 & 57.3 & 53.3 & 74.4 & 57.1 & 70.0 & 56.6 & 76.39\end{array}$

This table reports results from an experiment which takes all municipalities below median state capacity to the median, using the estimated parameters of the models measuring state capacity as the number of local state agencies. Panel I reports the medians of the empirical and counterfactual distributions using the structural parameters of the linear model estimated using the system GMM. Panell II reports the medians of the empirical and counterfactual distributions using the structural parameters of the non-linear model estimated using MLE. Panels la and Ila report the medians for the partial equilibrium exercise where municipalities' best responses are held fixed. Panels $\mathrm{lb}$ and $\mathrm{Ilb}$ report the medians for the general equilibrium exercise where municipalities have best responded to the shock. The life quality index is for 1998, the public utilities coverage (aqueduct, electricity, and sewage) is for 2002, the fraction of the population above the poverty line is for 2005, and the secondary enrollment rate is the 1992-2002 average. 
Table 6. Placebo Exercise: Nationally Determined Prosperity and Public Goods Outcomes Structural Equation

\begin{tabular}{|c|c|c|c|c|c|c|c|c|}
\hline \multirow{4}{*}{$\begin{array}{l}\text { State capacity measured as log of: } \\
\qquad \text { Panel I }\end{array}$} & \multicolumn{4}{|c|}{ Number of municipality state agencies } & \multicolumn{4}{|c|}{ Number of municipality employees } \\
\hline & \multicolumn{2}{|c|}{ Primary enrollment } & \multicolumn{2}{|c|}{ Vaccination coverage } & \multicolumn{2}{|c|}{ Primary enrollment } & \multicolumn{2}{|c|}{ Vaccination coverage } \\
\hline & (1) & $(2)$ & (3) & (4) & (5) & (6) & (7) & (8) \\
\hline & OLS & IV & OLS & IV & OLS & IV & OLS & IV \\
\hline & \multicolumn{8}{|c|}{ Prosperity equation } \\
\hline \multirow[t]{2}{*}{$\mathrm{dpi} / \mathrm{dsi}$} & -0.049 & 0.198 & 0.015 & 0.260 & -0.007 & 0.355 & 0.013 & 0.134 \\
\hline & $(0.051)$ & $(0.207)$ & $(0.046)$ & (0.199) & $(0.027)$ & $(0.154)$ & $(0.025)$ & $(0.143)$ \\
\hline \multirow[t]{2}{*}{$d p i / d s j$} & 0.001 & -0.002 & 0.004 & -0.002 & 0.000 & -0.011 & -0.002 & -0.005 \\
\hline & $(0.005)$ & $(0.007)$ & $(0.005)$ & $(0.008)$ & $(0.003)$ & $(0.007)$ & $(0.003)$ & $(0.006)$ \\
\hline Panel II & \multicolumn{8}{|c|}{ First stage on $\mathrm{si}^{2}$} \\
\hline F-test for excluded instruments: & & 36.41 & & 35.06 & & 29.33 & & 27.42 \\
\hline F-test $p$-value & & 0.000 & & 0.000 & & 0.000 & & 0.000 \\
\hline \multirow[t]{2}{*}{ First-stage R-squared } & & 0.663 & & 0.655 & & 0.597 & & 0.575 \\
\hline & \multicolumn{8}{|c|}{ First stage on $\mathrm{Ni}(\delta) \mathrm{s}$} \\
\hline F-test for excluded instruments: & & 585.0 & & 522.1 & & 490.5 & & 457.4 \\
\hline F-test $p$-value & & 0.000 & & 0.000 & & 0.000 & & 0.000 \\
\hline First-stage R-squared & & 0.773 & & 0.770 & & 0.768 & & 0.758 \\
\hline Observations & 963 & 963 & 975 & 975 & 1004 & 1004 & 1017 & 1017 \\
\hline
\end{tabular}

All reported estimates are average marginal effects. All models include department fixed effects and the following vector of controls: longitude, latitutde, surface area, elevation, annual rainfall, distance to current highway, and a department capital dummy. Columns (1)-(4) report estimates for models using the number of municipality agencies as the measure of state capacity, and columns (5)-(8) report estimates for models using the number of municipality employees as the measure of state capacity. Panel I reports the estimates of the prosperity equation for each of the two placebo outcomes, and Panel II reports the F-tests for joint significance of the excluded instruments in the first stages for the instrumental variables models of columns (2), (4), (6), and (8). The primary enrollment rate is the 1992-2002 average, and vaccination coverage is for 1998. All prosperity outcomes are standardized. In the models reported in columns (2), (4), 6), and (8), log population is instrumented using 1843 population. Standard errors reported in parenthesis are robust to arbitrary heteroskedasticity and allow for arbitrary spatial correlation within the network following Conley (1996) adapted to the network structure as described in the text. For models with more than one endogenous right-hand-side variable, the F-test is corrected following Angrist and Pischke (2009). 
Table 7. Placebo Exercise: Current vs. Historical Prosperity

Correlation between current prosperity and instruments

\begin{tabular}{|c|c|c|c|c|}
\hline \multirow[t]{4}{*}{ Panel I } & Life quality index & Public util. coverage & Not in poverty & Sec. enrollment \\
\hline & $(1)$ & $(2)$ & (3) & $(4)$ \\
\hline & OLS & OLS & OLS & OLS \\
\hline & \multicolumn{4}{|c|}{ Reduced form } \\
\hline \multirow[t]{2}{*}{ Neighbors' colonial state officials } & -0.286 & -0.521 & 0.192 & 0.349 \\
\hline & $(0.403)$ & $(0.400)$ & $(0.499)$ & $(0.570)$ \\
\hline \multirow[t]{2}{*}{ Neighbors' colonial state agencies } & 1.779 & 1.316 & 1.819 & 1.654 \\
\hline & $(0.540)$ & $(0.564)$ & $(0.526)$ & $(0.757)$ \\
\hline \multirow[t]{2}{*}{ Neighbors' distance to royal road } & -1.352 & -1.645 & -0.800 & -1.634 \\
\hline & $(0.362)$ & $(0.342)$ & $(0.307)$ & $(0.473)$ \\
\hline F-test for joint significance of instruments: & 12.53 & 10.26 & 7.59 & 9.38 \\
\hline F-test $p$-value & 0.000 & 0.000 & 0.000 & 0.000 \\
\hline Control for log population & Yes & Yes & Yes & Yes \\
\hline Observations & 683 & 683 & 683 & 683 \\
\hline
\end{tabular}

Correlation between historical (1918) prosperity and instruments

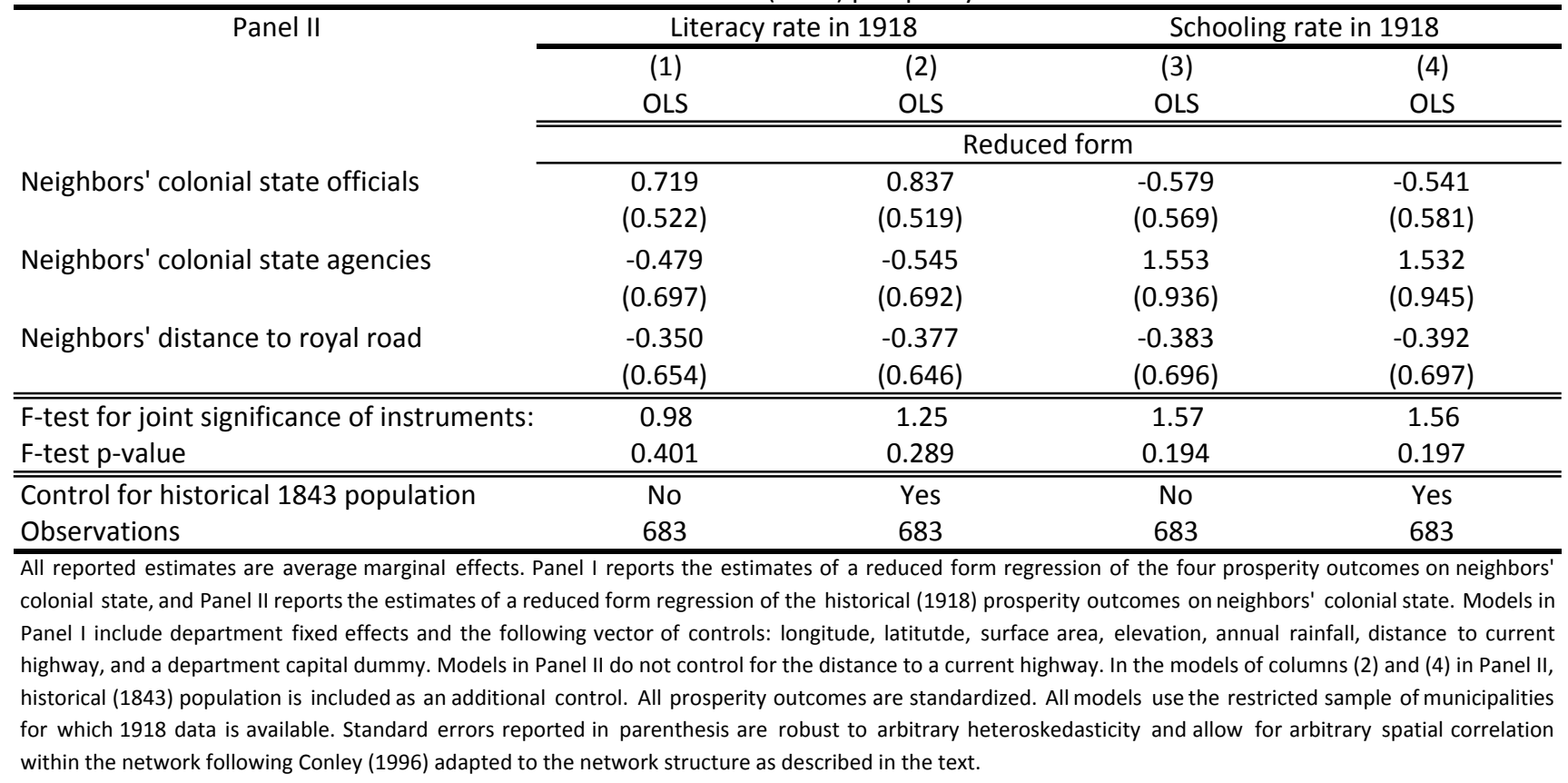


Table 8. Prosperity and Public Goods "Naïve" Equation

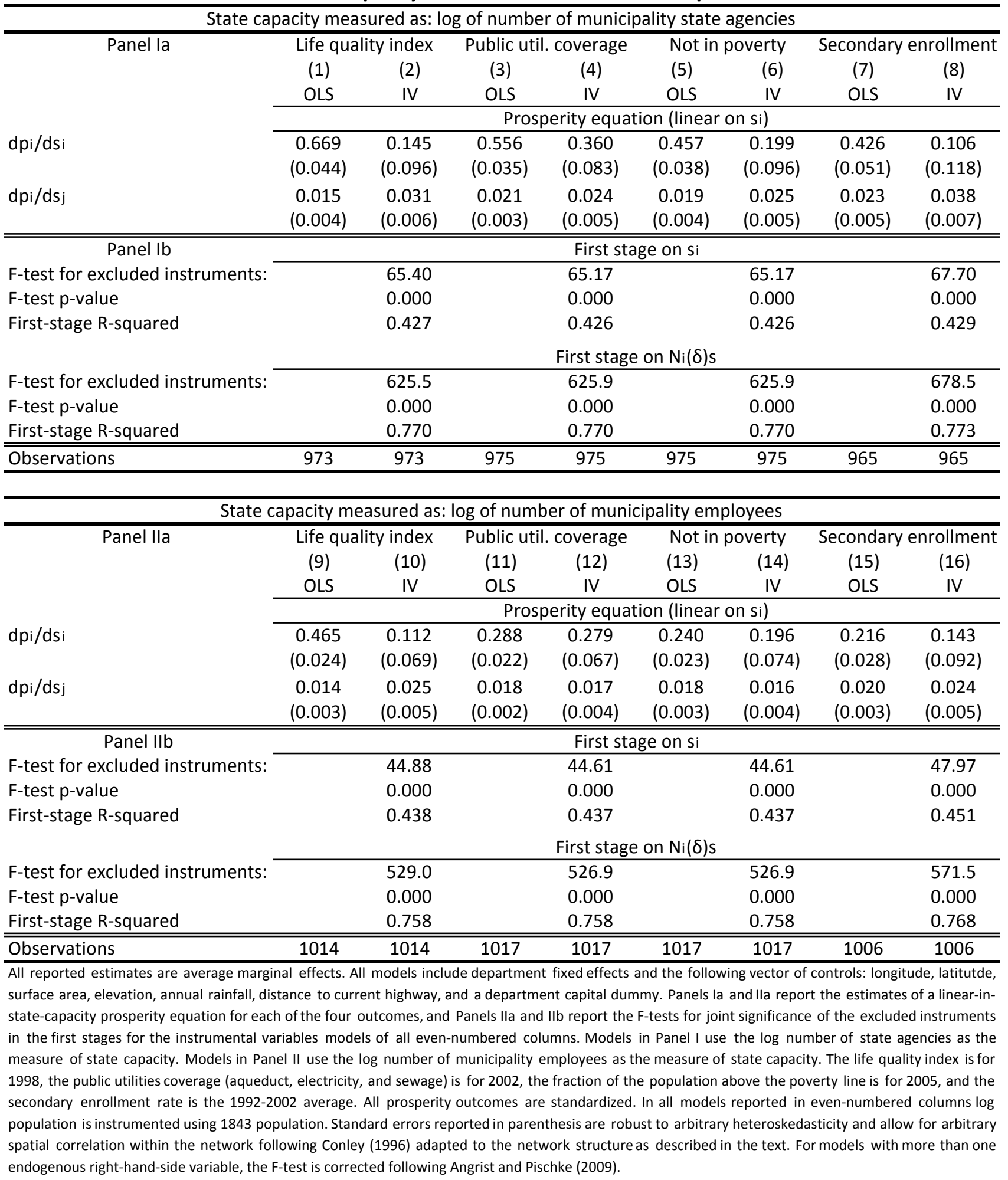


Table 9. Contemporary State Equilibrium Best Response

\begin{tabular}{|c|c|c|}
\hline \multicolumn{3}{|c|}{ Controlling for national-level bureaucracy } \\
\hline State capacity measured as log of number of: & Municipality state Agencies & Municipality employees \\
\hline & $(1)$ & $(2)$ \\
\hline & IV & IV \\
\hline & \multicolumn{2}{|c|}{ Equilibrium best response equation } \\
\hline \multirow[t]{2}{*}{$\mathrm{dsi} / \mathrm{dsj}$} & 0.018 & 0.017 \\
\hline & $(0.003)$ & $(0.001)$ \\
\hline \multirow[t]{2}{*}{ dsi/dcolonial state officialsi } & 0.102 & 0.002 \\
\hline & $(0.030)$ & $(0.007)$ \\
\hline \multirow[t]{2}{*}{ dsi/dcolonial state agenciesi } & -0.014 & 0.010 \\
\hline & $(0.032)$ & $(0.008)$ \\
\hline \multirow[t]{2}{*}{ dsi/ddistance to royal roadi } & 0.008 & -0.010 \\
\hline & $(0.020)$ & $(0.004)$ \\
\hline Observations & 975 & 1017 \\
\hline \multicolumn{3}{|c|}{$\begin{array}{l}\text { All reported estimates are average marginal effects of the best response equation. All models include department fixed effects and in } \\
\text { addition to the number of national-level public employees, the following vector of controls: longitude, latitutde, surface area, elevation, } \\
\text { annual rainfall, distance to a current highway, and a department capital dummy. Column (1) uses the log number of local state agencies as } \\
\text { the measure of state capacity, and column (2) uses the log number of municipality employees as the measure of state capacity. The first } \\
\text { stages of the instrumental variables models are omitted. Log population is instrumented using } 1843 \text { population. Standard errors reported in } \\
\text { parenthesis are robust to arbitrary heteroskedasticity and allow for arbitrary spatial correlation within the network following Conley (1996) } \\
\text { adapted to the network structure as described in the text. }\end{array}$} \\
\hline
\end{tabular}


Table 11. Stuctural Parameter Estimates

\begin{tabular}{|c|c|c|}
\hline National-level state capacity: & $\begin{array}{c}\text { Predetermined } \\
\text { estimates (conditional MLE) }\end{array}$ & $\begin{array}{c}\text { Endogenous } \\
\text { estimates (simulated GMM) }\end{array}$ \\
\hline Parameter & $(1)$ & $(2)$ \\
\hline$\Psi 1$ & $\begin{array}{c}6.731 \\
(0.042)\end{array}$ & $\begin{array}{c}1.670 \\
(0.674)\end{array}$ \\
\hline$\Psi 2$ (Life quality index) & $\begin{array}{c}4.180 \\
(0.049)\end{array}$ & $\begin{array}{c}7.132 \\
(1.316)\end{array}$ \\
\hline$\Psi 2$ (Public utilities) & $\begin{array}{c}4.083 \\
(0.045)\end{array}$ & $\begin{array}{c}7.580 \\
(1.317)\end{array}$ \\
\hline$\Psi 2$ (Not in poverty) & $\begin{array}{c}3.861 \\
(0.044)\end{array}$ & $\begin{array}{c}5.999 \\
(0.998)\end{array}$ \\
\hline$\Psi 2$ (Secondary enrollment) & $\begin{array}{c}0.690 \\
(0.033)\end{array}$ & $\begin{array}{c}9.893 \\
(1.774)\end{array}$ \\
\hline$\theta$ & $\begin{array}{c}0.037 \\
(0.005)\end{array}$ & $\begin{array}{c}0.013 \\
(0.005)\end{array}$ \\
\hline$E[k i]$ & $\begin{array}{c}0.126 \\
{[0.012]}\end{array}$ & $\begin{array}{c}0.019 \\
{[0.003]}\end{array}$ \\
\hline$\eta$ & & $\begin{array}{l}0.0003 \\
(0.003)\end{array}$ \\
\hline$\pi 1$ (Historical electoral variability) & & $\begin{array}{l}-2.43 \\
(0.745)\end{array}$ \\
\hline$\pi 2$ (Betweenness centrality) & & $\begin{array}{c}0.079 \\
(0.028)\end{array}$ \\
\hline$\pi 3$ (Bonacich centrality) & & $\begin{array}{l}-0.139 \\
(0.035)\end{array}$ \\
\hline \multicolumn{3}{|c|}{ CES parameters } \\
\hline$\alpha$ & \multicolumn{2}{|c|}{$\begin{array}{c}0.187 \\
(0.003)\end{array}$} \\
\hline$\sigma$ & \multicolumn{2}{|c|}{1.224} \\
\hline$\tau$ & \multicolumn{2}{|c|}{$\begin{array}{r}0.030 \\
(0.012) \\
\end{array}$} \\
\hline Observations & 963 & 962 \\
\hline
\end{tabular}




\section{Online Appendix for "State Capacity and Economic Development: A Network Approach"}

\section{Proofs}

\section{Proof of Proposition 1:}

The second-order condition for a municipality's maximization problem in equation (3) can be expressed as

$$
\alpha\left[\left(\kappa_{i}+\xi_{i}\right)+\psi_{1} \mathbf{N}_{i}(\boldsymbol{\delta}) \mathbf{s}\right] \frac{1}{\sigma} \frac{1}{l_{i}}\left[\frac{s_{i}}{l_{i}}\right]^{\frac{1}{\sigma}}\left\{\alpha \frac{1}{l_{i} s_{i}}\left[\frac{s_{i}}{l_{i}}\right]^{\frac{1}{\sigma}}-1\right\}-\theta .
$$

This expression being strictly negative is a sufficient condition for concavity and existence. It is satisfied for any $\left(\psi_{1}, \boldsymbol{\delta}, \theta\right)$ provided that

$$
\alpha \frac{1}{l_{i} s_{i}}\left[\frac{s_{i}}{l_{i}}\right]^{\frac{1}{\sigma}}-1<0
$$

or

$$
\alpha<l_{i}^{\frac{\sigma+1}{\sigma}} s_{i}^{\frac{\sigma-1}{\sigma}}
$$

Slope of the best response equation (5):

Implicitly differentiating equation (5) with respect to $\mathbf{N}_{i}(\boldsymbol{\delta})$ s yields

$$
\frac{\partial l_{i}}{\partial \mathbf{N}_{i}(\boldsymbol{\delta}) \mathbf{s}}=\alpha \sigma \frac{\psi_{1}}{\theta} \frac{1}{(\sigma+1)\left[\frac{l_{i}}{s_{i}}\right]^{\frac{1}{\sigma}}-\alpha\left[\frac{l_{i}}{s_{i}}\right]} .
$$

First note that when $\alpha=1, \frac{\partial l_{i}}{\partial \mathbf{N}_{i}(\boldsymbol{\delta}) \mathbf{s}}=\frac{\psi_{1}}{\theta}$.

More generally, denominator of this expression is strictly positive since $\sigma \geq 0$ and $\alpha \in(0,1)$. In particular,

$$
(\sigma+1)\left[\frac{l_{i}}{s_{i}}\right]^{\frac{1}{\sigma}}-\alpha\left[\frac{l_{i}}{s_{i}}\right]>0
$$

or equivalently

$$
\sigma+1>\frac{\alpha l_{i}^{\frac{\sigma-1}{\sigma}}}{\alpha l_{i}^{\frac{\sigma-1}{\sigma}}+(1-\alpha)\left(\tau b_{i}\right)^{\frac{\sigma-1}{\sigma}}} .
$$

Thus,

$$
\operatorname{sign}\left(\frac{\partial l_{i}}{\partial \mathbf{N}_{i}(\boldsymbol{\delta}) \mathbf{s}}\right)=\operatorname{sign}\left(\psi_{1}\right)
$$

Also notice that equation (19) implies $\frac{\partial l_{i}}{\partial \mathbf{N}_{i}(\boldsymbol{\delta}) \mathbf{s}}=\frac{\psi_{1}}{\theta}$ when $\alpha=1$. 


\section{Additional Tables and Figures}

Figure A1: Fit Scatterplots Linear Model (GMM estimates)

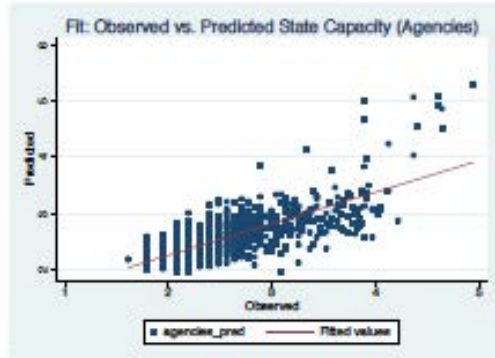

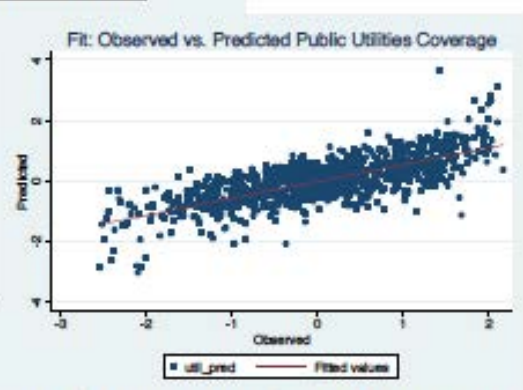
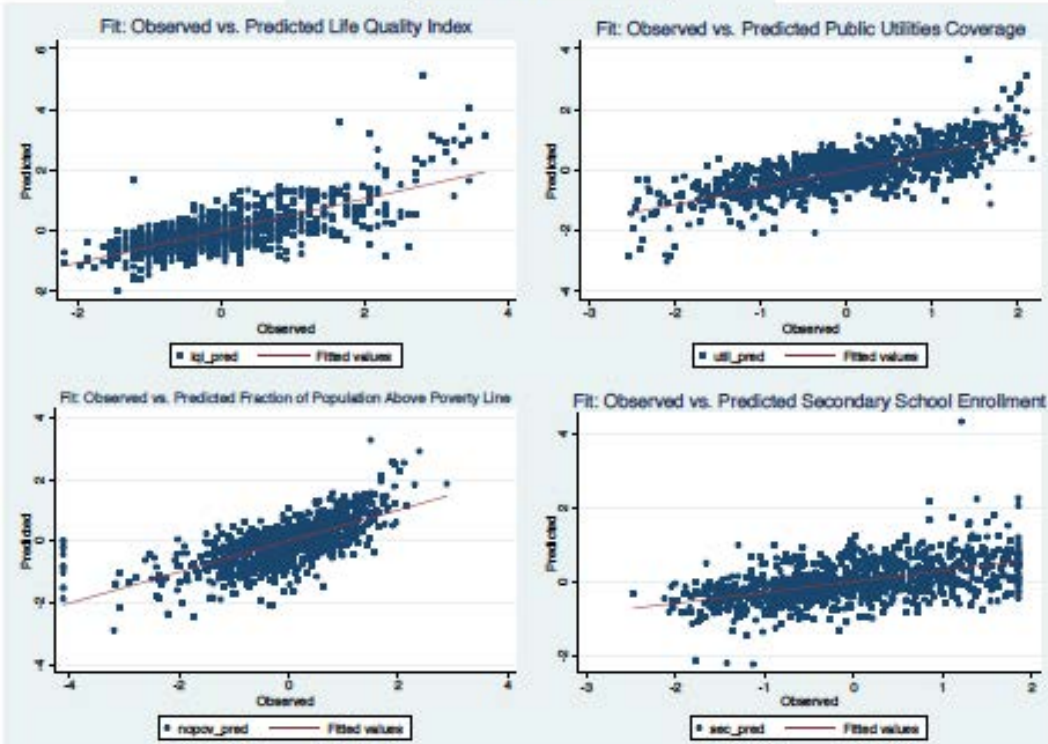

General Model (MLE estimates)
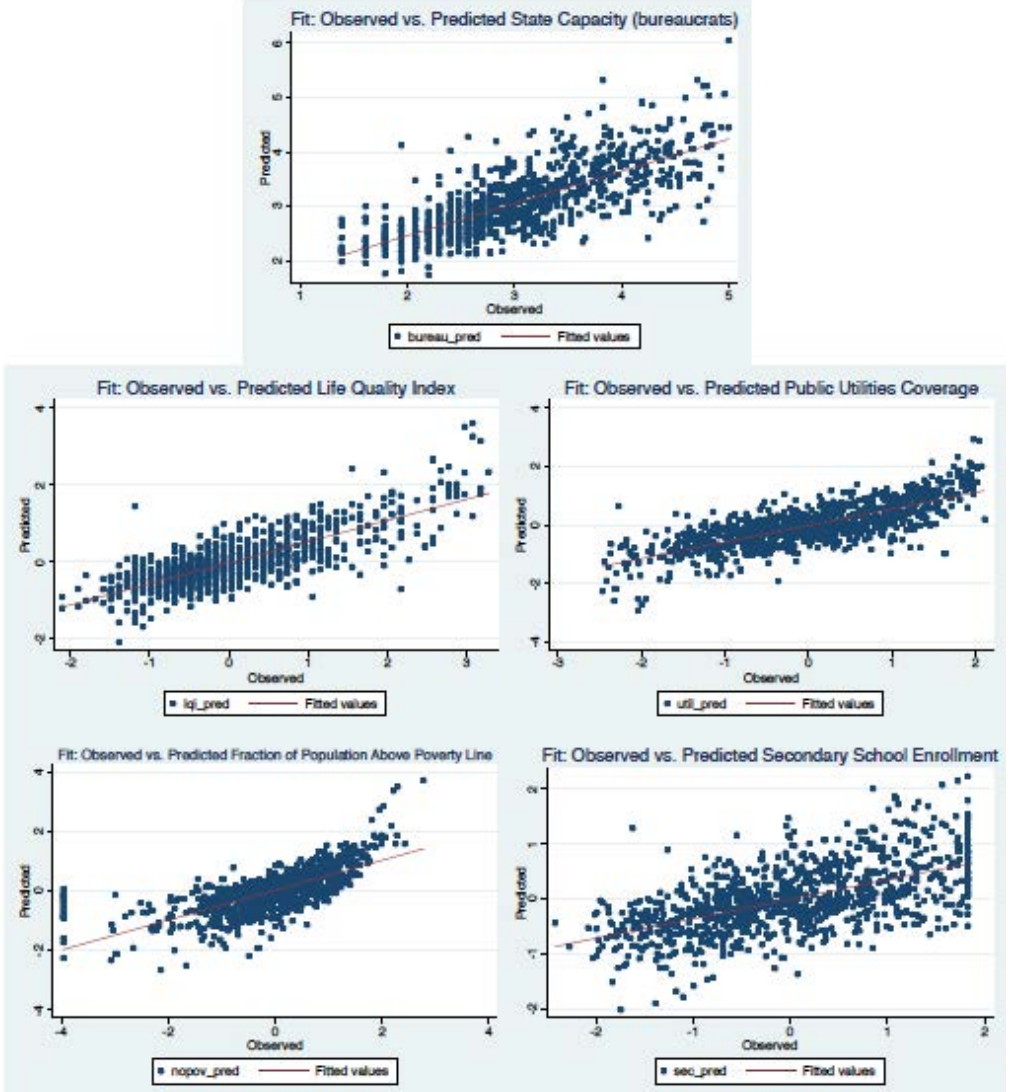

The figure plots the observed (x-axis) and predicted (y-axis) local state capacity and prosperity outcomes together with a linear fit line. The lefthand-side scatterplots are based on the model with linear best responses with the parameters estimated using system GMM. The predicted local state capacity vector is obtained by inverting the system of linear best responses at the estimated parameters. The right-hand-side scatterplots are based on the general model with non-linear best responses with parameters estimated using MLE. The predicted local state capacity vector is obtained by numerically (using a Newton-Raphson algorithm) finding the root of the system of non-linear best responses. In both cases predicted prosperity outcomes are obtained using the predicted state capacity and estimated parameters on the prosperity equations. 
Table A1. Robustness Exercises: Prosperity and Public Goods Outcomes Structural Equation

Panel I $\quad$ Without controlling for distance to current highway

State capacity measured as: Log of number of municipality state agencies $\quad$ Log of number of municipality employees

\begin{tabular}{|c|c|c|c|c|c|c|c|c|}
\hline & $\begin{array}{l}\text { Life quality } \\
\text { index } \\
\text { (1) } \\
\text { IV }\end{array}$ & $\begin{array}{c}\text { Public } \\
\text { utilities } \\
\text { coverage } \\
\text { (2) } \\
\text { IV }\end{array}$ & $\begin{array}{c}\text { Not in } \\
\text { poverty } \\
\text { (3) } \\
\text { IV }\end{array}$ & $\begin{array}{l}\text { Secondary } \\
\text { enrollment } \\
\text { (4) } \\
\text { IV }\end{array}$ & $\begin{array}{l}\text { Life quality } \\
\text { index } \\
\text { (5) } \\
\text { IV }\end{array}$ & $\begin{array}{c}\text { Public } \\
\text { utilities } \\
\text { coverage } \\
\text { (6) } \\
\text { IV }\end{array}$ & $\begin{array}{c}\text { Not in } \\
\text { poverty } \\
\text { (7) } \\
\text { IV }\end{array}$ & $\begin{array}{l}\text { Secondary } \\
\text { enrollment } \\
\text { (8) } \\
\text { IV }\end{array}$ \\
\hline & \multicolumn{8}{|c|}{ Prosperity equation } \\
\hline $\mathrm{dpi} / \mathrm{dsi}$ & $\begin{array}{c}0.436 \\
(0.140)\end{array}$ & $\begin{array}{c}0.648 \\
(0.133)\end{array}$ & $\begin{array}{c}0.400 \\
(0.148)\end{array}$ & $\begin{array}{c}0.304 \\
(0.182)\end{array}$ & $\begin{array}{c}0.270 \\
(0.086)\end{array}$ & $\begin{array}{c}0.395 \\
(0.105)\end{array}$ & $\begin{array}{c}0.337 \\
(0.115)\end{array}$ & $\begin{array}{c}0.286 \\
(0.131)\end{array}$ \\
\hline $\mathrm{dpi} / \mathrm{dsj}$ & $\begin{array}{c}0.025 \\
(0.006)\end{array}$ & $\begin{array}{c}0.020 \\
(0.006)\end{array}$ & $\begin{array}{c}0.022 \\
(0.006)\end{array}$ & $\begin{array}{c}0.035 \\
(0.007)\end{array}$ & $\begin{array}{c}0.021 \\
(0.005)\end{array}$ & $\begin{array}{c}0.015 \\
(0.005)\end{array}$ & $\begin{array}{c}0.013 \\
(0.005)\end{array}$ & $\begin{array}{c}0.020 \\
(0.006)\end{array}$ \\
\hline Observations & 973 & 975 & 975 & 965 & 1014 & 1017 & 1017 & 1006 \\
\hline Panel II & \multicolumn{8}{|c|}{ Controlling by additional geographic covariates } \\
\hline \multirow[t]{3}{*}{ State capacity measured as: } & \multicolumn{4}{|c|}{ Log of number of municipality state agencies } & \multicolumn{4}{|c|}{ Log of number of municipality employees } \\
\hline & $\begin{array}{l}\text { Life quality } \\
\text { index } \\
\text { (1) } \\
\text { IV }\end{array}$ & $\begin{array}{c}\text { Public } \\
\text { utilities } \\
\text { coverage } \\
\text { (2) } \\
\text { IV }\end{array}$ & $\begin{array}{c}\text { Not in } \\
\text { poverty } \\
\text { (3) } \\
\text { IV }\end{array}$ & $\begin{array}{l}\text { Secondary } \\
\text { enrollment } \\
\text { (4) } \\
\text { IV }\end{array}$ & $\begin{array}{l}\text { Life quality } \\
\text { index } \\
\text { (5) } \\
\text { IV }\end{array}$ & $\begin{array}{c}\text { Public } \\
\text { utilities } \\
\text { coverage } \\
\text { (6) } \\
\text { IV }\end{array}$ & $\begin{array}{c}\text { Not in } \\
\text { poverty } \\
\text { (7) } \\
\text { IV }\end{array}$ & $\begin{array}{l}\text { Secondary } \\
\text { enrollment } \\
\text { (8) } \\
\text { IV }\end{array}$ \\
\hline & \multicolumn{8}{|c|}{ Prosperity equation } \\
\hline $\mathrm{dpi} / \mathrm{dsi}$ & $\begin{array}{c}0.288 \\
(0.146)\end{array}$ & $\begin{array}{c}0.443 \\
(0.143)\end{array}$ & $\begin{array}{c}0.198 \\
(0.155)\end{array}$ & $\begin{array}{c}0.189 \\
(0.192)\end{array}$ & $\begin{array}{c}0.189 \\
(0.097)\end{array}$ & $\begin{array}{c}0.259 \\
(0.106)\end{array}$ & $\begin{array}{c}0.210 \\
(0.115)\end{array}$ & $\begin{array}{c}0.096 \\
(0.138)\end{array}$ \\
\hline $\mathrm{dpi} / \mathrm{dsj}$ & $\begin{array}{c}0.021 \\
(0.007)\end{array}$ & $\begin{array}{c}0.019 \\
(0.006)\end{array}$ & $\begin{array}{c}0.023 \\
(0.006)\end{array}$ & $\begin{array}{c}0.028 \\
(0.008)\end{array}$ & $\begin{array}{c}0.018 \\
(0.005)\end{array}$ & $\begin{array}{c}0.017 \\
(0.005)\end{array}$ & $\begin{array}{c}0.015 \\
(0.005)\end{array}$ & $\begin{array}{c}0.022 \\
(0.006)\end{array}$ \\
\hline Observations & 960 & 962 & 962 & 952 & 999 & 1002 & 1002 & 991 \\
\hline
\end{tabular}

All reported estimates are instrumental variables average marginal effects of the prosperity equation for each of the four outcomes. All models include department fixed effects and the following vector of controls: longitude, latitutde, surface area, elevation, annual rainfall, and a department capital dummy. Panel I reports the estimates of models that do not control for the distance to a current highway. Panel II reports the estimates of models that include the following as additional covariates: density of primary, secondary, and tertiary rivers, and the full distribution of land qualities (qualities 1-8), and types (under water, valley, mountain, hill, and plain). Columns (1)-(4) use the log number of municipality state agencies as the measure of local state capacity, and columns (5)-(8) use the log number of municipality employees as the measure of local state capacity. Estimates of the first stages for the IV models are omitted. The life quality index is for 1998, the public utilities coverage (aqueduct, electricity, and sewage) is for 2002, the fraction of the population above the poverty line is for 2005, and the secondary enrollment rate is the 1992-2002 average. All prosperity outcomes are standardized. In all models log population is instrumented using 1843 population. Standard errors reported in parenthesis are robust to arbitrary heteroskedasticity and allow for arbitrary spatial correlation within the network following Conley (1996) adapted to the network structure as described in the text. 
Table A2. Robustness Exercises: Prosperity and Public Goods Outcomes Structural Equation

Panel I $\quad$ Using neighbors of neighbors of neighbors as instruments

\begin{tabular}{|c|c|c|c|c|c|c|c|c|}
\hline \multirow{5}{*}{ State capacity measured as: } & \multirow{2}{*}{\multicolumn{4}{|c|}{ Log of number of municipality state agencies }} & \multirow{2}{*}{\multicolumn{4}{|c|}{ Log of number of municipality employees }} \\
\hline & & & & & & & & \\
\hline & $\begin{array}{l}\text { Life quality } \\
\quad \text { index }\end{array}$ & $\begin{array}{c}\text { Public } \\
\text { utilities } \\
\text { coverage }\end{array}$ & $\begin{array}{l}\text { Not in } \\
\text { poverty }\end{array}$ & $\begin{array}{l}\text { Secondary } \\
\text { enrollment }\end{array}$ & $\begin{array}{l}\text { Life quality } \\
\quad \text { index }\end{array}$ & $\begin{array}{c}\text { Public } \\
\text { utilities } \\
\text { coverage }\end{array}$ & $\begin{array}{c}\text { Not in } \\
\text { poverty }\end{array}$ & $\begin{array}{l}\text { Secondary } \\
\text { enrollment }\end{array}$ \\
\hline & (1) & (2) & (3) & (4) & (5) & (6) & (7) & (8) \\
\hline & IV & IV & IV & IV & IV & IV & IV & IV \\
\hline \multirow{3}{*}{$\mathrm{dpi} / \mathrm{dsi}$} & \multicolumn{8}{|c|}{ Prosperity equation } \\
\hline & 0.617 & 0.763 & 0.479 & 0.318 & 0.411 & 0.423 & 0.330 & 0.222 \\
\hline & $(0.111)$ & (0.115) & $(0.126)$ & $(0.161)$ & (0.066) & (0.079) & $(0.088)$ & $(0.102)$ \\
\hline $\mathrm{dpi} / \mathrm{dsj}$ & $\begin{array}{l}0.024 \\
(0.007)\end{array}$ & $\begin{array}{l}0.028 \\
(0.007)\end{array}$ & $\begin{array}{l}0.026 \\
(0.007)\end{array}$ & $\begin{array}{l}0.038 \\
(0.009)\end{array}$ & $\begin{array}{l}0.017 \\
(0.005)\end{array}$ & $\begin{array}{l}0.021 \\
(0.005)\end{array}$ & $\begin{array}{l}0.018 \\
(0.005)\end{array}$ & $\begin{array}{l}0.027 \\
(0.007)\end{array}$ \\
\hline Observations & 973 & 975 & 975 & 965 & 1014 & 1017 & 1017 & 1006 \\
\hline \multirow{6}{*}{$\begin{array}{c}\text { Panel II } \\
\text { State capacity measured as: }\end{array}$} & \multicolumn{8}{|c|}{ Defining links to include neighbors and neighbors of neighbors } \\
\hline & \multicolumn{4}{|c|}{ Log of number of municipality state agencies } & \multicolumn{4}{|c|}{ Log of number of municipality employees } \\
\hline & $\begin{array}{l}\text { Life quality } \\
\quad \text { index }\end{array}$ & $\begin{array}{c}\text { Public } \\
\text { utilities } \\
\text { coverage }\end{array}$ & $\begin{array}{c}\text { Not in } \\
\text { poverty }\end{array}$ & $\begin{array}{l}\text { Secondary } \\
\text { enrollment }\end{array}$ & $\begin{array}{l}\text { Life quality } \\
\quad \text { index }\end{array}$ & $\begin{array}{c}\text { Public } \\
\text { utilities } \\
\text { coverage }\end{array}$ & $\begin{array}{l}\text { Not in } \\
\text { poverty }\end{array}$ & $\begin{array}{l}\text { Secondary } \\
\text { enrollment }\end{array}$ \\
\hline & (1) & (2) & (3) & (4) & (5) & (6) & (7) & (8) \\
\hline & IV & IV & IV & IV & IV & IV & IV & IV \\
\hline & \multicolumn{8}{|c|}{ Prosperity equation } \\
\hline \multirow[t]{2}{*}{$\mathrm{dpi} / \mathrm{dsi}$} & 0.519 & 0.693 & 0.375 & 0.365 & 0.374 & 0.331 & 0.296 & 0.226 \\
\hline & $(0.114)$ & $(0.115)$ & (0.129) & $(0.164)$ & (0.069) & $(0.080)$ & $(0.095)$ & $(0.107)$ \\
\hline \multirow[t]{2}{*}{$\mathrm{dpi} / \mathrm{dsj}$} & 0.007 & 0.007 & 0.007 & 0.011 & 0.005 & 0.006 & 0.005 & 0.008 \\
\hline & $(0.002)$ & $(0.002)$ & $(0.002)$ & $(0.003)$ & $(0.001)$ & $(0.001)$ & $(0.002)$ & $(0.002)$ \\
\hline Observations & 973 & 975 & 975 & 965 & 1014 & 1017 & 1017 & 1006 \\
\hline
\end{tabular}

\begin{tabular}{|c|c|c|c|c|c|c|c|c|}
\hline \multirow{4}{*}{$\begin{array}{c}\text { Panel III } \\
\text { State capacity measured as: }\end{array}$} & \multicolumn{8}{|c|}{ All municipalities linked to each other with decaying link strength } \\
\hline & \multicolumn{4}{|c|}{ Log of number of municipality state agencies } & \multicolumn{4}{|c|}{ Log of number of municipality employees } \\
\hline & $\begin{array}{l}\text { Life quality } \\
\text { index } \\
\text { (1) } \\
\text { IV }\end{array}$ & $\begin{array}{c}\text { Public } \\
\text { utilities } \\
\text { coverage } \\
\text { (2) } \\
\text { IV }\end{array}$ & $\begin{array}{l}\text { Not in } \\
\text { poverty } \\
\text { (3) } \\
\text { IV }\end{array}$ & $\begin{array}{c}\text { Secondary } \\
\text { enrollment } \\
\text { (4) } \\
\text { IV }\end{array}$ & $\begin{array}{l}\text { Life quality } \\
\text { index } \\
\text { (5) } \\
\text { IV }\end{array}$ & $\begin{array}{c}\text { Public } \\
\text { utilities } \\
\text { coverage } \\
\text { (6) } \\
\text { IV }\end{array}$ & $\begin{array}{l}\text { Not in } \\
\text { poverty } \\
\text { (7) } \\
\text { IV }\end{array}$ & $\begin{array}{c}\text { Secondary } \\
\text { enrollment } \\
\text { (8) } \\
\text { IV }\end{array}$ \\
\hline & \multicolumn{8}{|c|}{ Prosperity equation } \\
\hline $\mathrm{dpi} / \mathrm{dsi}$ & $\begin{array}{l}0.375 \\
(0.114)\end{array}$ & $\begin{array}{l}0.487 \\
(0.107)\end{array}$ & $\begin{array}{l}0.196 \\
(0.111)\end{array}$ & $\begin{array}{c}0.155 \\
(0.142)\end{array}$ & $\begin{array}{c}0.380 \\
(0.070)\end{array}$ & $\begin{array}{c}0.339 \\
(0.079)\end{array}$ & $\begin{array}{l}0.216 \\
(0.079)\end{array}$ & $\begin{array}{l}0.276 \\
(0.100)\end{array}$ \\
\hline$d p_{i} / d s j$ & $\begin{array}{c}0.039 \\
(0.011) \\
\end{array}$ & $\begin{array}{c}0.051 \\
(0.012) \\
\end{array}$ & $\begin{array}{c}0.063 \\
(0.012) \\
\end{array}$ & $\begin{array}{c}0.052 \\
(0.015) \\
\end{array}$ & $\begin{array}{c}0.021 \\
(0.009) \\
\end{array}$ & $\begin{array}{c}0.038 \\
(0.010) \\
\end{array}$ & $\begin{array}{c}0.041 \\
(0.010) \\
\end{array}$ & $\begin{array}{c}0.028 \\
(0.012) \\
\end{array}$ \\
\hline Observations & 973 & 975 & 975 & 965 & 1014 & 1017 & 1017 & 1006 \\
\hline
\end{tabular}

All reported estimates are instrumental variables average marginal effects of the prosperity equation for each of the four outcomes. All models include department fixed effects and the following vector of controls: longitude, latitutde, surface area, elevation, annual rainfall, distance to a current highway, and a department capital dummy. Panel I reports the estimates of models that use neighbors of neighbors' colonial state presence as instruments following Bramoulle et al. (2009). Panel II reports the estimates of models where the network structure defines a link as existing between both neighbors and neighbors of neighbors. Panel III reports estimates of models where the network structure allows for links between all municipalities and decaying link strength. Columns (1)-(4) use the log number of municipality state agencies as the measure of local state capacity, and columns (5)-(8) use the log number of municipality employees as the measure of local state capacity. Estimates of the first stages for the instrumental variables models are omitted. The life quality index is for 1998, the public utilities coverage (aqueduct, electricity, and sewage) is for 2002, the fraction of the population above the poverty line is for 2005, and the secondary enrollment rate is the 1992-2002 average. All prosperity outcomes are standardized. In all models log population is instrumented using 1843 population. Standard errors reported in parenthesis are robust to arbitrary heteroskedasticity and allow for arbitrary spatial correlation within the network following Conley (1996) adapted to the network structure as described in the text. 
Table A3. Robustness Exercises: Prosperity and Public Goods Outcomes Structural Equation

Panel I

State capacity measured as:

Excluding distance to royal roads as instruments

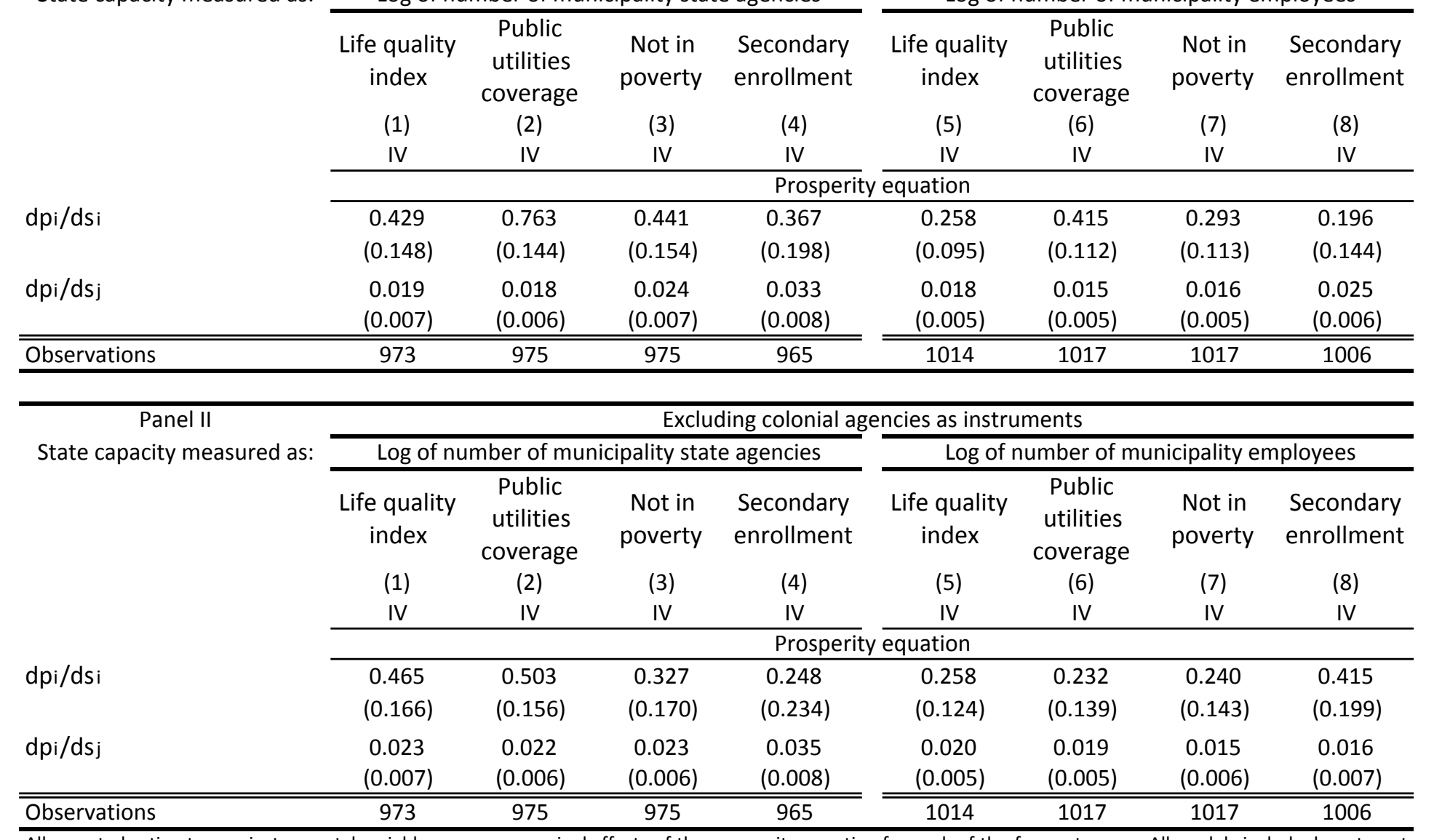

All reported estimates are instrumental variables average marginal effects of the prosperity equation for each of the four outcomes. All models include department fixed effects and the following vector of controls: longitude, latitutde, surface area, elevation, annual rainfall, distance to a current highway, and a department capital dummy. Panel I reports the estimates of models that exclude neighbors' distance to royal roads from the instrument set. Panel II reports the estimates of models that exclude neighbors' colonial state agencies from the instrument set. Columns (1)-(4) use the log number of municipality state agencies as the measure of local state capacity, and columns (5)-(8) use the log number of municipality employees as the measure of local state capacity. Estimates of the first stages for the instrumental variables models are omitted. The life quality index is for 1998, the public utilities coverage (aqueduct, electricity, and sewage) is for 2002 , the fraction of the population above the poverty line is for 2005, and the secondary enrollment rate is the 1992-2002 average. All prosperity outcomes are standardized. In all models log population is instrumented using 1843 population. Standard errors reported in parenthesis are robust to arbitrary heteroskedasticity and allow for arbitrary spatial correlation within the network following Conley (1996) adapted to the network structure as described in the text. 
Table A4. Contemporary State Equilibrium Best Response

\begin{tabular}{|c|c|c|c|c|c|}
\hline \multicolumn{6}{|c|}{ Subsets of municipality agencies } \\
\hline $\begin{array}{l}\text { State capacity measured as log of the } \\
\text { number of municipality: }\end{array}$ & All agencies & $\begin{array}{c}\text { Health } \\
\text { agencies }\end{array}$ & $\begin{array}{l}\text { Regulation } \\
\text { agencies }\end{array}$ & $\begin{array}{l}\text { Services } \\
\text { agencies }\end{array}$ & $\begin{array}{l}\text { Education } \\
\text { agencies }\end{array}$ \\
\hline \multirow[t]{3}{*}{$\begin{array}{c}\text { Panel I } \\
\end{array}$} & (1) & $(1)$ & $(2)$ & $(3)$ & $(4)$ \\
\hline & IV & IV & IV & IV & IV \\
\hline & \multicolumn{5}{|c|}{ Equilibrium best response } \\
\hline \multirow[t]{2}{*}{$\mathrm{dsi} / \mathrm{dsj}$} & 0.019 & 0.050 & 0.029 & 0.024 & 0.018 \\
\hline & $(0.003)$ & $(0.010)$ & (0.010) & $(0.005)$ & $(0.006)$ \\
\hline \multirow[t]{2}{*}{ Colonial state officialsi } & 0.108 & 0.119 & 0.046 & -0.068 & 0.103 \\
\hline & $(0.033)$ & $(0.083)$ & $(0.088)$ & $(0.053)$ & $(0.084)$ \\
\hline \multirow[t]{2}{*}{ Colonial state agenciesi } & -0.016 & -0.034 & 0.0326 & 0.011 & 0.031 \\
\hline & $(0.033)$ & $(0.063)$ & $(0.067)$ & $(0.040)$ & $(0.065)$ \\
\hline \multirow[t]{2}{*}{ Distance to royal roadi } & 0.007 & 0.012 & -0.037 & 0.027 & 0.009 \\
\hline & $(0.021)$ & $(0.020)$ & $(0.029)$ & $(0.011)$ & $(0.025)$ \\
\hline \multirow[t]{2}{*}{ Remaining municipality agencies } & & 0.0008 & -0.0002 & 0.004 & 0.002 \\
\hline & & $(0.002)$ & $(0.002)$ & $(0.002)$ & $(0.005)$ \\
\hline \multirow[t]{2}{*}{ Neighbors' remaining municipality agencies } & & -0.002 & -0.002 & 0.000 & 0.018 \\
\hline & & $(0.008)$ & (0.009) & $(0.005)$ & $(0.025)$ \\
\hline \multirow{3}{*}{$\begin{array}{c}\text { Panel II } \\
\text { Neighbors' colonial state officials }\end{array}$} & \multicolumn{5}{|c|}{ First stage for neighbors' state agencies } \\
\hline & 0.338 & 0.235 & 0.278 & 0.183 & 0.437 \\
\hline & $(0.100)$ & $(0.051)$ & $(0.054)$ & $(0.060)$ & $(0.098)$ \\
\hline \multirow[t]{2}{*}{ Neighbors' colonial state agencies } & 1.242 & 0.363 & 0.517 & 0.596 & 0.887 \\
\hline & $(0.131)$ & $(0.054)$ & $(0.066)$ & $(0.067)$ & $(0.115)$ \\
\hline \multirow[t]{2}{*}{ Neighbors' distance to royal road } & -0.992 & -0.347 & -0.460 & -0.507 & -0.743 \\
\hline & $(0.223)$ & $(0.077)$ & $(0.083)$ & (0.109) & $(0.184)$ \\
\hline \multirow[t]{2}{*}{ Neighbors' colonial state officials } & 0.269 & 0.033 & 0.122 & 0.098 & 0.259 \\
\hline & $(0.177)$ & $(0.066)$ & $(0.080)$ & $(0.079)$ & $(0.168)$ \\
\hline \multirow[t]{2}{*}{ Neighbors' colonial state agencies } & 0.568 & 0.259 & 0.214 & 0.311 & 0.379 \\
\hline & $(0.190)$ & $(0.074)$ & $(0.090)$ & $(0.094)$ & (0.169) \\
\hline \multirow[t]{2}{*}{ Neighbors' distance to royal road } & 0.172 & 0.041 & 0.091 & 0.099 & 0.149 \\
\hline & $(0.173)$ & $(0.060)$ & $(0.070)$ & $(0.085)$ & $(0.143)$ \\
\hline First-stage R-squared: & 0.671 & 0.644 & 0.684 & 0.675 & 0.626 \\
\hline Observations & 975 & 975 & 975 & 975 & 975 \\
\hline \multicolumn{6}{|c|}{$\begin{array}{l}\text { All reported estimates are instrumental variables average marginal effects of the best response equation. All models include department } \\
\text { fixed effects and the following vector of controls: longitude, latitutde, surface area, elevation, annual rainfall, distance to a current } \\
\text { highway, and a department capital dummy. Column (1) reproduces column (3) of Table } 3 \text { for comparison. Column (2) measures local state } \\
\text { capacity as the log number of health agencies and health posts. Column (3) measures local state capacity as the log number of notary } \\
\text { offices, jails, deeds registry offices, and tax collection offices. Column (4) measures local state capacity as the log number of Telecom } \\
\text { offices, post offices, and fire stations. Column (5) measures local state capacity as the log number of public schools and libraries. Panel I } \\
\text { reports the estimates of the best response equation, and Panel II reports the first stage for the instrumental variables models. In all models } \\
\text { log population is instrumented using } 1843 \text { population. Standard errors reported in parenthesis are robust to arbitrary heteroskedasticity } \\
\text { and allow for arbitrary spatial correlation within the network following Conley (1996) adapted to the network structure as described in the } \\
\text { text. }\end{array}$} \\
\hline
\end{tabular}


Table A5. Robustness Exercises: Prosperity and Public Goods Outcomes Structural Equation

Panel I

Excluding from the estimating sample municipalities above the 90th percentile of violence

\begin{tabular}{|c|c|c|c|c|c|c|c|c|}
\hline \multirow{4}{*}{ State capacity measured as: } & \multirow{2}{*}{\multicolumn{4}{|c|}{ Log of number of municipality state agencies }} & \multirow{2}{*}{\multicolumn{4}{|c|}{ Log of number of municipality employees }} \\
\hline & & & & & & & & \\
\hline & $\begin{array}{l}\text { Life quality } \\
\text { index } \\
\text { (1) }\end{array}$ & $\begin{array}{l}\text { Public utilities } \\
\text { coverage } \\
\text { (2) }\end{array}$ & $\begin{array}{l}\text { Not in poverty } \\
\text { (3) }\end{array}$ & $\begin{array}{l}\text { Secondary } \\
\text { enrollment } \\
\text { (4) }\end{array}$ & $\begin{array}{l}\text { Life quality } \\
\text { index } \\
\text { (5) }\end{array}$ & $\begin{array}{l}\text { Public utilities } \\
\text { coverage } \\
\text { (6) }\end{array}$ & $\begin{array}{l}\text { Not in poverty } \\
\text { (7) }\end{array}$ & $\begin{array}{c}\text { Secondary } \\
\text { enrollment } \\
\text { (8) }\end{array}$ \\
\hline & IV & IV & IV & IV & IV & IV & IV & IV \\
\hline \multirow[b]{2}{*}{$\mathrm{dpi} / \mathrm{dsi}$} & \multicolumn{8}{|c|}{ Prosperity equation } \\
\hline & $\begin{array}{c}0.401 \\
(0.139)\end{array}$ & $\begin{array}{c}0.569 \\
(0.132)\end{array}$ & $\begin{array}{c}0.307 \\
(0.140)\end{array}$ & $\begin{array}{c}0.322 \\
(0.189)\end{array}$ & $\begin{array}{c}0.184 \\
(0.099)\end{array}$ & $\begin{array}{c}0.284 \\
(0.117)\end{array}$ & $\begin{array}{c}0.212 \\
(0.114)\end{array}$ & $\begin{array}{c}0.240 \\
(0.141)\end{array}$ \\
\hline $\mathrm{dpi} / \mathrm{dsj}$ & $\begin{array}{c}0.026 \\
(0.007) \\
\end{array}$ & $\begin{array}{c}0.021 \\
(0.006) \\
\end{array}$ & $\begin{array}{c}0.023 \\
(0.006) \\
\end{array}$ & $\begin{array}{c}0.032 \\
(0.008) \\
\end{array}$ & $\begin{array}{c}0.024 \\
(0.005) \\
\end{array}$ & $\begin{array}{c}0.018 \\
(0.005) \\
\end{array}$ & $\begin{array}{c}0.016 \\
(0.005) \\
\end{array}$ & $\begin{array}{c}0.020 \\
(0.006) \\
\end{array}$ \\
\hline Observations & 850 & 852 & 852 & 842 & 887 & 890 & 890 & 879 \\
\hline Panel II & \multicolumn{8}{|c|}{ Excluding from the network municipalities above the 90th percentile of violence } \\
\hline \multirow[t]{4}{*}{ State capacity measured as: } & \multicolumn{4}{|c|}{ Log of number of municipality state agencies } & \multicolumn{4}{|c|}{ Log of number of municipality employees } \\
\hline & $\begin{array}{l}\text { Life quality } \\
\text { index } \\
\text { (1) }\end{array}$ & $\begin{array}{c}\text { Public utilities } \\
\text { coverage } \\
\text { (2) }\end{array}$ & $\begin{array}{c}\text { Not in poverty } \\
\text { (3) }\end{array}$ & $\begin{array}{c}\text { Secondary } \\
\text { enrollment } \\
\text { (4) }\end{array}$ & $\begin{array}{l}\text { Life quality } \\
\text { index } \\
\text { (5) }\end{array}$ & $\begin{array}{c}\text { Public utilities } \\
\text { coverage } \\
\text { (6) }\end{array}$ & $\begin{array}{c}\text { Not in poverty } \\
\text { (7) }\end{array}$ & $\begin{array}{c}\text { Secondary } \\
\text { enrollment } \\
\text { (8) }\end{array}$ \\
\hline & IV & IV & IV & IV & IV & IV & IV & IV \\
\hline & \multicolumn{8}{|c|}{ Prosperity equation } \\
\hline $\mathrm{dpi} / \mathrm{dsi}$ & $\begin{array}{c}0.663 \\
(0.145)\end{array}$ & $\begin{array}{c}0.778 \\
(0.148)\end{array}$ & $\begin{array}{c}0.386 \\
(0.151)\end{array}$ & $\begin{array}{c}0.772 \\
(0.210)\end{array}$ & $\begin{array}{c}0.355 \\
(0.107)\end{array}$ & $\begin{array}{c}0.379 \\
(0.125)\end{array}$ & $\begin{array}{c}0.266 \\
(0.125)\end{array}$ & $\begin{array}{c}0.400 \\
(0.157)\end{array}$ \\
\hline $\mathrm{dpi} / \mathrm{dsj}$ & $\begin{array}{c}0.021 \\
(0.007) \\
\end{array}$ & $\begin{array}{c}0.017 \\
(0.007) \\
\end{array}$ & $\begin{array}{c}0.022 \\
(0.006) \\
\end{array}$ & $\begin{array}{c}0.024 \\
(0.008) \\
\end{array}$ & $\begin{array}{c}0.019 \\
(0.006) \\
\end{array}$ & $\begin{array}{c}0.016 \\
(0.006) \\
\end{array}$ & $\begin{array}{c}0.014 \\
(0.006) \\
\end{array}$ & $\begin{array}{c}0.017 \\
(0.008) \\
\end{array}$ \\
\hline Observations & 850 & 852 & 852 & 842 & 887 & 890 & 890 & 879 \\
\hline
\end{tabular}


Table A6. Experiment: Implications of Moving all Municipalities with National State Capacity below Median to Median

\begin{tabular}{|c|c|c|c|c|c|c|c|c|c|c|c|}
\hline \multicolumn{12}{|c|}{ General equilibrium change in median of: } \\
\hline \multicolumn{4}{|c|}{ State capacity } & \multirow{2}{*}{\multicolumn{2}{|c|}{ Life quality index }} & \multirow{2}{*}{\multicolumn{2}{|c|}{ Utilities coverage }} & \multirow{2}{*}{\multicolumn{2}{|c|}{$\%$ not in poverty }} & \multirow{2}{*}{\multicolumn{2}{|c|}{ Secondary enrollment }} \\
\hline \multicolumn{2}{|c|}{ National: } & \multicolumn{2}{|c|}{ Local: } & & & & & & & & \\
\hline From & To & From & To & From & To & From & To & From & To & From & To \\
\hline \multicolumn{2}{|c|}{ Percent change: } & \multicolumn{2}{|c|}{$8.7 \%$} & \multicolumn{2}{|c|}{$1.1 \%$} & \multicolumn{2}{|c|}{$3.5 \%$} & \multicolumn{2}{|c|}{$1.6 \%$} & \multicolumn{2}{|c|}{$2.5 \%$} \\
\hline
\end{tabular}

This table reports results from an experiment which takes all municipalities below median national state capacity to the median, using the estimated parameters of the model. Local state capacity is measured as the number of local state agencies. National-level state capacity is measured as the number of national-level public employees. The table reports the medians of the empirical and counterfactual distributions using the structural parameters of the non-linear model estimated using MLE, in the general equilibrium exercise where municipalities have best responded to the shock. The life quality index is for 1998, the public utilities coverage (aqueduct, electricity, and sewage) is for 2002 , the fraction of the population above the poverty line is for 2005, and the secondary enrollment rate is the 1992-2002 average. 